\title{
Identification of Target Structures for New Vaccines Specifically Directed at Dendritic Cells
}





\section{Identification of Target Structures for New Vaccines Specifically Directed at Dendritic Cells}

PhD Thesis by

\section{Lotte Hatting Pugholm}

Laboratory of Immunology, Department of Health Science and Technology, Aalborg University, Aalborg, Denmark

River Publishers

Aalborg 
ISBN 978-87-93102-21-7(e-book)

Published, sold and distributed by:

River Publishers

P.O. Box 1657

Algade 42

9000 Aalborg

Denmark

Tel.: +45369953197

www.riverpublishers.com

Copyright for this work belongs to the author, River Publishers have the sole right to distribute this work commercially.

All rights reserved (c) 2013 Lotte Hatting Pugholm.

No part of this work may be reproduced, stored in a retrieval system, or transmitted in any form or by any means, electronic, mechanical, photocopying, microfilming, recording or otherwise, without prior written permission from the Publisher. 


\section{Preface}

This $\mathrm{PhD}$ thesis "Identification of target structures for new vaccines specifically directed at dendritic cells" has been submitted to the Faculty of Medicine, Aalborg University, Denmark. The thesis presents the results obtained throughout my $\mathrm{PhD}$ study performed in the period from April 2007 to June 2012. The study was carried out at Department of Clinical Immunology, Aalborg Hospital and Laboratory of Immunology, Department of Health Science \& Technology, Aalborg University. The period included two maternity leaves.

The project was originally divided in 2 parts; 1) Investigation of the effect of targeting different surface markers on human monocyte-derived dendritic cells (DCs) using peripheral blood mononuclear cells (PBMCs) from patients in treatment with Infliximab (Remicade), 2) Investigation of the effect of targeting different surface-markers on murine DCs.

However, after spending the first year trying to include suitable patients without success, we decided to discontinue the human part of the project.

This dissertation is therefore based on the results obtained in the murine part of the project leading to the following two manuscripts:

Manuscript I.

Lotte Hatting Pugholm, Kim Varming, Ralf Agger. Augmented $\mathbf{T}$ cell activation by targeting antigen to dendritic cells. A comparison of ten different targets (2013). Manus in prep.

Manuscript II.

Lotte Hatting Pugholm, Kim Varming, Ralf Agger. Antibody responses induced by targeting antigen to ten different receptors on dendritic cells in vivo (2013). Manus in prep. 


\section{Acknowledgements}

Firstly, I will express my gratitude to my supervisor Ralf Agger for enthusiastic and competent supervision during the study and for always keeping a positive approach even in periods with much struggle. Secondly, I would like to thank my second supervisor, Kim Varming, for contributing with inspiring ideas and for keeping the project on track financially.

I also wish to thank laboratory technicians Brita Holst Jensen \& Linda Hartun Konggaard for their tremendous technical assistance during the project.

Additionally, I wish to thank Annette Schlemmer at Department of Rheumatology, Aalborg Hospital for providing biological material to the project and Jørgen Agnholt at Department of Medicine V, Aarhus University Hospital for help and materials.

At the Department of Clinical Immunology, Aalborg Hospital, I thank my colleagues, especially in the research unit, for their help and friendliness - you were all a great support during the project. I would also like to thank Romana Maric and Thomas Carlsen for keeping a good atmosphere in our office.

Finally, I would like to thank my family and friends for their support and patience during the entire project. Without your support I could not have made it to the end.

Aalborg, March 2013

Lotte Hatting Pugholm 


\section{Table of contents}

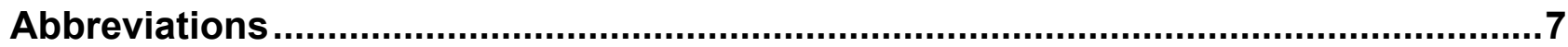

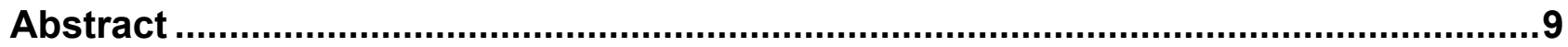

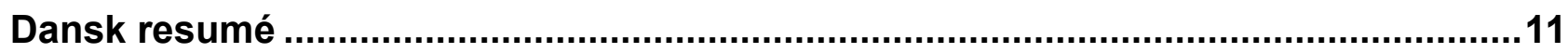

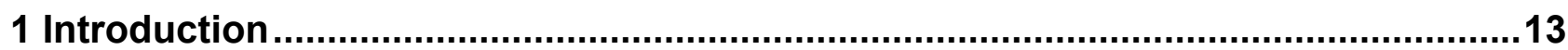

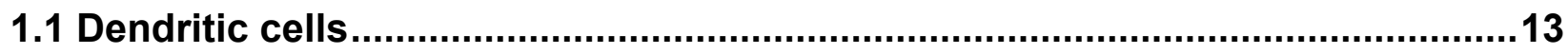

1.1.1 DC functions

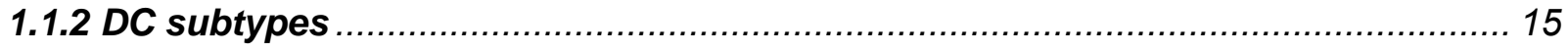

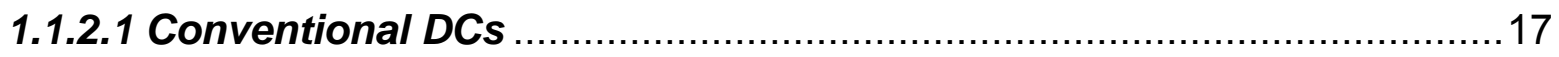

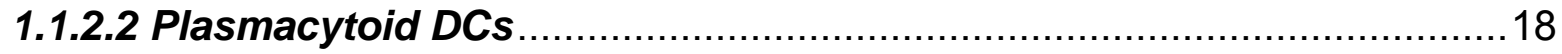

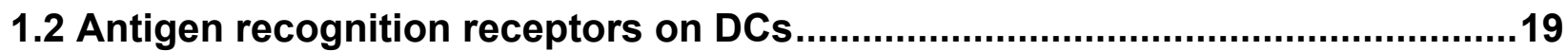

1.2.1 C-type lectin receptors .................................................................................. 20

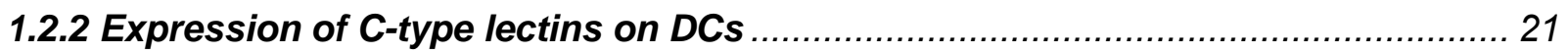

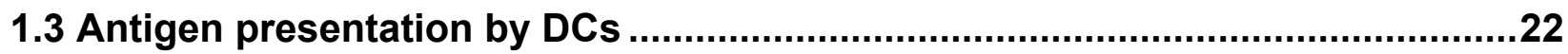

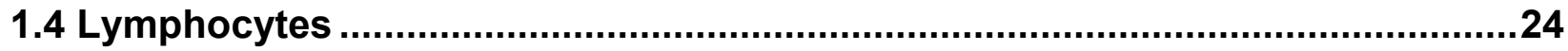

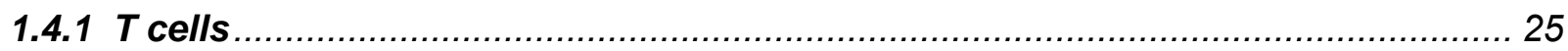

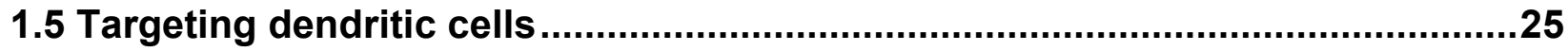

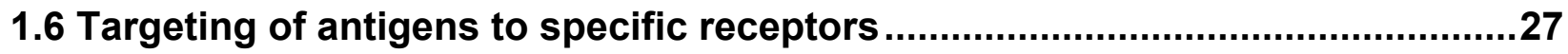

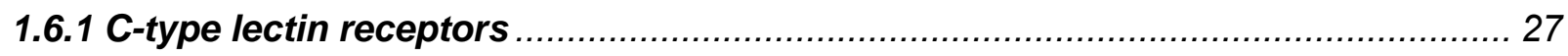

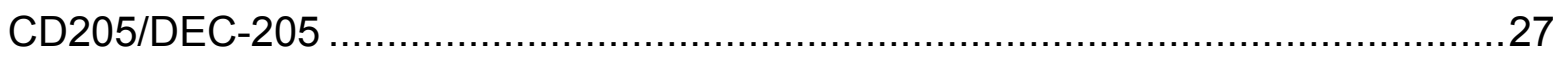

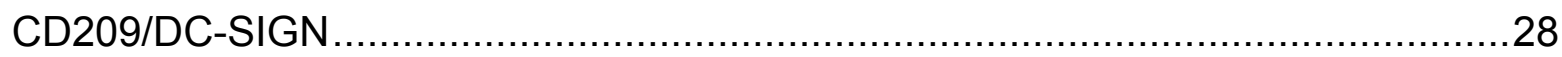

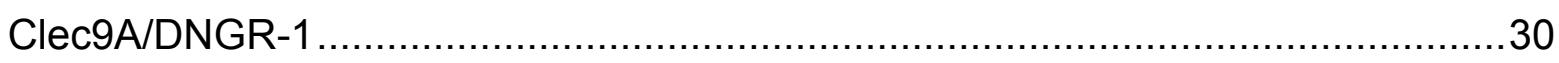

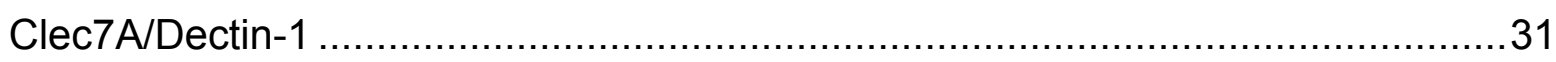

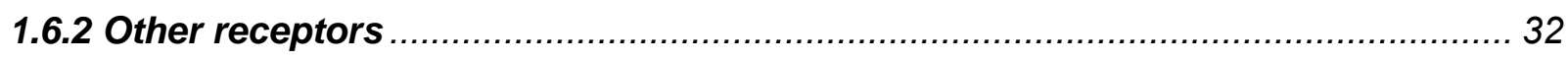

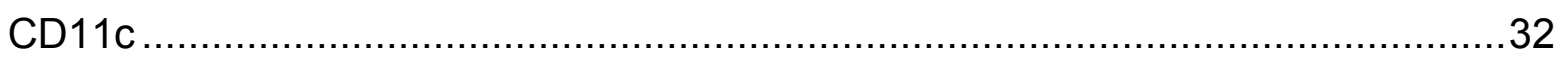

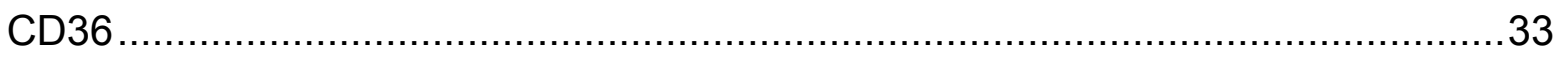

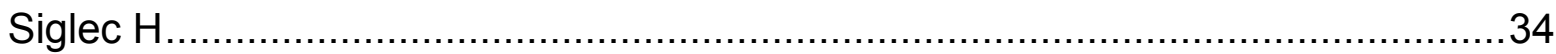

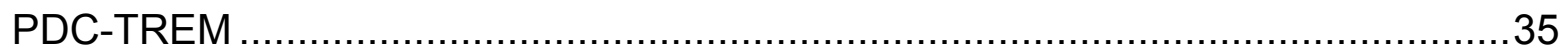

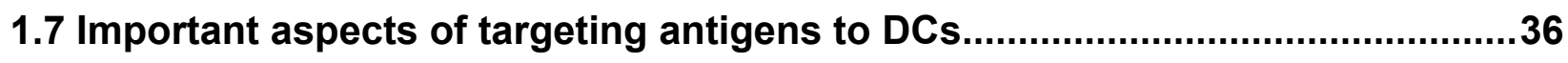

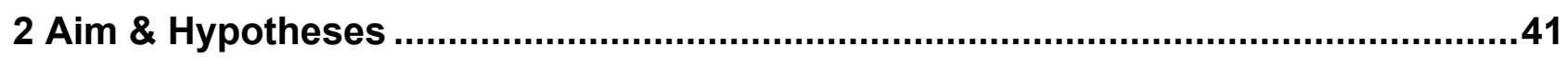

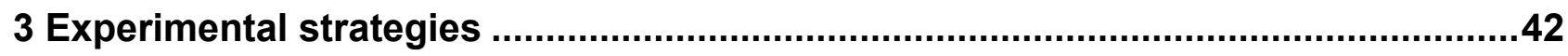


4 Study design and limitations

Manuscript I: Augmented T cell activation by targeting antigen to dendritic cells. A comparison of ten different targets.

Manuscript II: In vivo targeting of antigen to ten different receptors on dendritic cells induced distinctive humoral responses...................................................77

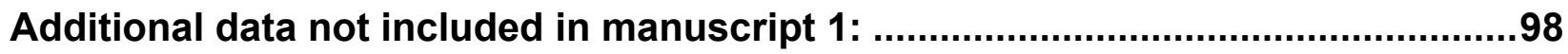

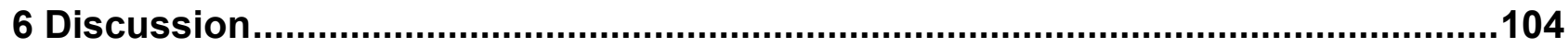

7 Future perspectives.................................................................................. 111

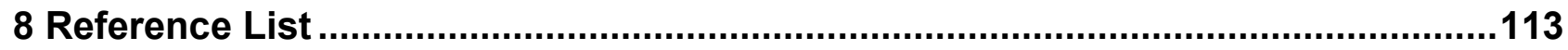




\section{Abbreviations}

$\begin{array}{ll}\text { Ag } & \text { Antigen } \\ \text { APC } & \text { Antigen presenting cell } \\ \text { BM-DCs } & \text { Bone marrow-derived DCs } \\ \text { BSA } & \text { Bovine serum albumine } \\ \text { CFA } & \text { Complete Freund's adjuvant } \\ \text { CLP } & \text { Common lymphoid progenitor } \\ \text { CLR } & \text { C-type lectin receptor } \\ \text { CMP } & \text { Common myeloid progenitor } \\ \text { CPPs } & \text { Cell penetrating peptides } \\ \text { CRD } & \text { Carbohydrate recognition domain } \\ \text { DCs } & \text { Dendritic cells } \\ \text { EDTA } & \text { Ethylenediaminetetraacetic acid } \\ \text { EE } & \text { Early endosomes } \\ \text { EF } & \text { Extrafollicular foci } \\ \text { ELISPOT } & \text { Enzyme-linked immunospot assay } \\ \text { ER } & \text { Endoplasmic reticulum } \\ \text { FcR } & \text { Fc-receptor } \\ \text { FCS } & \text { Foetal calf serum } \\ \text { FIt3 } & \text { Fms-like tyrosine kinase receptor-3 } \\ \text { GC } & \text { Germinal center } \\ \text { GM-CSF } & \text { Granulocyte-macrophage colony stimulating factor } \\ \text { ICS } & \text { Intracellular cytokine staining } \\ \text { IFNAR } & \text { IFN a/ } \beta \text { receptor } \\ \text { IFNs } & \text { Interferons } \\ \text { IFN-Y } & \text { Interferon-gamma } \\ \text { Ig } & \text { Immunoglobulin } \\ \text { IL-4 } & \text { Interleukin-4 } \\ \text { iNOS } & \text { Inducible nitric-oxide synthase } \\ \text { ITAM } & \text { Immunoreceptor tyrosine-based activation motif } \\ \text { ITIM } & \text { Immunoreceptor tyrosine-based inhibitory motif } \\ \text { KLH } & \text { Keyhole limpet hemocyanin } \\ \text { LC } & \text { Langerhans cell } \\ \text { LE } & \text { Late endosomes } \\ \text { LPS } & \text { Lipopolysaccharide } \\ \text { mAb } & \text { Monoclonal antibody } \\ \text { NK } & \text { Natural killer } \\ \text { PBMC } & \text { Peripheral blood mononuclear cells } \\ \text { PBS } & \text { Phosphate buffered saline } \\ \text { PRR } & \text { Pattern-recognition receptor } \\ \text { PSGL-1 } & \text { P-selectin glycoprotein ligand-1 } \\ \text { RPMI } & \text { Roswell Park Memorial Institute } \\ \text { RT } & \text { Room temperature } \\ \text { S.C } & \text { Subcutaneously } \\ \text { sPBS } & \text { Sterile phosphate buffered saline } \\ \text { SPF } & \text { Spot forming colony } \\ \text { TAP } & \text { Transporter associated with antigen processing } \\ & \end{array}$


Follicular helper T cell

TLR Toll-like receptor

TNF- $\alpha \quad$ Tumour-necrosis factor-alpha

TREM Triggering receptor expressed on myeloid cells 


\section{Abstract}

Dendritic cells (DCs) are superior antigen presenting cells (APCs) that are important for the initiation adaptive of immune responses. They are uniquely equipped for the activation and expansion of both naïve and memory T cells. In fact, studies have shown that direct delivery of antigens (Ags) to DCs may augment both $T$ cell responses and humoral immunity. For this purpose, DCs express a unique pattern of cell surface receptors that can be employed as target structures for such targeted delivery of Ags to DCs. Different surface receptors on DCs will, to a varying extent, lead to internalization, processing and presentation of the Ag to T cells. Depending on the intracellular routing of the Ag, antigenic peptides are presented on MHC class I and/ or class II facilitating induction of different $\mathrm{T}$ cell responses. A number of different target receptors have been assayed for this purpose, but several other DC surface molecules deserve examination for their usefulness for Agdelivery. Antibodies against several of these surface receptors have become commercially available, and these monoclonal antibodies (mAbs) can be used as vehicles to deliver Ag to DCs. The present thesis employs a strategy in which monoclonal rat antibodies against surface receptors on murine DCs act as both targeting devices (the Ag-binding parts of the molecule) and as $\mathrm{Ag}$ (epitopes on the rat immunoglobulin that are immunogenic in the mouse). A panel of such rat anti-mouse mAb directed against different receptors on DCs was employed in this thesis. Ten potential target receptors were selected - CD11C, CD36, CD205, CD206, CD209, Clec6A, Clec7A, Clec9A, Siglec H and PDC-TREM - and each receptor was investigated for its ability to lead to $\mathrm{Ag}$ presentation and thereby $\mathrm{T}$ cell activation.

In the first part of this thesis, targeted delivery of $\mathrm{Ag}$ to ten different target receptors was studied in vitro on murine spleen cell cultures using Ag-induced cytokine production from $T$ cells as readout. The assay developed for this purpose allowed simultaneous screening of a large number of potential target receptors and facilitated direct comparison between the different targets regarding strength and character of the $T$ cell responses induced by the targeted DCs. We found that targeting of Ag to CD11c, CD36, CD205 and Clec7A led to positive IFN-y responses compared to the non-targeted isotype control. Regarding induction of IL-4, CD36 and CD205 did also produce positive IL-4 responses, while no positive responses were obtained by the non-targeted isotype control. 
In the second part of this thesis, Ag-delivery to DCs was performed in vivo. Mice were immunized with monoclonal target antibodies specific for the ten receptors, and functional presentation of antigenic peptides by DCs were measured as the ability to induce humoral and cellular responses in the mice.

The results demonstrated that Ag-delivery to different targets on DCs in vivo elicited humoral responses of varying strength and IgG subclass composition. Targeting $\mathrm{Ag}$ to CD11c, CD36, CD205, PDC-TREM, Clec6A and Clec7A induced very strong antibody responses compared to the non-targeted control. In contrast, Ag-delivery to CD206, CD209, Clec9A and Siglec H showed responses comparable to those elicited by the nontargeted controls. The IgG subclass composition of the antibody responses induced by Agdelivery to the different receptors was also determined. All responses were dominated by IgG1, but high lgG1 levels were obtained by CD11C, CD36 and CD205. In contrast, Agdelivery to Clec7A induced robust amounts of IgG2a indicating the presence of a manifest Th1 component in the immune responses of these mice.

To the best of our knowledge, PDC-TREM has not previously been investigated as a target receptor for Ag-delivery to DCs. The results obtained in this study indicate that PDCTREM, besides being involved in the production of type I IFNs by pDCs, may function as an endocytic receptor mediating Ag presentation for T cells. As such, PDC-TREM might be a potential target for future DC-directed vaccines. 


\section{Dansk resumé}

Dendritiske celler (DCs) er potente antigen præsenterende celler (APCs), som er vigtige for initieringen af et adaptivt immunrespons. DCs er unikke sammenlignet med andre APCs, idet de er i stand til at aktivere både naive og memory T-celler. Studier har faktisk vist, at hvis et antigen ( $\mathrm{Ag}$ ) målrettes (targeteres) direkte mod DCs opnås både et stærkere T-celle respons og et stærkere antistofrespons. Dendritiske celler udtrykker en lang række overflade receptorer, som netop kan udnyttes som mål-strukturer for en sådan targetering af $\mathrm{Ag}$ til DCs. Forskellige receptorer vil i varierende grad føre til optagelse og kløvning af Ag samt til præsentation af antigene peptider for T-celler. Afhængigt af selve internaliseringsvejen, vil disse peptider præsenteres i kompleks med MHC klasse I og/eller klasse II og dermed initiere forskellige T-celle responser. En række forskellige receptorer er allerede blevet evalueret $\mathrm{i}$ denne sammenhæng, men der findes mange andre receptorer, som endnu ikke er afprøvet i forbindelse med targetering af DCs. Eftersom at antistoffer rettet mod flere af disse receptorer er blevet kommercielt tilgængelige, kan man netop anvende antistoffer rettet mod udvalgte receptorer som et "transportmiddel" til direkte at targetere Ag til DCs.

Denne $\mathrm{PhD}$ afhandling anvender en strategi, hvori monoklonale rotte antistoffer med specificitet mod forskellige overflade receptorer på murine DCs fungerer som både $\mathrm{Ag}$ (rotte immunoglobulin vil indeholde sekvenser/epitoper som er immunogene i musen) og "transportmiddel" (de Ag-bindende dele af antistoffet). Et panel bestående af sådanne antistoffer rettet mod ti forskellige receptorer udtrykt på DC er anvendt til targetering af DCs, og hver receptor er undersøgt for evnen til at præsentere Ag for T-celler og dermed føre til T-celle aktivering.

Den første del af dette studie var et in vitro studie, og målet var at undersøge effekten af at targetere $\mathrm{Ag}$ til ti forskellige receptorer vha. murine miltcelle-kulturer. Effekten af targeterings-processen blev vurderet ud fra antallet af aktiverede Ag-specifikke T-celler, målt på produktionen af både IFN-y og IL-4. Metoden, som blev optimeret til dette formål, tillod undersøgelse af et stort antal potentielle receptorer på samme tid samt direkte sammenligning af effekten af de forskellige receptorer med hensyn til styrken og typen af T-celle respons, som blev initieret af de Ag-targeterede DCs. 
Resultaterne viste at targetering af Ag til CD11c, CD36, CD205 og Clec7A førte til et positiv IFN- $\gamma$ respons sammenlignet med den ikke-targeterede kontrol. Med hensyn til IL-4 produktionen, så udløste CD36 og CD205 positive IL-4 responser, hvilket ikke var aktuelt for den ikke-targeterede kontrol.

I anden del af studiet blev targetering af DC undersøgt in vivo. Musene blev immuniseret med et monoklonalt antistof rettet mod en bestemt receptor, og en eventuel funktionel præsentation af $\mathrm{Ag}$ på overfladen af $\mathrm{DC}$ blev målt som evnen til at inducere et antistof respons. På samme måde blev effekten af alle ti receptorer undersøgt.

Resultaterne viste at targetering af $\mathrm{Ag}$ til flere forskellige receptorer på DC in vivo førte til et antistof respons af varierende styrke og med forskellige niveauer af IgG subklasser. Targetering af Ag til CD11c, CD36, CD205, Clec6A, Clec7A og PDC-TREM udløste et stærkt forøget antistof respons sammenlignet med en ikke-targeteret kontrol.

Undersøgelse af de forskellige IgG subklasser viste, at alle receptorer, som fremkaldte et forstærket antistof respons, også inducerede produktion af IgG1 hvilket indikerer et generelt Th2 respons. Clec7A var eneste target som inducerede produktion af IgG2a, hvilket indikerer tilstedeværelse af et Th1 respons i disse mus.

PDC-TREM har ikke tidligere været undersøgt som potentiel receptor for targetering af Ag til DC. Resultaterne af dette studie antyder at PDC-TREM, udover at være involveret $\mathrm{i}$ produktionen af type I interferoner via plasmacytoide DC, også kan fungere som en receptor, der medierer endocytose af $\mathrm{Ag}$ og dermed fører til Ag præsentation for T-celler. PDC-TREM kan derfor tænkes at være en potentiel receptor imod hvilken fremtidige DCrettede vacciner kunne målrettes. 


\section{Introduction}

\subsection{Dendritic cells}

Dendritic cells (DCs) are specialized antigen-presenting cells (APCs) that initiate immune responses and link innate responses to the development of adaptive immunity. In addition, they play a dual role in inducing adaptive immune responses to foreign antigens (Ags) and in maintaining $T$ cell tolerance to self $(1,2)$. DCs are found in most tissues including skin and mucosal surfaces, which are the most common sites of entry for microbial pathogens, but also in secondary lymphoid organs, in which adaptive immune responses to such pathogens are initiated (3). In 1973 DCs were identified in mouse spleen by Steinman and Cohn (4), who subsequently initiated a series of experiments that investigated the phenotype, distribution and functional properties of these cells, which identified them as potent stimulators of primary immune responses (5-7). Since then, many studies have focused on characterizing these cells further and it is now widely accepted that the DC family is composed of several subtypes that vary in location, migratory capacity and immunological function $(8,9)$. Nevertheless, the different subtypes share enough features to include them in a single family (10).

\subsubsection{DC functions}

Dendritic cells are bone marrow-derived leukocytes that are specialized in picking up, processing and presenting Ags to T cells (11). DCs are the most potent APC of the body and they are the only cells capable of inducing naïve T-cell responses $(2,6)$. The interaction of DCs with naïve $T$ cells can lead to either different forms of immune responses or to T cell tolerance, depending on the maturation state of the DCs (Figure 1) (10). At the immature stage or in steady state, the migratory DCs act as sentinels in peripheral tissues, continuously sampling the environment for Ags using a series of receptors for pathogen-associated molecular patterns (PAMPs) and damaged cell- or danger-associated molecular patterns (DAMPs) $(8,12)$. DAMPs are danger signals from distressed or injured cells and include mammalian DNA, RNA, heat shock proteins, CD40ligand (which are expressed on activated platelets and activated $\mathrm{T}$ cells) and breakdown products of hyaluron (made when vessels are damaged) (13). Upon encounter with microbial structures and/or danger signals, DCs undergo maturation transforming the 
immature DCs, having low T cell stimulatory capacity, into potent T cell stimulating mature DCs (14).

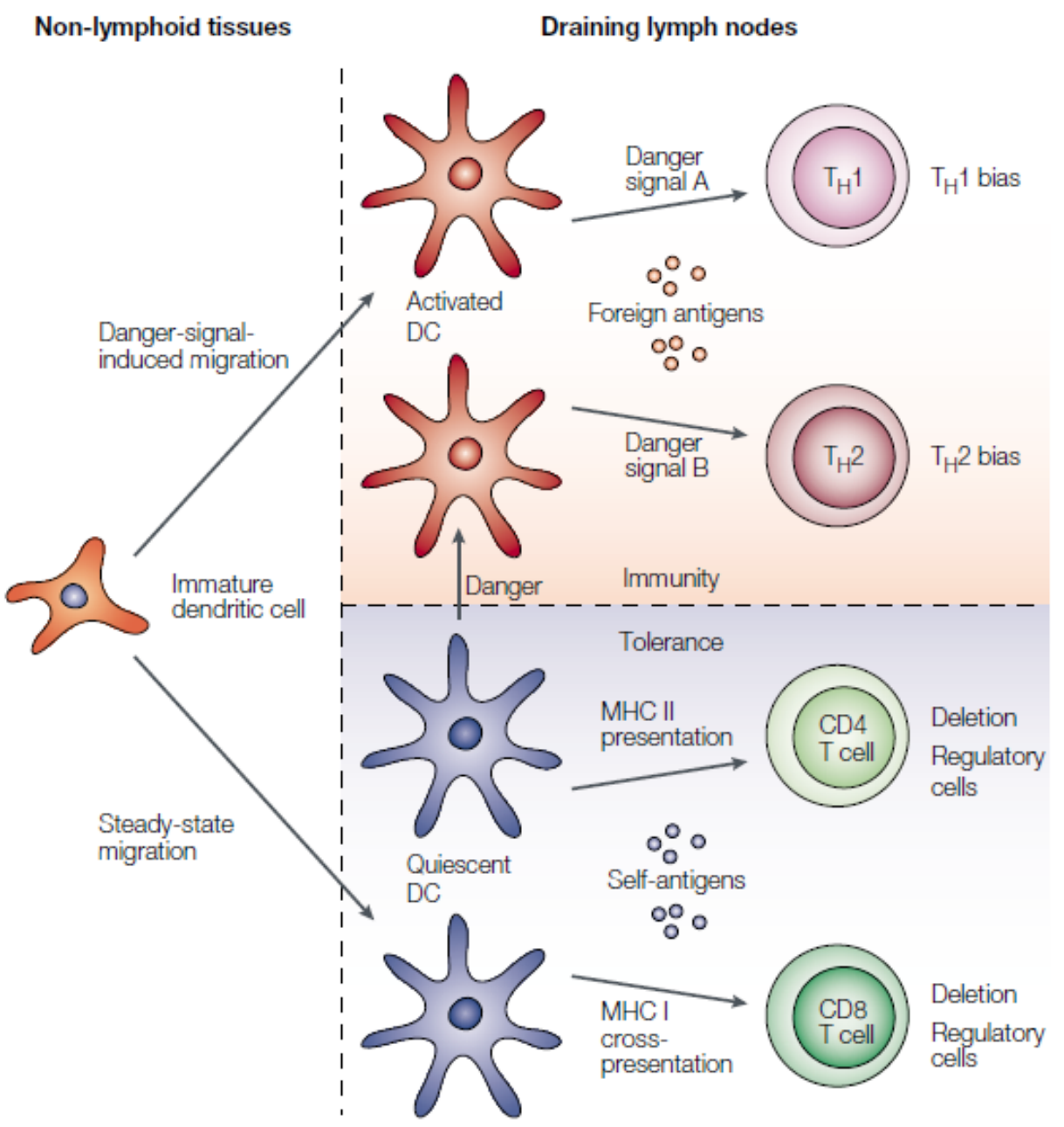

Figure 1. Immunoregulatory properties of DCs.

A simplistic way of showing how the different activation stages of DCs can determine the nature of the T cell responses. In the absence of "danger" signals steady-state DCs migrate into lymphoid tissues leading to maintenance of a peripheral T cell tolerance to self-Ags. In cases of infection, inflammation or tissue damage DCs are activated and increase the rate of migration into lymphoid tissues, where they prime Ag-specific $T$ cells. Figure adapted from (8).

MHC: Major Histocompatibility Complex. $T_{H} 1: T$ helper 1 cell. $T_{H} 2:$ T helper 2 cell.

The maturation process involves redistribution of $\mathrm{MHC}$ molecules from intracellular endocytic compartments to the cell surface, decrease in $\mathrm{Ag}$ internalization and upregulation of the surface expression of co-stimulatory molecules required for $\mathrm{T}$ cell activation (14). In addition, DC maturation results in a switch in chemokine receptor expression with down-regulation of receptors for inflammatory chemokines and up- 
regulation of receptors for chemokines produced in secondary lymphoid tissues, which facilitate the migration of DCs from peripheral tissues to these tissues. Immature DCs express a unique repertoire of inflammatory chemokine receptors, e.g CCR1, CCR2, CCR5 and CCR6, that bind to chemokines such as CCL2, CCL5 and CCL20 allowing their access into peripheral tissues (15-17). When DC mature, many of these chemokine receptors are down-regulated while other receptors are up-regulated, e.g. CCR7 (18). CCR7 recognizes two chemokines, CCL19 and CCL21, which mediates entry of DCs into secondary lymphoid tissues. CCL21 is expressed by endothelial cells of high endothelial venules (HEV) and of lymphatic vessels but also by stromal cells present in the T cell zone of secondary lymphoid tissues. CCL19 is produced by stromal cells and mature DCs in the T cell zone $(19,20)$. Besides attracting maturing DCs to lymphoid tissues, CCL19 and CCL21 also promote extravasation of $\mathrm{CCR} 7^{+}$naïve and memory $\mathrm{T}$ cells through HEV thereby orchestrating encounter of DCs and T cells in the T cell zone of lymph nodes (19). Arriving in the secondary lymphoid tissues, Ag-bearing DCs efficiently trigger an immune response by $T$ cells that recognize one of the antigenic peptides presented in complex with a MHC molecule (8). Migration to the lymph nodes also occurs in the steady state, although at lower rates $(21,22)$. In this case, antigenic peptides are presented on immature DCs and engagement with a T cell receptor, recognizing the peptide-MHC complex, will in most cases lead to $\mathrm{T}$ cell tolerance by i) $\mathrm{T}$ cell anergy (23), ii) peripheral clonal deletion (24-26) or iii) generation of regulatory $T$ cells (Tregs) (27-29). This reaction has been proposed as a mechanism by which peripheral tolerance complements central tolerance as a means of controlling autoreactive $T$ cells $(22,30)$. The dual function of DCs in immunity and tolerance obviously play an important role in prevention of anti-self-immune responses (31).

\subsubsection{DC subtypes}

DCs are a heterogeneous population of cells derived from haematopoietic stem cells. Although these cells share many common features, multiple subtypes of DCs with distinct phenotype, localization and immune functions have been identified. The DC subtypes found in steady state in mouse as well as in human can be grouped into two major subsets: conventional DCs ( $\mathrm{CDCs}$ ) and plasmacytoid DCs (pDCs), both of which, although in varying numbers, occur in the peripheral tissues, in the circulation and in lymphoid 
tissues (32). In addition, several other DC subtypes develop upon infection or inflammation including monocyte-derived DCs and Tip DCs (TNF- $\alpha$ and iNOS producing DCs) (33-35).

The exact pathways leading to the generation of the different DC populations are still not completely understood $(36,37)$. Initially, DCs were thought to originate from the common myeloid progenitors (CMP) (38); however, subsequent studies on mouse common lymphoid progenitors (CLP) also showed the potential of these progenitors to differentiate into DCs both in vitro and in vivo $(39,40)$. The fact that both the CMP and CLP may give rise to different DC subtypes demonstrates that DCs can be of either myeloid or lymphoid origin and that the phenotype of the different DC subsets is not related to its lineage of origin (32). Studies have identified a common feature of the DC progenitors as being the surface expression of the fms-like tyrosine kinase receptor-3 (Flt3) receptor (39). A role of Flt3 in DC development is further supported by studies showing that the Flt3-ligand is crucial for development of steady state pDCs and cDCs (41). Murine bone marrow cultures treated with Flt3-L were shown to generate $\mathrm{pDCs}$ and $\mathrm{CDCs}$ that corresponded to the steady state DCs found in vivo (42).

DCs were originally considered to be terminally differentiated, non-dividing cells with a short half-life (43), which is corroborated by the observation that DCs in secondary lymphoid organs are continually replaced by blood-borne precursors $(44,45)$. However, subsequent studies revealed that in the steady state, DC homeostasis in secondary lymphoid tissues is maintained by a dynamic balance of three processes: i) constant replacement by DC precursors from blood, ii) division of pre-DCs (about $5 \%$ of the cells are dividing), and iii) DC cell death upon a limited number of divisions (44). Furthermore it was demonstrated that daughter cells of dividing DCs presented Ags captured by their progenitors suggesting that division of DCs in these tissues mediates prolonged duration of Ag presentation in vivo (44).

Two populations of DC precursors in mouse blood have been identified (46). The $\mathrm{CD} 45 \mathrm{RA}^{-} \mathrm{CD} 11 \mathrm{c}^{\mathrm{int}} \mathrm{CD} 11 \mathrm{~b}^{+}$population represents immature $\mathrm{cDCs}$ that in the presence of

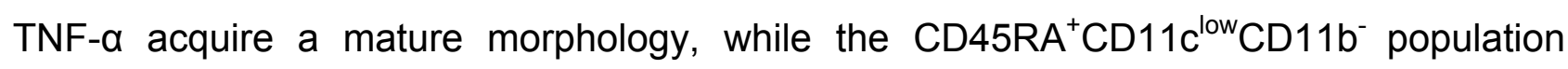
represents the pDCs which mature in the presence of stimuli such as CpG (46). Both pDCs and cDCs precursors are constantly produced in the bone marrow during adult life and are also continuously released into the circulation. However, from here the two subsets display quite different migration patterns (47). Precursor cDCs both seed 
peripheral and lymphoid tissues, in which they convert into migratory cDCs and lymphoid tissue-resident cDCs, respectively (48). While the migratory DCs serve as Ag-sampling DCs in the peripheral tissues and migrate to lymphoid tissues upon maturation, lymphoid tissues-resident cDC collect Ags directly in the lymphoid tissue $(10,36)$. Plasmacytoid DCs migrates predominantly to secondary lymphoid tissues and are relatively infrequent in most peripheral tissues $(47,49,50)$. Despite expressing many of the same inflammatory chemokine receptors as immature migratory cDCs, pDCs exhibit only a weak capacity in vitro to migrate toward chemokines like CCL2, CCL5 and CCL20. Instead, pDCs migrate effectively toward CCL19 and CCL21 allowing them to directly enter lymph nodes through HEV (51). Both cDCs and pDCs also reside in the spleen and they enter the spleen from the circulation in the marginal zones (52), but the exact signals that recruit DCs to the spleen are still unknown (3). The different migration pattern of cDCs and pDCs points to a primary involvement of $\mathrm{cDCs}$ in inflammation while pDCs may be involved in the homeostatic control of the immune response (51).

Lymphoid tissue-resident cDCs and pDCs will be described in detail below.

\subsubsection{Conventional DCs}

In mice lymphoid tissue-resident cDCs can be further divided in three major subsets based on their expression of CD8 $\alpha$ and CD4; i) the CD8 $\alpha^{+}$DC subset expresses CD8 $\alpha$ but lacks CD4, ii) the $\mathrm{CD}^{+}$subset expresses CD4 but lacks CD8a, and iii) the double negative subset that is negative for both CD8 $\alpha$ and CD4 (53). The DC subset denoted the CD8 $\alpha^{-}$ DCs includes both the CD4 ${ }^{+} \mathrm{DCs}$ and the double negative DCs. All three subsets express CD11C (54). The CD8a ${ }^{+}$DCs are generally located in the T cell areas of the spleen, whereas the CD8 $\alpha^{-}$DCs are located in the red pulp and the marginal zones (55-57). Upon treatment with lipopolysaccaride (LPS) all DCs translocate to the T cell areas (58). cDCs are specialized Ag processing and presenting cells $(56,59)$. A number of studies suggest that the two subsets, $C D 8 \alpha^{+}$vs $C D 8 \alpha^{-} D C s$, have different capabilities for activating $B$ and $\mathrm{T}$ cells. Both subsets can prime Ag-specific $\mathrm{T}$ cells, but $\mathrm{CD} \alpha^{+} \mathrm{DCs}$ trigger the development of a Th1 response, whereas the CD8 $\alpha^{-}$DCs induce a Th2 response $(55,60)$. Furthermore, the CD8 $\alpha^{+}$and $\mathrm{CD}^{-} \alpha^{-}$DCs differ in their ability to process $\mathrm{Ag}$ and present the antigenic peptides. Studies have shown that $C D 8 \alpha^{+} \mathrm{DCs}$ are superior in their capacity to cross-present $\mathrm{Ag}$ and thereby to prime $\mathrm{CD}^{+} \mathrm{T}$ cells $(54,61)$. In contrast, CD8 $\alpha^{-} \mathrm{DCs}$ are 
shown to be more efficient at activating $\mathrm{CD}^{+} \mathrm{T}$ cells and inducing strong humoral responses upon Ag uptake $(56,62)$.

\subsubsection{Plasmacytoid DCs}

Plasmacytoid DCs (pDCs) are a group of DCs that are characterized by the expression of CD11c ${ }^{\text {low }}, B 220$, Ly6C (Gr-1), CD4, CD8 a and Siglec H $(49,50,63)$. Steady-state pDCs are located in the $\mathrm{T}$ cell areas of lymph nodes, primarily around high endothelial venules, and in the spleen (64). Immature pDCs appear round in shape with a plasma cell-like morphology, whereas the mature counterparts acquire a dendritic morphology (50).

pDCs are specialized in secretion of type I interferons (IFN- $\alpha / \beta)$, which makes them critical mediators of antiviral responses (65). pDCs detect RNA and DNA viruses through two Tolllike receptors (TLRs) (TLR7 and TLR9), which induce secretion of type I IFNs via MyD88 and IRF7 signalling. Type I IFNs provide resistance to viral infections and promote the function of NK cells, DCs, T and B cells $(66,67)$. Recently, Swiecki et al. showed that the numbers and/or the function of pDCs appear to be regulated during viral infections, possibly by a feedback control mechanism by which type I IFNs regulate the number of pDCs. Such a mechanism could be used to fine-tune systemic type I IFN responses following viral infections (65).

In addition to production of type I IFNs, pDCs may also activate adaptive immunity. As with immature cDCs, freshly isolated pDCs are poor inducers of T cells and have even been shown to convert Ag-specific T cells into regulatory T cells $(68,69)$. On the other hand, several studies have also demonstrated that pDCs were capable of initiating $\mathrm{T}$ cell proliferation, suggesting a flexibility of pDCs in directing $\mathrm{T}$ cell responses, which is likely related to the specific activating stimuli, the maturation stage and the nature of the $\mathrm{Ag}$ (7073). Activation of pDCs leads to up-regulation of $\mathrm{MHC}$ class II and co-stimulatory molecules (CD80, CD86) and presentation of $\mathrm{Ag}$ to $\mathrm{T}$ cells, although not as efficient as cDCs (73-75).

With the identification of several different DC subsets it becomes increasingly evident that Ag-delivery to specific DC subsets, that display distinct Ag processing and presenting capabilities, allows for the design of vaccination strategies that more precisely control the type of immune response initiated upon Ag-delivery $(76,77)$. 


\subsection{Antigen recognition receptors on DCs}

In order to sample the environment in peripheral tissues, immature DCs constitutively take up extracelluar fluid by macropinocytosis, but DCs also take up Ags via phagocytosis and receptor-mediated endocytosis (78). For this purpose they express different groups of receptors that can be divided into three major classes: C-type lectin receptors (CLRs), Fc receptors (FcRs) and scavenger receptors $(14,79)$. The different immunological outcomes mediated by activation of distinct DC subsets may partly be based on differential expression of these Ag receptors. CLRs are predominantly expressed by phagocytic cells like DCs and macrophages (80). They recognize different carbohydrate structures but are not able to differentiate between carbohydrate structures of self or non-self origin. Thus, Ag uptake by CLRs does not necessarily result in potent $T$ cell activation (81). Nevertheless, CLRs are important for recognition and internalization of glycosylated Ags leading to processing and presentation of antigenic peptides on MHC I and MHC II molecules on DCs $(77,81)$. The CLRs will be described in more details below.

Fc receptors are expressed on a wide variety of immune cells, e.g. on phagocytic cells like macrophages, DCs and neutrophils and on non-phagocytic cells like NK cells and mast cells (82). Fc-receptors do not directly bind Ags but recognize the Fc portion of antibodies and through this interaction they mediate uptake of Ag-antibody complexes leading to increased Ag presentation compared to macropinocytosis. Engagement with FcRs can result in either immune activation or inhibition, depending on the particular type of FcR that is affected (82-84). Scavenger receptors (SR) are expressed by macrophages, DCs and certain endothelial cells. They play an important role in uptake and clearance of effete components, such as modified host molecules and apoptotic cells. They bind and internalize pathogens and pathogenic products including Gram-positive bacteria (lipoteichoic acid), Gram-negative bacteria (LPS), intracellular bacteria and CpG DNA $(85,86)$.

Antigen recognition by these different receptors facilitates Ag-delivery to distinct endosomal compartments and may ultimately favour either the class I or class II MHC presentation pathway. Thus, the route of $\mathrm{Ag}$ internalization may be important for crosspresentation of the antigenic peptides (14,87). For instance, immunoglobulin (lg)opsonized $\mathrm{Ag}$ endocytosed by $\mathrm{Fc}$ receptors promotes presentation on MHC class I molecules (88), whereas Ag endocytosed by the CLR, CD205, promotes presentation on 
MHC class II (89). Another difference between FcRs and CD205 is that while FcR is degraded together with its ligand, CD205 recycles to the surface and mediates additional rounds of $\mathrm{Ag}$ uptake (79). Thus, Ag binding to these different $\mathrm{Ag}$ receptors may indeed facilitate varying presentation of antigenic peptides to $T$ cells resulting in induction of different types of immune responses.

\subsubsection{C-type lectin receptors}

CLRs bind sugar residues in a calcium-dependent manner using highly conserved carbohydrate recognitions domains (CRDs), which contain calcium-binding pockets (77). Besides being directly involved in ligand binding, $\mathrm{Ca}^{2+}$-ions are also involved in maintaining the structural integrity of the CRD that is necessary for the lectin activity (90). The number of CRDs present in the lectin receptors differs ranging from expression of a single CRD (e.g. mouse CD209) and to a sequence of up to ten CRDs (e.g. human CD205). The structure of the CRDs as well as the combination of different CRDs expressed by one receptor allows the binding of specific carbohydrates (79). For example, CD206 binds to end-standing single mannose residues, whereas CD209 binds to mannose only when complexed with other carbohydrate structures (91).

CLRs are either produced as transmembrane proteins or secreted as soluble proteins. Based on their molecular structure, two groups of membrane-bound CLRs can be distinguished on DCs and are divided depending on the orientation of their amino terminus. Type I CLRs have their amino termini pointing outwards whereas type II CLRs have their $\mathrm{N}$ termini directed into the cytoplasm (77,90,92). Type I CLRs contain several CRDs or CRD-like domains, while the type II receptors identified so far only contain a single CRD (Figure 2) (77). 


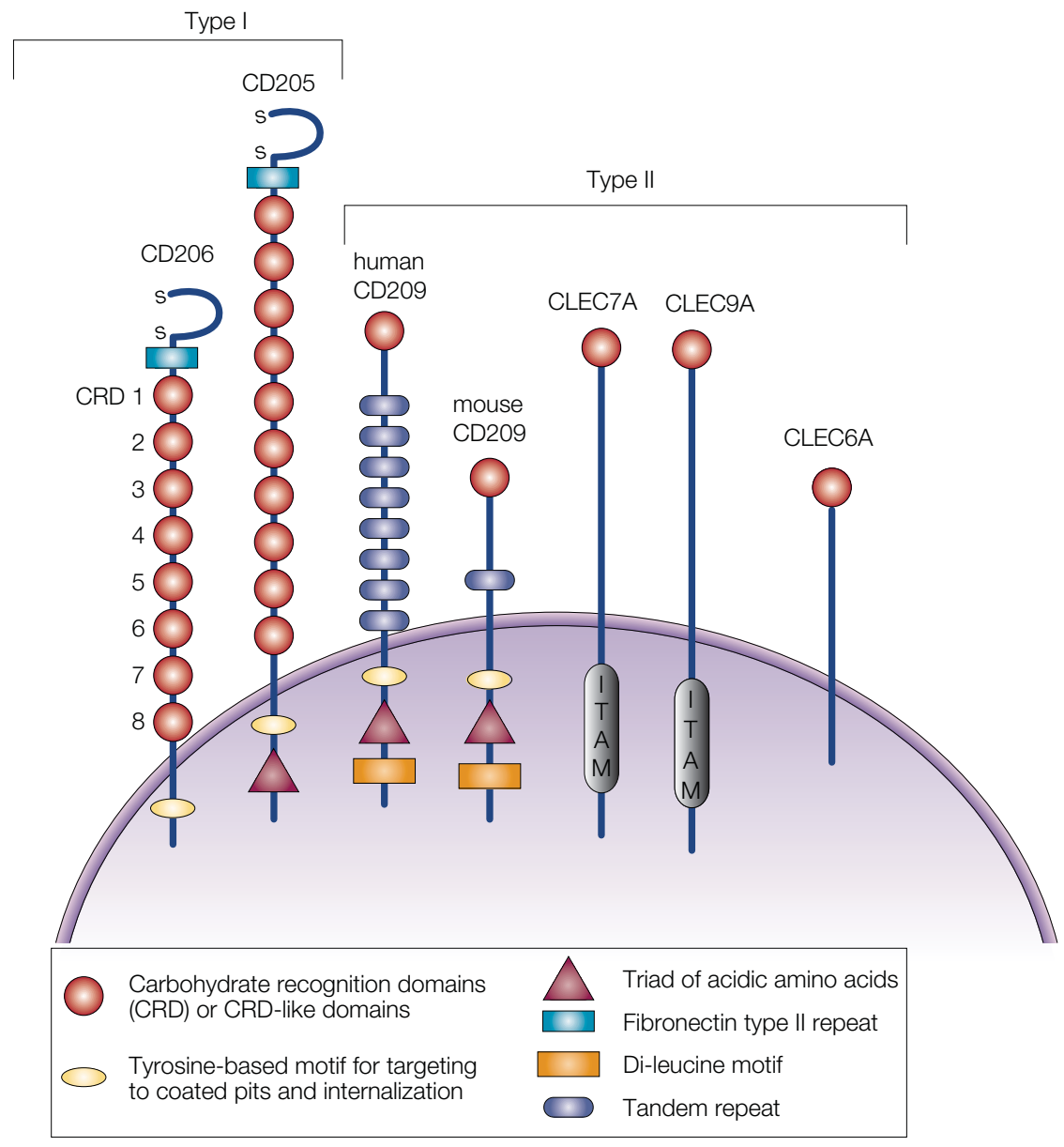

Figure 2. The two groups of C-type lectins or lectin-like molecules produced by DCs or LCs. The structure of the human and mouse homologues of CD209 is very different and both are shown in the figure. All other CLRs shown are structurally very similar between human and mouse and only the human homologues are shown.

ITIM: Immunoreceptor tyrosine-based inhibitory motif, ITAM: Immunoreceptor tyrosine-based activation motif). The figure is modified from (77).

\subsubsection{Expression of C-type lectins on DCs}

According to current literature, the CLRs tested in this project have an expression profile as displayed in table $1(61,62,76,77,93-98)$. 


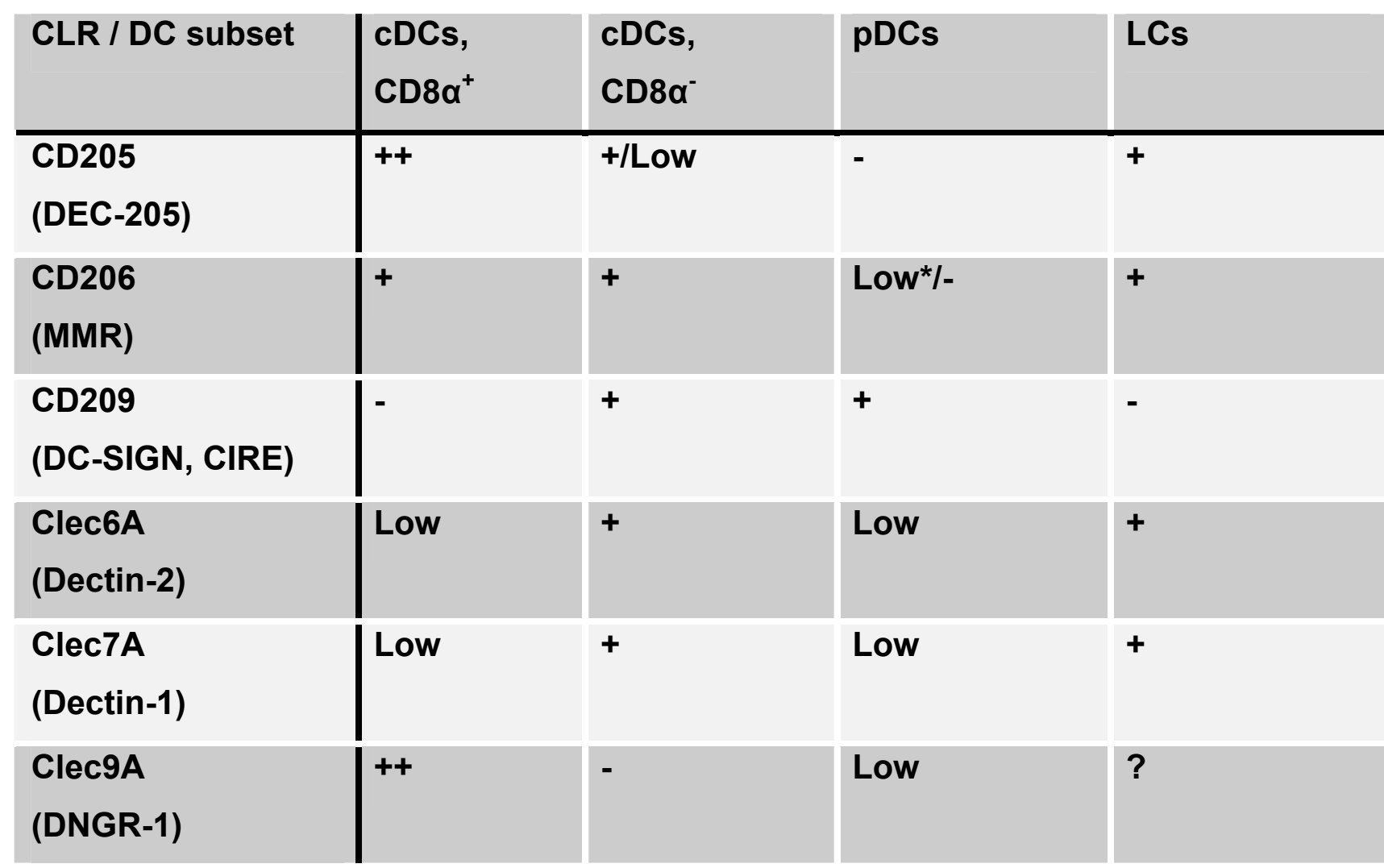

Table 1. Expression of C-type lectin receptors on different mouse DC subsets.

* MMR was detected in permeabilized pDCs from 129/SvEv mice, but this finding could not be confirmed in C57BL/6J mice (95).

\subsection{Antigen presentation by DCs}

APCs usually present extracellular Ags on MHC class II molecules and activate $\mathrm{CD}^{+} \mathrm{T}$ helper cells, while Ags that are synthesized intracellularly, like cytosolic Ags of viral origin, usually are presented on $\mathrm{MHC}$ class I molecules and activate $\mathrm{CD} 8^{+}$cytotoxic $\mathrm{T}$ cells $(87,99)$. However, DCs have the capacity to cross-present exogenous Ags on MHC class I molecules $(14,100,101)$.

Internalization of Ags mostly leads to degradation into peptides that associate with MHC class II molecules via the endosomal pathway (78). Upon internalization from the plasma membrane, $\mathrm{Ag}$ is located in vesicular compartments named early endosomes (EE), characterized by neutral $\mathrm{pH}$. Endosomal maturation causes fusion of $\mathrm{EE}$ with late compartments resulting in late endosomes (LE) displaying lower pH than EE. Further acidification of LE is mediated by fusion with lysosomes containing proteases and hydrolases with low $\mathrm{pH}$ optima which can degrade the luminal contents into small peptides for presentation on the MHC class II molecules also present in this compartment 
$(102,103)$. Notably, DCs harbour mechanisms that prevent the rapid acidification of endosomal compartments allowing endocytosed contents to remain intact for a prolonged time which have been associated with enhanced cross-presentation $(104,105)$.

For presentation of endogenous Ags on MHC class I molecules, cytosolic proteins are degraded into small peptides by proteasomal proteolysis, translocated via TAP transporters into the endoplasmic reticulum (ER) and loaded onto MHC class I molecules (78). For presentation of exogenous Ags on MHC class I molecules, two main routes have been proposed: the cytosolic and vacuolar pathway (103). The cytosolic pathway involves transport of endocytosed $\mathrm{Ag}$ into the cytosol for proteasomal degradation followed by translocation of peptides into ER and thereby entrance into the classical MHC class I pathway (106). In contrast, the vacuolar pathway does not require translocation of Ag from endosomal compartments to the cytosol, but utilizes endosomal proteases for generation of antigenic peptides $(107,108)$. For efficient endosomal peptide/MHC class I loading, class I MHC molecules must be delivered into the peptide loading compartment, which is achieved by constitutively internalization of cell surface MHC class I molecules (109). Internalized peptide-class I MHC complexes disassociate in the acidic environment $(\mathrm{pH} \sim$ 5 ) in LE, which facilitates peptide exchange (107). Endosomal peptide loading may contribute to rapid cross-presentation of endocytosed antigenic peptides decreasing the risk for competition with endogenous peptides present in the ER (103). Following assembly of peptide-class I MHC complexes, these complexes must be translocated to the cell surface. The route by which this happens depends on the location for peptide loading. Peptides loaded in the ER are probably transported via the biosynthetic pathway to the cell surface, whereas endosomal loading may rely on the endosomal recycling pathway for surface presentation of peptide-class I complexes (107). During endocytosis, membrane proteins and lipids are continuously taken up into endosomal compartments and to ensure steady surface display most of these proteins and lipids must rapidly be returned to the plasma membrane through endosomal recycling. Studies on inhibition of endosomal recycling demonstrated impaired cross-presentation of exogenous Ags supporting the hypothesis that endosomal recycling pathways are involved in cross-presentation (110113).

Regardless of the particular pathways used, the ability of DCs to cross-present Ags is an important feature for vaccination strategies aiming at generating potent cellular responses 
directed against tumours or pathogens that are inefficiently cleared by the humoral immune response (100).

\subsection{Lymphocytes}

Lymphocytes originate from a common lymphoid progenitor, which give rise to $T$, $B$ and NK cells. T and B cells are antigen-specific lymphocytes of the adaptive immune response, while the NK cells is part of the innate immune response and respond to infection in an unspecific manner. NK cells will not be described further.

Both $\mathrm{T}$ and $\mathrm{B}$ cells originate in the bone marrow, but while $\mathrm{B}$ cells mature in this organ, $\mathrm{T}$ cell precursors migrate to the thymus and mature here. Once matured both types of lymphocytes enter the bloodstream and circulate through secondary lymphoid organs until they either meet their corresponding Ags or die. Interaction between Ags and lymphocytes takes place in the secondary lymphoid organs. T cells recognize its specific Ag only when it is presented as peptides in complex with MHC on the surface of an APC $(114,115)$. On the contrary, B cells can recognize Ags in their native three-dimensional conformation. Beside Ag recognition, lymphocytes require additional signals in order to become activated and acquire effector function. For $\mathrm{T}$ cells, the essential secondary signal is initiated through co-stimulatory molecules expressed mainly on the surface of APCs, including DCs, monocytes/macrophages and B cells, where only DCs are able to activate naive T cells efficiently and thereby to initiate primary immune responses (6). For B cells, these signals are delivered by activated $T$ helper cells $(116,117)$. Antigen encounter without accompanying co-stimulatory signals leads to anergy or peripheral clonal deletion. In contrast, $\mathrm{Ag}$ encounter in the presence of co-stimulatory signals, induce proliferation of lymphocytes and differentiation into effector cells $(24,26)$. Some effector T cells remain in the lymphoid tissues to activate B cells (follicular helper $\mathrm{T}$ cells), while others migrate to the site of infection (cytotoxic and helper $T$ cells) (118). In the case of B cells, the differentiated effector cells are the antibody-secreting plasma cells. Some of these cells stay in the lymphoid tissues, but most plasma cells migrate to the bone marrow for production of large amounts of antibodies $(118,119)$. 


\subsubsection{T cells}

T cells can be divided in two major classes, which have different effector functions and are distinguished by the expression of the cell-surface co-receptors CD4 and CD8. These coreceptors bind to invariant sites on the $\mathrm{MHC}$ molecule and are required for an effective $\mathrm{T}$ cell response. CD4+ T cells recognize peptides presented on $\mathrm{MHC}$ class II molecules whereas CD8+ $\mathrm{T}$ cells recognize pathogenic peptides presented on $\mathrm{MHC}$ class I molecules. Ag-specific activation of naïve $\mathrm{T}$ cells and the subsequent proliferation and differentiation into effector cells constitute a primary cell-mediated immune response. In addition to providing effector cells, primary immune responses generate memory $\mathrm{T}$ cells, which provide protection from subsequent challenge by the same Ag/pathogen. Effector cells have undergone important changes, one of which is a change in their activation requirements. Once a $\mathrm{T}$ cell has differentiated into an effector cell subsequent $\mathrm{Ag}$ encounter elicits immune responses without the need for co-stimulatory signals. This feature is important for CD8+ T cells as they have to act on any infected cell regardless of the presence of co-stimulatory molecules on these cells. In addition, CD4+ T cells must be able to activate B cells and macrophages that have taken up Ags, even if these cells do not express co-stimulatory molecules (118).

Naïve CD8+ T cells differentiate into cytotoxic T cells specialized for antigen-specific killing via cell-cell contacts and production of cytokines like IFN-y. Cytotoxic T cells are important in the defence against intracellular pathogens, especially viruses, but also in antitumour immune responses (120). Naïve CD4+ T cells differentiate into a number of subsets of effector cells (Th1, Th2, Th17, $\mathrm{T}_{\text {regs }}, \mathrm{T}_{\mathrm{FH}}$ ) depending on the nature of the signals they receive during priming (118).

\subsection{Targeting dendritic cells}

Since the 1990s, the immunotherapeutic potential of DCs has been explored in clinical settings $(100,121)$. The idea of harnessing the potential of DCs to induce immune responses, coupled with the capacity to generate large numbers of DCs ex vivo, gave rise to DC-based vaccines $(100,121)$. Such vaccines consist of ex vivo generated Ag-loaded autologous DCs that are administered to patients with the intention of inducing Ag-specific immune responses (100). Although these vaccines proved safe, clinical results have been limited. Furthermore, the production of these cell-based vaccines are very laborious and 
expensive (76). An alternative strategy to the ex vivo-generated DC-based vaccines, is to directly deliver Ags to specific surface receptors on DCs in vivo. During the past decades numerous studies have explored the effect of targeted delivery of Ag to several different receptors on DCs (Figure 3). Targeted delivery of Ags to DCs in vivo might benefit from reaching multiple and even rare DC populations in their natural environments and avoiding the step of in vitro generation of DCs from monocytes. In fact, one of the problems of the cell-based DC vaccines may be the generation of DCs with poor immuno-stimulatory potential, which most likely contributes to the disappointing clinical effects obtained with these vaccines. In contrast, targeted delivery of Ag to distinct subpopulations in vivo may circumvent this problem and even allow for the design of DC-targeted vaccines that more precisely control the type of immune response initiated upon vaccination (76).

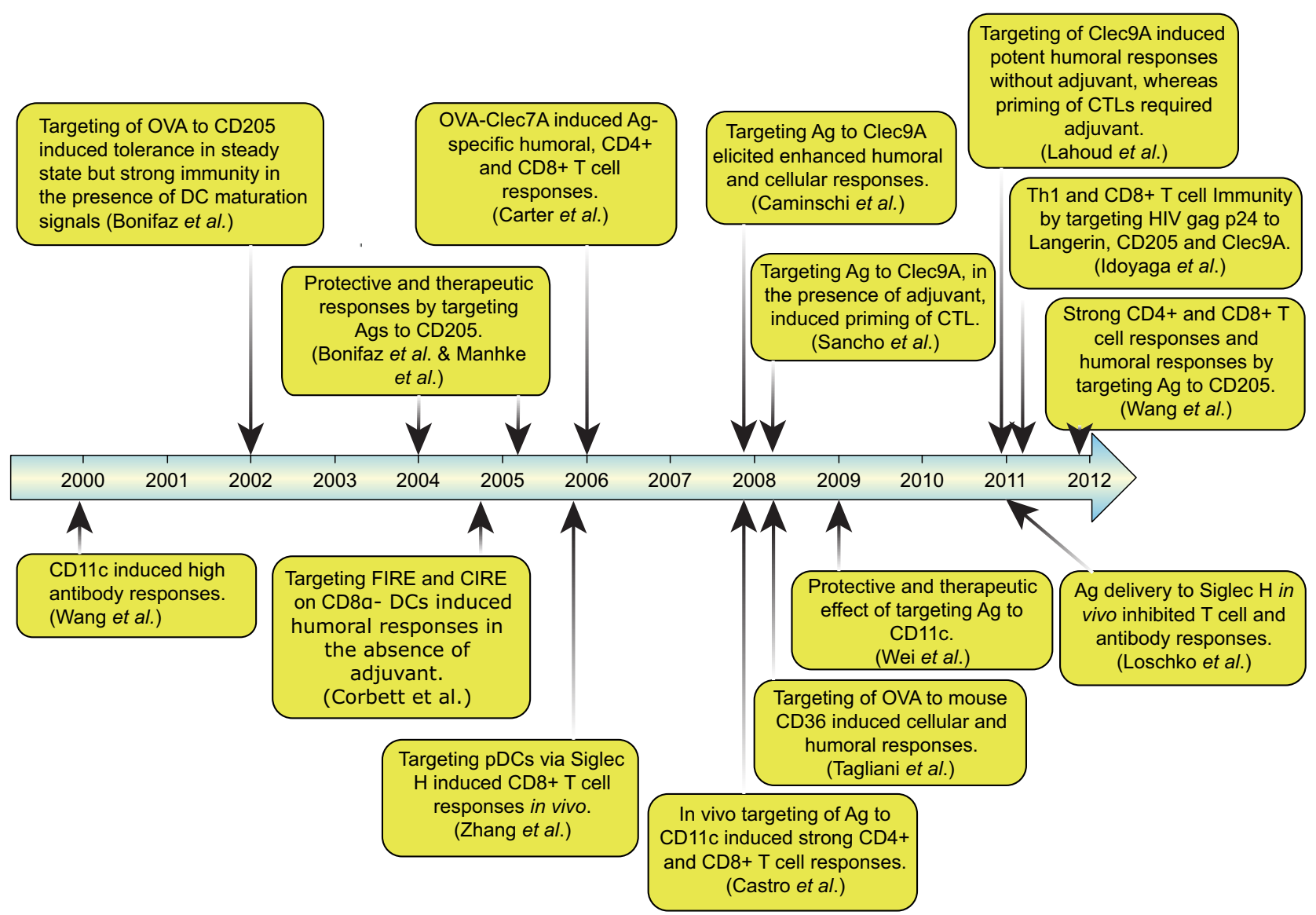

Figure 3. Progress in DC-targeted Ag-delivery. The figure depicts a timeline of some selected targeting studies performed from 2000 to 2012 . The figure is modified from (76). 


\subsection{Targeting of antigens to specific receptors}

\subsubsection{C-type lectin receptors}

The majority of receptors explored in DC-targeting studies belong to the family of CLRs (76). A review of the targeting of Ag to different CLRs is presented below.

\section{CD205/DEC-205}

CD205 is a type I CLR containing 10 CRDs and a specific triad of acidic amino acids in its carboxyl terminus $(89,122)$. The human and mouse CD205 are structurally similar, and the only difference is the number of CRDs of which human CD205 contains 10 CRDs while mouse CD205 contains 9 CRDs. Unlike mouse CD205, which is predominantly expressed on DCs (123), human CD205 is expressed on several cell types, including DCs, monocytes and B, T and NK cells (122). CD205 is an endocytic receptor, with still unknown ligand specificity, but its high-level expression on DCs in the T cell area of lymphoid tissues suggests a function in regulation of T cell responses $(124,125)$. CD205 is internalized by means of coated pits and vesicles, and recycles beyond early endosomes but through late endosomes or lysosomes rich in MHC class II molecules. This distinct intracellular trafficking of CD205 is mediated by the specific acidic amino acids present at its cytoplasmic tail $(89,124)$.

Initial studies on targeting of Ag to CD205 using rabbit antibodies specific for mouse CD205 demonstrated a 100-fold more efficient $T$ cell response compared to a nontargeting rabbit lgG (124). Later, Bonifaz et al. demonstrated that in vivo targeting of ovalbumin (OVA) to CD205 induced tolerance in the steady state whereas strong immunity required co-administration of DC maturation signals, like anti-CD40 or CFA (26). The necessity for DC maturation was supported in a study by Corbett et al. in which targeting of CD205 only triggered antibody responses in the presence of CpG adjuvant (62). In addition, two separate groups demonstrated that, in the presence of adjuvant, targeting of the HIV Gag p24 to CD205 using a fusion monoclonal antibody (mAb) induced both high levels of Ag-specific Th1 responses as well as improved cross-presentation and priming of Ag-specific CD8 ${ }^{+} \mathrm{T}$ cells $(126,127)$. Cheong et al. did also describe strong humoral responses following targeted delivery of $\mathrm{Ag}$ to $\mathrm{CD} 205$, still in the presence of adjuvant (126). Several studies have explored the effect of targeting tumour-specific Ags to CD205 
as a means of inducing protective and therapeutic immune responses. Mahnke et al. described that targeting of different melanoma Ags (tyrosine-related protein-2 and gp100) to CD205 in vivo induced potent melanoma-specific CD4 and CD8 responses when a Tolllike receptor ligand (CpG) was co-injected. The CD205-targeted vaccination protected mice against challenge with tumour cells and slowed the growth of established B16 cells (128). In addition, Bonifaz et al. demonstrated that simultaneous injection of an OVA-linked mAb specific for CD205 and anti-CD40 primed naïve CD4 ${ }^{+}$and CD8 ${ }^{+} \mathrm{T}$ cells and mediated both protective and therapeutic effects towards an OVA-expressing B16 melanoma (129). Recently, a study by Wang et al. determined the immunogenicity of a CD205-HER2 (human epidermal growth factor) fusion $\mathrm{mAb}$ in a mouse breast cancer model and described that the fusion mAb elicited strong $C D 4^{+}$and $C D 8^{+} \mathrm{T}$ cell responses as well as humoral immunity specific for HER2 Ags. In addition, CD205-HER2 vaccinated mice were protected from tumour challenge, a protection mediated by both $\mathrm{CD} 4^{+}$and $\mathrm{CD} 8^{+} \mathrm{T}$ cells (130).

\section{CD209/DC-SIGN}

CD209/DC-SIGN (DC-specific ICAM-grabbing non-integrin) is a member of the type II CLRs with a single CRD displaying specificity for mannose residues (131). Importantly, the structure of the mouse and human homologues of CD209 is very different. A major structural difference is the length of the neck region as the human CD209 contains a long extracellular neck region with 7 complete and 1 incomplete tandem repeats. In contrast, the mouse CD209 has a shorter neck region sharing considerable homology with the single repeat unit present in the neck of human CD209 $(132,133)$. The exact function of the neck region remains unknown, but studies have indicated that the neck region is involved in multimerization of the receptor which may be important for high-avidity binding to pathogens (133). The expression pattern of human and mouse CD209 is similar with both receptors predominantly expressed on DCs and some macrophages $(96,134,135)$. CD209 was first identified in human placenta as a gp120 (a HIV envelope glycoprotein)binding protein (131) that facilitates DC-mediated transmission of HIV to CD4 ${ }^{+} \mathrm{T}$ cells suggesting that binding of virus to CD209 in humans could be involved in mucosal transmission of HIV as CD209 ${ }^{+}$DCs are present at mucosal surfaces (136). In addition, human CD209 interact with several other pathogens including viruses such as human 
cytomegalovirus (HCMV) and Ebolavirus, bacteria such as Mycobacterium and parasites such as Leishmania mexicana (137). In contrast, studies on mouse CD209 could not demonstrate interaction with HIV, HCMV, Ebolavirus glycoprotein or Leishmania mexicana, which may be due to the structural differences of the CRD and neck region of the two receptors $(96,133)$. CD209 has also been reported to be a cell adhesion receptor that upon binding to ICAM-3 mediates transient interaction between DCs and resting T cells (134). Furthermore, CD209 functions as an Ag receptor that endocytoses soluble ligands into late endosomal/lysosomal compartments, resulting in processing and subsequent presentation of antigenic peptides in complex with MHC class II to $\mathrm{CD}^{+}{ }^{\mathrm{T}}$ cells (91). The dual role of CD209 in adhesion and Ag uptake provides DCs with a functional receptor that in peripheral tissues takes up $\mathrm{Ag}$ and upon arrival in secondary lymphoid tissues mediates interaction with T cells (91).

Based on the great functional differences among human and mouse CD209, mouse CD209 is inadequate as a model for human CD209 explaining the lack of in vivo targeting studies on mouse CD209 (138). Instead, several targeting studies have been performed using the human CD209 (91,139-142). A study from 2008 compared the efficiency of in vitro targeting of $\mathrm{Ag}$ to DCs using either a humanized antibody specific for human CD209 or cell-penetrating peptides (CPPs) (140). CPPs are positively charged peptides that deliver macromolecules such as proteins, oligo-nucleotides, and plasmid DNA into living cells (143). The exact mechanism by which CPPs mediate intracellular delivery of their cargo is still not clear, but it has been demonstrated that CPPs enter cells via endocytosis (144). CPPs have been proposed to favour cross-presentation as they may facilitate uptake and endosomal escape of conjugated Ags (145). The study demonstrated that CPPs and anti-CD209 were equally potent in mediating cross-presentation of conjugated Ags when targeted to human monocyte-derived DCs in vitro (145). Another study by Tacken et al. demonstrated that cross-linking of a model $\mathrm{Ag}$, keyhole limpet hemocyanin (KLH), to an anti-human CD209 antibody effectively induced both Ag-specific naïve and recall T cell responses in vitro (139). Later on, in 2011, Tacken et al. evaluated the effect of targeting CD209 through antibodies specific for the anti-neck region of the receptor, as previous studies all used antibodies directed at the CRD of CD209 (141). They found that anti-neck and anti-CRD antibodies were differentially internalized. Anti-CRD induced a clathrin-dependent internalization and mainly channelled Ags into late endosomal 
compartments, whereas the uptake of anti-neck was clathrin-independent and shuttle Ags into early endosomal compartments rich in MHC class I molecules (146). This study demonstrated that intracellular routing of targeted Ags depends on the particular epitope recognized by the targeting antibodies. In addition, Tacken et al. investigated the effect of targeting anti-neck/OVA-conjugates to bone marrow-derived DCs (BM-DCs) from mice carrying the human CD209 transgene under the promoter of CD11c and described induced proliferation of both OT-II and OT-I T cells (146).

\section{Clec9A/DNGR-1}

Clec9A is a type II CLR with one CRD and a cytoplasmic immunoreceptor tyrosine-based activating motif (ITAM)-like motif (147). Clec9A has been shown to be expressed by the mouse CD8 $\alpha^{+}$subset of cDCs as well as on mouse pDCs $(93,148)$. Clec9A is expressed at the cell surface as a glycosylated dimer and can mediate endocytosis but not phagocytosis (147). Clec9A is a DAMP recognition molecule that senses the presence of necrosis and is specialized for the uptake and processing of dead-cell associated Ags $(12,149)$. A newly published study identified the dead cell ligand for Clec9A as being a cytoskeletal component of normal cells, exposed upon cell death or membrane rupture which may occur during lysis or physical damage. The cytoskeletal DAMPs recognized by this receptor were identified as a filamentous form of actin complexed with molecules containing the calponin homology-based actin binding domain (ABD) motif of skeletal molecules (12).

Several studies have investigated the potential of targeting Ags to Clec9A $(93,148-150)$. The first study on targeting of Ags to Clec9A was published in 2008 by Caminschi et al. who described that targeted delivery of Ags to Clec9A using $\mathrm{mAb}$ induced a marked enhancement of humoral responses as well as enhanced CD4 and CD8 T cell proliferative responses, even in the absence of adjuvants (148). At the same time Sancho et al. demonstrated that $\mathrm{Ag}$ epitopes covalently linked to a mAb specific for Clec9A were presented on $\mathrm{CD}^{+} \mathrm{\alpha}^{+} \mathrm{DCs}$ in complex with $\mathrm{MHC}$ class I molecules and when coadministered with adjuvants induced potent priming of cytotoxic $T$ cells that were able to eradicate tumours (93). In addition, they described that a single injection of anti-Clec9A linked to an OVA peptide injected in combination with anti-CD40 prevented B16-OVA implantation (93). A later study by Joffre et al. demonstrated that targeted delivery of Ag to 
Clec9A could also promote MHC class II Ag presentation by CD8 $\alpha^{+} \mathrm{DCs}$. However, in the absence of adjuvants, Clec9A induced weak antibody responses and instead of $\mathrm{T}$ cell priming, targeting of $\mathrm{Ag}$ lead to proliferation of $\mathrm{Ag}$-specific naïve $\mathrm{CD}^{+} \mathrm{T}$ cell that differentiated into Foxp $^{+}$regulatory T cells (149). In contrast, when anti-Clec9A was administered in combination with an adjuvant, tolerance was prevented and targeting promoted development of potent antibody and Th1 or Th17 responses (149). In 2011, Lahoud et al. compared Ag-delivery to three different receptors predominantly expressed by $\mathrm{CD} \mathrm{a}^{+} \mathrm{DCs}$, namely Clec9A, CD205 and Clec12A. They found that induction of cytotoxic $T$ cells required co-administration of adjuvants and were mediated by Clec9A and CD205 but not by Clec12A (150). In addition, targeting of Ags to Clec9A induced potent humoral responses, even in the absence of adjuvant, while Clec12A and CD205 only elicited moderate antibody responses. Co-administration of adjuvant enhanced the humoral responses obtained from targeting $\mathrm{Ag}$ to Clec12A and CD205 but the response seen with Clec9A was still superior. This superior effect of targeting Ag to Clec9A could be explained by the ability to induce more extensive $\mathrm{CD}^{+} \mathrm{T}$ cell expansion and by a greater transformation of these cells into follicular helper $\mathrm{T}$ cells, which are crucial for antibody production (150).

\section{Clec7A/Dectin-1}

Clec7A is a type II CLR with a single CRD and an activating ITAM-like motif in its cytoplasmic tail (151). Clec7A is atypical compared to other CLRs in that carbohydrate recognition is $\mathrm{Ca}^{2+}$-ion independent (152). Clec7A is a major receptor for $\beta$-glycans with the ability to recognize and endocytose a number of fungal species including Candida Albicans, Pneumocystis carinii and Saccharomyces cerevisiae $(153,154)$. Upon interaction with such organisms in vitro, Clec7A mediates uptake and killing of live fungal particles through induction of the respiratory burst and production of protective inflammatory cytokines and chemokines $(153,155)$. Signalling from Clec7A is sufficient for some of these responses, but induction of respiratory burst and proinflammatory cytokines requires cooperative signalling from MyD88-coupled TLRs, like TLR2 and TLR6 (156). Based on this ability to recognize fungal pathogens and initiate an inflammatory response, Clec7A displays the characteristics of a pattern recognition receptor that could serve to link innate and adaptive immunity, and although the function of Clec7A in vivo is not entirely clear, 
studies on Clec7A-deficient mice support a role for Clec7A in anti-fungal immunity (157). Clec7A might also display other functions beside the anti-fungal activity. Clec7A is thought to recognize an endogenous ligand on $T$ cells leading to activation and proliferation suggesting that Clec7A may function as a co-stimulatory molecule (151); a function supported by its expression on APCs in the T cell areas of secondary lymphoid tissues. In the mouse Clec7A was originally identified as a DC-specific marker (151), however, later studies demonstrated its expression on several other cell types, including macrophages, monocytes and neutrophils $(158,159)$. Carter et al. characterized the expression of Clec7A on splenic mouse DC subpopulations and showed that Clec7A was expressed on the CD8a- subset of DCs. In addition, they investigated the effect of targeting Ags to Clec7A in vivo in mice and demonstrated that injection of OVA-anti-Clec7A conjugates, in combination with poly I:C, induced both $\mathrm{CD} 4^{+}$and $\mathrm{CD} 8^{+} \mathrm{T}$ cell responses as well as OVAspecific antibody responses (98).

\subsubsection{Other receptors}

\section{$\underline{\mathrm{CD} 11 \mathrm{C}}$}

CD11c is also known as the integrin $\alpha X$ and forms with the $\beta 2$ integrin (also known as CD18) a receptor designated complement receptor 4 . The receptor is a member of the family of $\beta 2$-integrins that also includes LFA-1 and Mac-1. CD11c have been reported to be involved in binding iC3b, iC3b-opsonized particles as well as in adhesion of monocytes and granulocytes to endothelium, but the exact role of CD11c is unclear (160-162). The human CD11c/CD18 complex is expressed on macrophages, monocytes, granulocytes, activated $B$ cells and some $T$ cell populations (161), while the mouse CD11c complex has a more restricted expression pattern and CD11C are widely used as a DC-specific surface marker in mice (163-165).

Several studies have investigated the effect of Ag-delivery to CD11c on DCs. Castro et al. showed that in vivo targeting of $\mathrm{Ag}$ to DCs via CD11c resulted in efficient $\mathrm{Ag}$ processing and presentation of peptides on both $\mathrm{MHC} \mathrm{I} \mathrm{and} \mathrm{MHC} \mathrm{II} \mathrm{molecules} \mathrm{inducing} \mathrm{robust} \mathrm{CD4}{ }^{+}$ and $\mathrm{CD}^{+} \mathrm{T}$ cell responses (160). Others have shown that Ag-delivery to CD11c elicited high antibody responses (166). Furthermore, studies using fusion proteins, consisting of the extracellular domain of human HER2 fused to the single-chain fragment variable 
specific for CD11c, have shown that vaccination with such fusion proteins induced strong HER2-specific $\mathrm{CD}^{+}$and $\mathrm{CD}^{+}{ }^{+} \mathrm{T}$ cell responses as well as HER2 antibody responses. Additionally, vaccination protected mice from subsequent challenge with HER2-positive murine breast tumour cells. Therapeutic effects were also seen as vaccination elicited rejection of established HER2-positive tumours (164).

\section{CD36}

CD36 is a multi-ligand receptor that belongs to the class $B$ scavenger receptor family (167). CD36 recognizes a wide range of hydrophobic ligands of either endogenous or exogenous origin. The endogenous ligands are native molecules, such as collagen and long-chain fatty acids (LCFA), or modified molecules like oxidized low density lipoprotein (LDL), apoptotic cells or cell-derived micro-particles, whereas the exogenous ligands may be microbial diglycerides, LCFA or pheromones (168). CD36 is expressed in a broad number of tissues, including adipose tissue, skeletal and cardiac muscles, small intestine but also in various hematopoietic cells, e.g. monocytes/macrophages, platelets and DCs (168). The diverse expression pattern of CD36 is reflective of its multiple cellular functions. Among many other functions, CD36 is involved in the regulation of energy balance, as it facilitates the transport of LCFAs into adipocytes and myocytes, and through its affinity for thrombospondin-1 and other related proteins it functions as a negative regulator of angiogenesis $(168,169)$. On phagocytes, CD36 uses the scavenger function to recognize specific lipid and lipoprotein components of apoptotic cells, bacterial or fungal pathogens and thereby triggers the production of pro-inflammatory cytokines and induces pathogen internalization $(168,169)$. In vitro studies with human DCs have demonstrated that CD36 is involved in cross-presentation of antigenic peptides processed from engulfed apoptotic cells (170). Subsequent studies on mouse splenic DCs showed that CD36 is in fact expressed by the CD8 $\alpha^{+}$DCs supporting a role for CD36 in cross-presentation, but in vivo studies using CD36\% mice did not determine a requirement for CD36 in cross-presentation of cellular Ags (171). Despite these findings, it can not be excluded that CD36 may be involved in cross-presentation but through a mechanism that can be compensated in CD36-deficient mice. In 2008 a study identified a high-affinity antibody against murine CD36 and demonstrated that in vivo targeting of OVA to DCs via CD36 induced both 
humoral and cellular responses, indicating that CD36 is a potential candidate for DCdirected vaccines (167).

\section{Siglec $\mathrm{H}$}

Siglec $\mathrm{H}$ is a member of the sialic acid binding lg-like lectin (Siglec) family. Siglecs are type I transmembrane proteins that bind to sialic acids, which are present on a variety of host cell-surface glycoproteins as well as on different pathogens. With few exceptions, Siglec expression has been demonstrated mainly on haematopoietic cells $(172,173)$. Siglecs are thought to promote cell-cell interactions and regulate the functions of cells in the innate and adaptive immune systems through glycan recognition (174).

Siglec $\mathrm{H}$ was in 2006 identified as the first specific surface marker for pDCs in mice (175). However, subsequent studies have detected intracellular Siglec $\mathrm{H}$ expression in a subset of spleen marginal zone macrophages and medullary lymph node macrophages (176). The surface expression of Siglec-H requires the presence of DNAX activation protein 12 (DAP12), an adaptor protein containing an ITAM motif (175). Unlike several other related Siglecs, Siglec H lacks a ITIM (Immunoreceptor tyrosine-based inhibitory motif) in its cytoplasmic tail (176). Furthermore, Siglec $\mathrm{H}$ has all the typical features required for sialic acid binding, but no binding between Siglec $\mathrm{H}$ and a variety of sialic acid ligands could be demonstrated. The physiological function of Siglec $\mathrm{H}$ might be uptake of viruses and other pathogens facilitating their delivery into TLR- and MHC-containing endosomal compartments, but the identity of such ligands is still to be determined (172). Studies with antibodies against Siglec-H demonstrated efficient uptake of anti-Siglec $\mathrm{H}$ antibodies supporting a function in endocytosis (176). Zhang et al. showed that Anti-Siglec $\mathrm{H}$ antibodies were internalized and delivered to the endosomal-lysosomal compartment of pDCs. Furthermore, they showed that targeting $\mathrm{Ag}$ to $\mathrm{pDCs}$ via Siglec $\mathrm{H}$ antibodies generated Ag-specific $\mathrm{CD}^{+} \mathrm{T}$ cells in vivo (176). Paradoxically, Siglec $\mathrm{H}$ has also been shown to lead to negative regulation of the type I IFN response of pDCs following TLR stimulation. This inhibitory effect is executed in association with the adaptor protein DAP12, which is unexpected as DAP12 contains an ITAM motif that normally triggers activation signals. It was suggested that low-level activation of DAP12 by low-avidity endogenous ligand or certain mAbs elicits partial activation of DAP12 that are sufficient to recruit activating signalling mediators, but insufficient to mediate downstream signalling. 
The signalling mediators are functionally sequestered with DAP12 and unable to participate in downstream TLR-mediated cellular activation, leading to a net inhibition in TLR signalling by DAP12 (175). Recently, another study supported an inhibitory effect of Siglec-H by demonstrating that Ag-delivery to Siglec $\mathrm{H}$ in vivo inhibited $\mathrm{Th}$ cell and antibody responses. Siglec $\mathrm{H}$-mediated Ag-delivery led to continuous low-level Ag presentation on MHC class II. This weak but persistent antigenic signal induced initial proliferation and IL-2 production in naïve $\mathrm{CD}^{+} \mathrm{T}$ cells but did not support differentiation into effector cells. Hence, the continuous presence of low-level Ag on pDCs may have led to exhaustion and hyporesponsiveness of CD4 ${ }^{+} \mathrm{T}$ cells after initial priming (177). Based on the current literature it seems that targeting $\mathrm{Ag}$ to Siglec $\mathrm{H}$ can be tailored to either activate or inhibit immune responses, but confirmatory studies are still needed.

\section{PDC-TREM}

PDC-TREM is a member of the family of triggering receptors expressed on myeloid cells (TREM). The TREM family of receptors is immune receptors that modulate the innate immune response by amplifying or dampening TLR-induced signals. Consequently, TREM receptors play an important role in fine-tuning the inflammatory response (178). TREM receptors are expressed on a variety of innate cells of the myeloid lineage, e.g. neutrophils, monocytes, macrophages, microglia, DCs and platelets. PDC-TREM, however, is an early activation marker expressed only by pDCs $(63,65,178)$. Studies have shown that PDC-TREM is important for the production of type I IFNs by pDCs. The receptor is inducible and preferentially expressed on pDCs following TLR7/9 stimulation. PDC-TREM is reported not to be expressed on unstimulated pDCs or other cell types. The TLRinducible expression of PDC-TREM is unique among pDC-specific surface receptors so far identified in human and mouse (63). Studies with MyD88/IFNAR (IFN $\alpha / \beta$ receptor)deficient and DAP12-deficient mice have demonstrated that TLR/-IFNAR-mediated signalling and DAP12 is necessary for cell surface expression of PDC-TREM (63). In addition, PDC-TREM has been shown to be associated with another transmembrane protein, Plexin-A1, at the cell surface. When this receptor complex binds to Sema6D, a ligand for Plexin-A1, signalling through PDC-TREM and DAP12 is induced resulting in production of type I IFNs $(63,65)$. Thus, PDC-TREM is responsible for the production of type I IFNs, whereas TLR signalling is essential for PDC-TREM expression. 


\subsection{Important aspects of targeting antigens to DCs}

Several strategies have been developed to deliver Ag to DC surface receptors. One approach for specific delivery of Ags to DCs is to covalently conjugate the Ag of choice to mAbs specific for selected DC surface molecules $(138,179)$. Alternatively, the Ag can be fused to a single-chain fragment variable (scFv) specific for the target receptor by genetic engineering (180). Another approach is to incorporate the Ag or DNA encoding the Ag, into more complex Ag-delivery systems, like liposomes or viruses, carrying a receptor ligand or receptor-specific antibody on their surface $(138,181)$.

When using mAbs as Ag targeting devices the outcome of the immune response induced by DCs depends on several parameters of which some are related to the DC subset that is targeted, whereas others are related to the choice of target receptor or to the particular antibody (76). Prior to discussing the parameters related to the DC subset or the particular target receptor, a brief description of antibody structure and function as well as its relevance for the targeting process is given.

Antibodies are the archetypal molecules of the immunoglobulin superfamily, a large family of proteins that all share a particular three-dimensional structure, the immunoglobulin domain. An antibody, or immunoglobulin ( $\mathrm{lg}$ ), is composed of two pairs of polypeptide chains, each pair containing a heavy $(H)$ and a light $(L)$ chain (Figure 4). The light chain consist of one variable domain $\left(V_{L}\right)$ and one constant domain $\left(\mathrm{C}_{\mathrm{L}}\right)$, while the heavy chain consist of one variable domain $\left(\mathrm{V}_{\mathrm{H}}\right)$ and three to four, depending on the subclass, constant domains $\left(\mathrm{C}_{\mathrm{H}} 1, \mathrm{C}_{\mathrm{H}} 2, \mathrm{C}_{\mathrm{H}} 3\right.$ etc). The heavy chains are covalently linked in the hinge region and the light chains are covalently linked to the heavy chains.

The antibody can be divided in different regions, each with separate functions: 1) the variable domains of both chains compose the antigen-binding site of the molecule termed Fv or Fab, in which case the $\mathrm{C}_{\mathrm{L}}$ and $\mathrm{C}_{\mathrm{H}} 1$ is included, 2) the Fc fragment $\left(\mathrm{C}_{\mathrm{H}} 2-\mathrm{C}_{\mathrm{H}} 3\right.$ or $\mathrm{C}_{\mathrm{H}} 2-$ $\mathrm{C}_{\mathrm{H}} 4$ ) mediates effector function by activating complement or by binding to the Fc-receptor on effector cells $(119,182,183)$. 


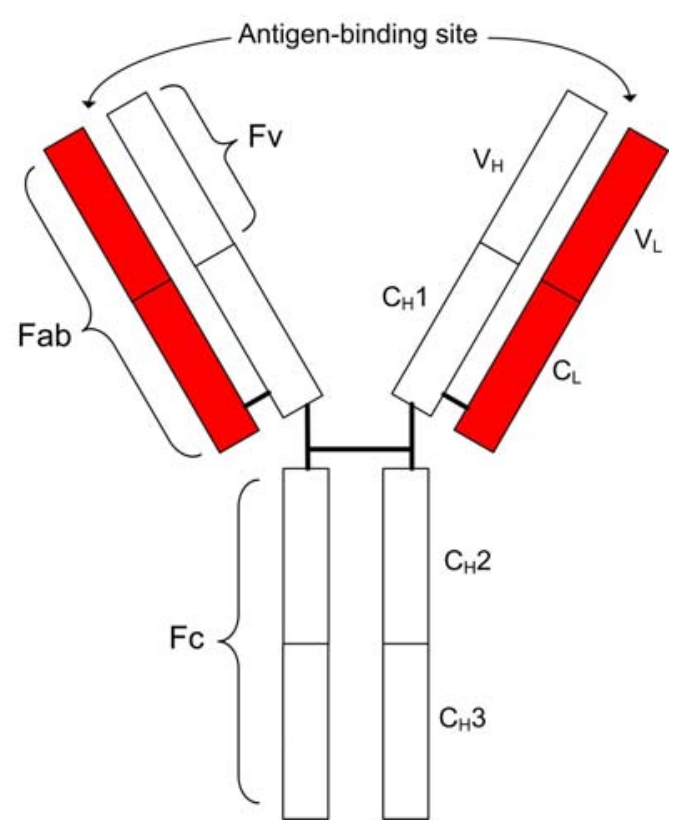

Figure 4. Antibody structure.

Antibodies serve two main purposes in vivo: 1) acting as cell-surface receptors for $\mathrm{Ag}$, permitting cell signalling and activation, and 2) acting as soluble effector molecules, which may individually recognize and bind Ags at a distance leading to their destruction by phagocytes or initiating killing of invading organisms $(119,184)$. While individual Abs bind a limited and defined set of Ags, Abs as a population possess the ability to bind a unlimited number of Ags sharing little or no similarity (119). This diversity is generated by a complex series of gene rearrangement leading to a potential preimmune $A b$ repertoire of greater than $10^{16}$ different Abs. Further diversity is obtained by somatic hypermutation permitting affinity maturation of the $\mathrm{Ab}$ repertoire upon $\mathrm{Ag}$ encounter (119).

Due to their high specificity, broad repertoire and different effector functions, Abs has been widely used as therapeutic agents to fight cancer, autoimmune diseases and infections. Depending on the clinical application some Abs have been conjugated to effector molecules, e.g. drugs, Ags or toxic molecules, while others are designed to function naturally (183). Following the first therapeutic use of mAbs in humans in 1982, it was soon discovered that murine mAbs entailed a problem with the production of human anti-murine Abs, which diminished their effectiveness (185). Attempts to overcome these difficulties led to the development of chimeric or even humanized Abs (Figure 5). Chimeric Abs, contrary to murine mAbs, contain variable regions of murine origin, while the remaining heavy and light chain regions are of human origin. In humanized Abs, only the hypervariable 
sequences of the light and heavy chains are murine, which minimizes their immunogenicity and improves the clinical tolerance (185).

A

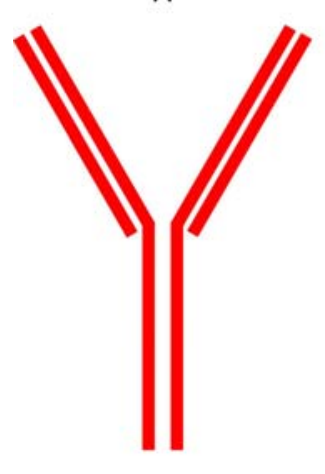

Murine $\mathrm{mAb}$
B

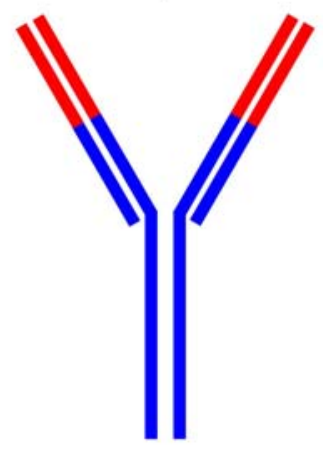

Chimeric mAb
C

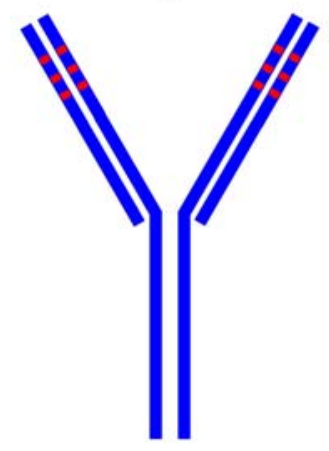

Humanized mAb
D

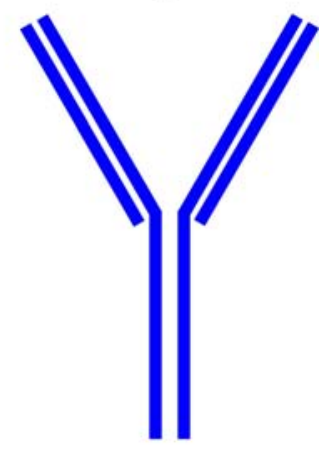

Human mAb

Figure 5. Schematic overwiev of chimeric and humanized monoclonal antibodies.

A) murine $\mathrm{mAb}$ (red), B) Chimeric murine-human $\mathrm{mAb}$, in which the variable domain of both the heavy and light chains are of murine origin (indicated in red), while the constant domains are human (blue), C) Humanized $\mathrm{mAb}$, in which only the hypervariable sequences are of murine origin (red), D) Human mAb (blue).

When mAbs are used for targeted delivery of Ags, several factors related to the particular targeting antibody are important for this process. It is very likely that features like the affinity of the mAb for the target receptor as well as the particular epitope recognized by the antibody affects the immunogenicity (180). For example, studying targeting to CD209, Tacken et al. described that intracellular routing of targeted Ags depends on the particular epitope recognized by the targeting antibodies. They showed that antibodies directed at the CRD of CD209 mainly channelled Ags into late endosomal compartments, whereas the uptake of anti-neck Abs shuttle Ags into early endosomal compartments rich in MHC class I molecules (146). Furthermore, studies using different mAb directed against Clec9A demonstrated very different outcomes; one anti-Clec9A antibody (10B4) induced strong humoral responses in the absence of adjuvant, whereas a different anti-Clec9A (7H11) was unable to mediate humoral responses in the absence of adjuvant $(93,148,150)$. Another prerequisite for an effective immune response is the presence of both $T$ and $B$ cell epitopes in the mAb or the accompanying Ag. The targeting complex must contain an appropriate B cell epitope present in the native molecule, but also a T cell epitope buried in the three-dimensional structure, which provide the necessary B cell help. In support of this, 
several studies have shown that when mAbs are used as both targeting device and as Ag, the isotype of the mAb may affect the outcome of targeting $(150,186,187)$, which possibly arise from a lack of appropriate $T$ cell epitopes in some subclasses, while present in others (180). When the mAbs used for targeting are full-length Abs, containing the Fc portion, the uptake of Ag after targeting DC surface molecules may partly be due to FcR binding rather than specific binding via the mAb variable regions. Antibody binding to FcRs may either enhance the immune response by providing additional stimulating signals or block the immune response by binding to irrelevant cells expressing FcRs (180). Regardless of the outcome, the interaction with FcRs is not the purpose of DC targeting with Abs and the interaction with FcRs is undesirable. The present study used a non-targeting isotype control mAb which controls for FcR uptake of monomeric Ig, but not polymeric Ig, and the results showed that FCR-dependent uptake of targeted $\mathrm{Ag}$ is of little importance for the immune response and that the $\mathrm{mAb}$ binding was specific. Other groups have also investigated the importance of FcR-mediated uptake in this kind of experiments. Two studies showed that targeting with intact antibodies also induced equally strong humoral responses in FcR $y$-chain deficient mice upon injection of a targeting $\mathrm{mAb}$ indicating that the Fc portion of the targeting mAb plays no role in the enhancement of immune responses $(186,188)$. Furthermore, Corbett et al. demonstrated strong Ig responses with the use of $F\left(a b^{\prime}\right) 2$ fragments, confirming that Ag-delivery was due to specific rather than FcR or complement-mediated binding (188).

Other important features unrelated to the targeting $A b$, concerns the targeted $D C$ and the targeted receptor. One level of specialization is given by the differential expression of the target receptor on DC subsets. The DC subset presenting the Ag may determine the type of immune response obtained, why targeting specific subsets can be utilized as a means of controlling the outcome. For instance, studies have demonstrated that in vivo the CD8 $\alpha^{+}$ DCs confer superior ability to present exogenous Ags on MHC class I molecules (54), whereas $\mathrm{CD} \alpha^{-} \mathrm{DCs}$ are more efficient at presenting $\mathrm{Ag}$ to $\mathrm{CD} 4^{+} \mathrm{T}$ cells $(56,62)$. The second level of specialization is the way the different target receptors handle Ags for presentation of antigenic peptides on their MHC I and MHC II molecules. Different receptors shuttles Ags into distinct endosomal pathways leading to specific processing and presentation (76). For instance, targeting of Ag to the CLR, CD205, channels Ag directly to late endosomal/lysosomal compartments, which are rich in MHC class II molecules (89). In 
contrast, another CLR, CD206, mediates Ag localization to early endosomal compartments rich in recycling $\mathrm{MHC}$ class I molecules, which elicits cross-presentation of antigenic peptides (87). Such cross-presentation of Ags is essential for the priming of antiviral and antitumor immunity (167).

Ultimately, the DC subset, the nature of the target receptor, the type of $m A b$ and even other cell types expressing the target receptor may all impact the outcome of targeting Ags to DCs by the use of antibodies (189). 


\section{Aim \& Hypotheses}

The purpose of this Ph.D. project was to identify receptors on the surface of DCs that constitute useful target structures for DC-targeted vaccines.

The project is based on the basic hypothesis stated below.

1) DCs carry on their surface different receptors which participate in Ag uptake. Some of these receptors facilitate the presentation of the Ags to $T$ cells more than others.

2) The Ag receptors on DCs may differ regarding whether the antigenic peptides are presented on MHC class I and/or MHC class II molecules.

3) Vaccines that are specifically directed against surface receptors on DCs will induce stronger and more adjustable immune responses than the current non-targeted vaccines.

This dissertation is part of a larger project with the major goal to develop vaccines that are directed at DCs. Such vaccines are expected to contain three functionally different domains:

I) a region with specificity towards a target receptor expressed on DCs,

II) a region comprising the antigenic structure(s),

III) a structure that functions as a maturation signal for DCs, e.g. TLR ligand.

The aim of this $\mathrm{PhD}$ project was to identify receptors that could function as target for such DC-directed vaccines. 


\section{Experimental strategies}

The experimental strategy for identification of candidate target receptors for DC-targeted vaccines was based on mAb. During the last decades a wide number of monoclonal rat antibodies against surface molecules on murine DCs have been produced and become commercially available. The strategy was to use these antibodies as both targeting devices (variable regions) and as Ags (epitopes on rat $\lg G$ that are immunogenic in the mouse). This strategy was novel at the beginning of this project, but has now been employed in other targeting studies $(186,188,190,191)$.

A panel of monoclonal rat antibodies with specificity towards different DC surface receptors was tested both in an in vitro screening assay and subsequently in an in vivo DC-targeting study. The panel contains mAb against ten different surface receptors, of which many have already been tested in DC-targeting assays. However, this study is the first to simultaneously investigate the targeting-potential of a panel of receptors. In addition, inclusion of target receptors that have already been investigated provided the opportunity to compare the outcome with other studies using the same targets.

Importantly, we investigated one receptor, PDC-TREM, which had not previously been investigated as a target receptor for Ag-delivery to DCs.

The in vitro screening assay determined the capacity of Ag-targeted DCs to induce $T$ cell activation using the enzyme-linked immunospot assay (ELISPOT). T cell activation was ascertained by measuring the expression of the Th1 and Th2 cytokines, IFN- $\mathrm{Y}$ and IL-4, respectively. The assay was performed with crude splenocytes isolated from mice immunized with a non-targeted isotype control antibody of either isotype rat lgG2a or rat $\lg \mathrm{G} 2 \mathrm{~b}$.

The in vivo study investigated the effect of targeting Ag to DCs in vivo based on the induced humoral responses. The humoral responses were determined by measuring the levels of mouse anti-rat antibodies by ELISA.

Figure 6 depicts the experimental strategy. 


\section{Rat monoclonal antibody against murine $\mathrm{DCs}=$ antigen \& targeting device}

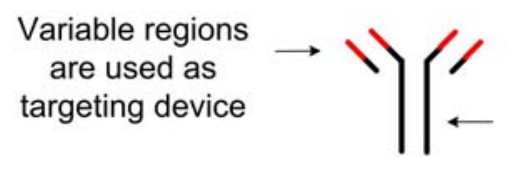

The antigens are the epitopes on the rat immunoglobulin that are immunogenic in the

Mice are immunized with a non-targeted isotype control

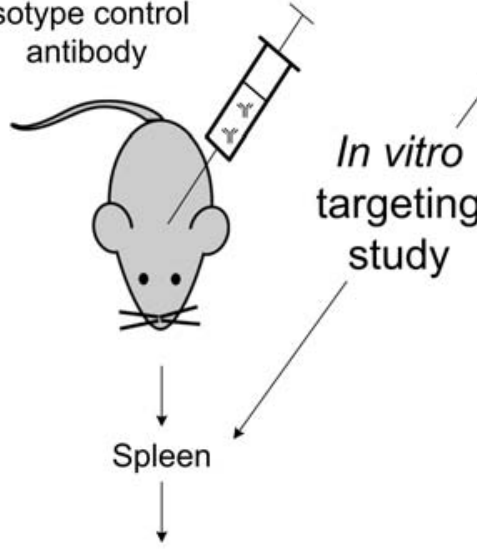

ELISPOT

Antigen: monoclonal target antibodies directed against the selected DC surface receptors mouse

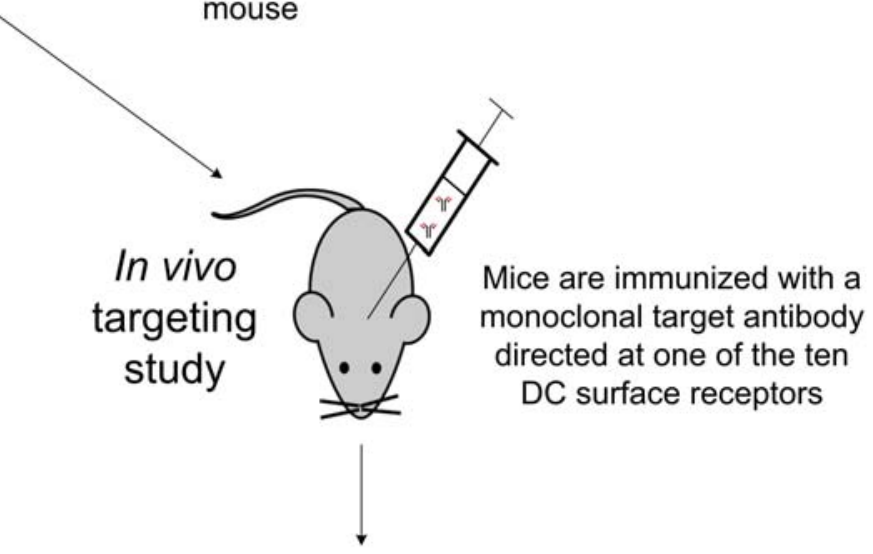

Blood samples

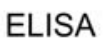

Determine the levels of mouse anti-rat antibodies

Figure 6. Overview of the experimental strategy. 


\section{Study design and limitations}

\subsection{The human study}

The human study aimed at identifying potential target receptors on DCs that could be used for Ag-delivery to DCs. Targeting Ag to DCs can be exploited as a means for inducing stronger immune responses and thereby improving the effectiveness of vaccines.

The strategy was based on the knowledge that a fraction of patients in treatment with Infliximab (Remicade ${ }^{\circ}$, Schering-Plough), a human-murine hybrid $A b$ directed against tumor necrosis factor- $\alpha$ (TNF- $\alpha$ ), react by generating antibodies against Infliximab. Infliximab is a chimeric mAb consisting of $V_{L}$ and $V_{H}$ domains deriving from murine $\lg G 1, \kappa$ and constant domains deriving from human $\lg \mathrm{G} 1, \mathrm{~K}(192)$ and it is therefore more prone to induce human anti-murine Abs than a humanized $A b$ (see figure 5). The sequence variability within each of the variable domain is concentrated in three hypervariable regions, which, in the three-dimensional structure, form the Ag-binding site of the molecule. These hypervariable regions are flanked by four regions composed of highly conserved regions, termed the framework regions $(119,182,193)$. By taking advantage of the fact that the patients have been immunized against epitopes derived from murine $V_{L}$ and $\mathrm{V}_{\mathrm{H}}$ chains, it may be possible to test the efficiency of targeting Ag to DCs by the use of monoclonal mouse anti-human antibodies of the isotype $\lg \mathrm{G} 1, \mathrm{~K}$. Some of the immunogenic epitopes likely contain the hypervariable regions, while others may derive from the less variable framework regions and a some of these framework-epitopes are expected to be conserved between murine Abs. Thus, by using murine IgG1,k mAbs as Ags, it was hypothesized that some of the resulting antigenic peptides - the peptide sequences obtained by processing of the murine $\mathrm{V}_{\mathrm{L}}$ and $\mathrm{V}_{\mathrm{H}}$ chains - would be recognized by the "mouse"-specific T cells present in the immunized patients.

A prerequisite for this experiment was identification of patients with anti-Infliximab antibodies. Setting up a test for measuring the presence of anti-Infliximab in serum was commenced at Department of Clinical Immunology, Aalborg Hospital, approximately 3 months before initiation of this project. The procedure was modified from (194). The test was performed on serum samples from patients treated at the Department of Rheumatology, Aalborg Hospital. In spite of substantial optimization it was not possible to avoid false-positive reactions and a reliable test could not be established. The presence of 
anti-Infliximab in serum from patients was therefore determined by a biotechnology company (Biomonitor, Copenhagen, DK). The majority of the patients were negative for anti-Infliximab, which was surprising as the literature describes a frequency of $44 \%$ for patients being in treatment for longer than 6 months (195). One explanation for the lower occurrence of anti-Infliximab in these patients may be the fact that they were treated with Infliximab in combination with Methotrexate. Several studies described that the use of concomitant immunomodulators prior to initiation of treatment with Infliximab was effective in reducing antibody production $(196,197)$. In contrast, Bendtzen et al. described that cotreatment with methotexate resulted in only a minor decrease in antibody levels but did not alter the frequency of antibody-positive patients (195).

We obtained blood samples from five patients with anti-Infliximab antibodies. For each patient, PBMCs were isolated and monocytes were cultured with interleukin-4 (IL-4) and granulocyte-macrophage colony stimulating factor (GM-CSF) for differentiation into DCs. Immature DCs were exposed to individual mAbs antibodies against the selected surface receptors. Following maturation, DCs were co-cultured with autologous T cells and the degree of $\mathrm{T}$ cell activation was investigated by measurement of the cytokine production (IFN- $\gamma$ \& IL-4) by ELISPOT.

Unfortunately, we were not able to demonstrate DC-mediated T cell activation. The lack of $T$ cell activation could be due to a very low number of monocyte-derived DCs in the coculture. Generation of DCs from monocytes requires a large number of cells and for each patient the number of peripheral blood mononuclear cells (PBMCs) available was limited. Therefore it was decided to try to target the DCs present in the PBMC population. This approach was based on the knowledge that addition of $\mathrm{Ag}$ or other immunomodulators to a PBMC suspension led to immune responses (198). The assay was useful despite the limited number of cells. Nonetheless, the assay demonstrated very different results. The patient from Department of Rheumatology did not react in the assay at all. In contrast, targeting of $\mathrm{Ag}$ to PBMCs from the other patients did induce production of IFN-y but at levels comparable to the level induced by Ag-delivery to PBMCs from a healthy donor. Thus, the $\mathrm{T}$ cell activation was probably not mlgG1,k-specific. Due to limited material only few optimization steps was possible and a reliable assay was not established. Due to the various obstacles and the time perspective, it was agreed to focus on the murine study and to discontinue the human study. 
The lack of $\mathrm{T}$ cell responses using the PBMC assay may be due to the fact that there are limited numbers of DCs in PBMC populations or that the DCs present are in a maturation stage unsuitable for Ag presentation and T cell activation. Moser et al. described that CD4 ${ }^{+}$ T cell activation in PBMC assays may be inhibited by other cell types within the leukocyte population, e.g. the B cells. They proposed that B cells, present at much higher numbers than the DCs, may engage the $T$ cells and hinder the more efficacious DC-T cell engagements (199). A second explanation for the lack of $T$ cell responses could be that the patients were immuno-compromised. As mentioned above, the patients were also treated with the immuno-modulating drug, Methotrexate. Methotrexate has been described as a potent immunosuppressor that may delete $\mathrm{T}$ cell clones that are activated during treatment (200). Thus, it is likely that the PBMCs obtained from these patients are in a compromised state with reduced ability to elicit $\mathrm{T}$ cell responses.

\subsection{The murine study}

The major aim of this study was to investigate and identify receptors that were effective in delivering Ag to DCs.

The first strategy was based on targeting of Ag to specific receptors using cultured DCs and subsequently measure the strength of the $\mathrm{T}$ cell responses induced by these Agtargeted DCs. The T cell responses were determined by ELISPOT.

Secondly, Ag delivery to these target receptors should be investigated in vivo by immunization of mice with the target $A b s$ and subsequently measure the strength of the rat-specific Ig response by ELISA

\subsubsection{In vitro study \& ELISPOT}

The DCs used for this assay were generated from bone marrow progenitors - bone marrow-derived DCs (BM-DCs). The T cells used in the assay were isolated from mice that had been immunized with a non-targeted isotype control antibody. Immunization with this antibody elicited production of mouse anti-rat antibodies of IgG character determined by ELISA. An Ab response to protein Ags requires specific recognition of the same Ag by both $\mathrm{B}$ and $\mathrm{T}$ cells. Hence, the presence of a strong IgG response implied that immunization also elicited Ag-specific T cells with specificity towards epitopes generated from the rat $\operatorname{lgG}(116,117,119)$. Bone marrow-derived DCs were co-cultured with $\mathrm{T}$ cells 
from immunized mice in IFN-y or IL-4 ELISPOT assays. To include additional controls, BM-DCs were also co-cultured with $\mathrm{T}$ cells isolated from unimmunized mice. Surprisingly, the assay displayed pronounced T cell activation when Ag-targeted DCs were cultured with $T$ cells from both immunized and unimmunized of mice. In addition, untreated DCs DCs that had not been treated with any antibody - did also lead to enhanced $\mathrm{T}$ cell activation. Thus, the assay demonstrated substantial $\mathrm{T}$ cell activation that was not ratspecific. Over a series of experiments, we found that some of the unspecific activation of $\mathrm{T}$ cells may be caused by the foetal calf serum (FCS) present in the culture medium. The BM-DCs were generated from bone marrow progenitors using media with $10 \%$ FCS. The co-culture of BM-DCs and T cells were also set up in media with $10 \%$ FCS. The results indicated that the BM-DCs internalized molecules that originated from the FCS. These molecules were subsequently presented on $\mathrm{MHC}$ molecules and recognized by the T cells leading to cytokine production. The exact nature of these molecules was not identified, and the difficulties were unfortunately not solved.

Therefore a second approach was applied. We established a method based on spleen cell suspensions isolated from immunized mice. Briefly described, splenocytes were isolated from mice immunized with a non-targeted isotype control antibody. Splenocytes were then treated with the monoclonal target antibodies, and the production of IFN-Y and IL-4 was determined by ELISPOT.

With minor optimization, this assay proved efficient at identifying target receptors that elicited $T$ cell activation. One of the optimization steps involved a change from FCS to mouse serum. As also noted with the assay using BM-DCs, this assay displayed some T cell activation that was not related to presence of rat Ags. It might be explained by sequence similarities between structures present in the antibody used for immunization and structures present in the FCS leading to cross-activation of T cells. However, the antibodies used for immunization were LEAF products (Low endotoxin, Azide free) produced in ascites in athymic nude mice thus these antibody products ought not to contain any structures related to bovine/calf. Irrespective of the cause, the obstacles were overcome by adding $2 \%$ mouse serum instead of $10 \%$ FCS to the culture medium.

Having established an assay based on Ag-delivery to DCs present in isolated splenocytes, we reintroduced the assay using BM-DCs in order to investigate the targeting-potential of the receptors further. The BM-DCs were still generated in 10\% FCS but the isolation of T 
cells as well as the ELISPOT co-culture of DCs and T cell was performed with $2 \%$ mouse serum. These optimization steps improved the assay, but did not completely abolish the T cell activation induced by the untreated LPS-matured DCs.

Overall, the ELISPOT technique displayed considerable variations in the number of cytokine producing cells among repeated experiments, but the assay using BM-DCs displayed larger variations than the assay using splenocytes. The variation among the assays using BM-DCs may be explained by varying levels of reactivity towards LPS or other substances present in culture media (e.g. from FCS) among the vaccinated mice.

The ELISPOT technique was chosen for enumeration of the number of Ag-specific T cells activated by Ag-targeted DCs for several reasons. Some of the advantages by the ELISPOT technique are increased sensitivity compared to techniques like ELISA and intracellular cytokine staining (ICS) $(201,202)$ and, in contrast to tetramer staining, ELISPOT detects $\mathrm{T}$ cells based on their functional response to $\mathrm{Ag}$. The increased sensitivity is partly due to immediate capture of the cytokine by the capture antibody, but may also be explained by minimal degradation of the cytokine by enzymatic cleavage and minimal capture by cytokine receptor-bearing bystander cells. The ELISPOT technique provides information about both the frequency (each spot corresponds to a single cytokine-producing cell) and the productivity (spot size reflects the amount of cytokine produced by the individual cell). In addition, this technique provides high throughput allowing investigation of a high number of samples/stimulants in a single experiment. Importantly, as every cell plated is analyzed, ELISPOT can in some case be optimized to require much fewer cells compared to ICS, which is of great importance when working with limited numbers of cells.

To the other end ELISPOT also possesses some disadvantages. The assay is currently not able to distinguish the cytokine-producing cells, e.g. $\mathrm{CD}^{+}{ }^{+}$or $\mathrm{CD}^{+} \mathrm{T}$ cells, which, if possible, would be valuable information. Another drawback we experienced in this project was difficulties in enumerating the Ag-specific T cells generated from in vivo targeting of DCs. This problem may be caused by a poor/insufficient presentation of antigenic peptides on the surface of the DCs (and other APCs), and/or by a too low frequency of Ag-specific $\mathrm{T}$ cells present in the spleen cell suspension. The ELISPOT assay was performed at day 
63-85 after the second vaccination and at this stage the majority of the Ag-specific T cells may have diminished.

\subsubsection{Analysis of ELISPOT data}

The raw data obtained from the ELISPOT assays was evaluated by the statistical methods recommended by Moodie et al. $(203,204)$ and supplied as a Web tool found at http://www.scharp.org/zoe/runDFR.

The raw data was, prior to the statistical analysis, subjected to a quality control considering the intra-replicate variation. Moodie et al. recommend using the ratio of the variance to median +1 as a measure of the variability of the spot counts within a replicate, which would filter out replicates containing "extreme" outliers $(203,204)$. The threshold for the variance ratio was set to 10 and any replicate exceeding a variance ratio of 10 was excluded from the dataset.

The data that passed the variance filter and was subjected to statistical analysis using the distribution-free resampling (DFR) methods in order to investigate whether the mean spot counts obtained with Ags was significantly different from the background (wells containing splenocytes and medium without Ag). The DFR methods are examples of nonparametric methods of which one method, the DFR(eq) tests a null hypothesis of equal background and experimental well means using a permutation test with Westfall-Young Stepdown max $\mathrm{T}$ adjustment for multiple testing in order to control the family-wise error rate, while the second method, the $\operatorname{DFR}(2 x)$ tests a null hypothesis that the mean of the experimental wells is less than or equal to twice the mean of the background wells using a bootstrap test with the same multiplicity adjustment $(203,205)$. The DFR(eq) criterion was chosen for the present study. Another factor of relevance for the response determination is the limit of detection (LOD) of the assay. The LOD of the assays was estimated from the median of the triplicate background means of the all identical runs and a cut-off for a positive response was subsequently set to a signal-to-noise ratio of $2: 1$. A triplicate was only accepted as positive if the it passed the DFR(eq) test and had a mean spot count above the LOD. 


\subsubsection{In vivo study and ELISA}

The in vivo study investigates the humoral responses induced by immunization with the ten targeting Abs. Mice were immunized with monoclonal target antibodies twice (day 0 and day 28) and blood samples were collected with 2 weeks intervals from day 14 to day 84. The total level of mouse IgG specific for rat IgG as well as the two subclasses mouse IgG1 and IgG2a was determined by ELISA. Based on the many drawbacks associated with a non-quantitative ELISA, a quantitative ELISA test was established. To ensure high detection sensitivity a chemiluminescence assay was chosen.

Setting up the quantitative ELISA for measuring mouse anti-rat Abs there were several challenges relating to cross-reactivity between mouse and rat. For measuring the total level of mouse anti-rat IgG, a rabbit anti-mouse $A b$ that was preabsorbed against rat serum was used. This Abs did not show cross-reactivity to the rat IgG in the ELISA wells.

The subclass specific secondary Abs (goat anti-mouse) were not preabsorbed for crossreactivity to rat $\lg G$ and both $A b s$ displayed pronounced binding to the rat $\lg G$ in the ELISA wells. Both Abs were therefore purified on a HiTrap NHS-activated HP column (GE Healthcare, Uppsala, Sweden) coupled with $1 \mathrm{mg}$ rat IgG (ChromPure rat IgG, Jackson Immunoresearch). The procedure is explained in detail in "materials and methods" of manuscript 2.

\subsubsection{Analysis of ELISA data}

A measure of the concentrations of mouse anti-rat IgG Abs in the serum of the immunized mice was obtained by comparing the values obtained with the serum samples with standard curves made from dilution series of known concentration of mouse $\lg G$ (ChromPure mouse IgG, Jackson Immunoresearch), mouse IgG1 (Mab1.1, Serotec) or mouse IgG2a (Mab9.2, Loke Diagnostics).

The standard curve-fitting was performed by the OPTIMA software or by KaleidaGraph 3.5 using the four-parameter log-logistic (4PL) curve-fitting method, which is a reliable and flexible curve-fitting technique for immunoassays (206). The equation of the fitted standard curve was used to quantify the level of mouse anti-rat lgG in the serum samples. Due to several differences between the serum immunoglobulin and the immunoglobulin standards, the measure of total $\lg G$, IgG1 or IgG2a Abs in the serum is useful in comparison between serum samples, but cannot be expected to represent the exact 
concentrations. This may be explained by the way the Abs presents themselves in the ELISA wells (bound to the rat IgG coating the wells as the serum samples versus coated directly onto the wells as done for the standard Abs) and by differences in their antigenic nature, e.g. polyclonal serum IgG1 present in serum samples versus a monoclonal IgG1 $A b$ used as standard. To reflect this fact, the measure of concentration is expressed as $\mu \mathrm{g}$ equivalents $/ \mathrm{ml}$.

The limit of detection of the three assays was $0.0002 \mu \mathrm{g} \mathrm{eq} / \mathrm{ml}, 0.0018 \mu \mathrm{g} \mathrm{eq} / \mathrm{ml}$, and $0.0006 \mu \mathrm{g} \mathrm{eq} / \mathrm{ml}$ respectively. The pre-immunization level was calculated from the values obtained from the pre-bleed samples and specified as mean $+2 x S D$ in each figure. Intraassay coefficients of variability was determined from the calculated concentrations and were $<10 \%$. 


\section{Results}

Manuscript I: (page $53-76$ )

Augmented $\mathrm{T}$ cell activation by targeting antigen to dendritic cells. A comparison of ten different targets.

Pugholm $\mathrm{LH}^{1,2}$, Varming, $\mathrm{K}^{1}$ \& Agger, $\mathrm{R}^{2}$

${ }^{1}$ Department of Clinical Immunology, Aalborg Hospital, Aalborg, Denmark

${ }^{2}$ Laboratory of Immunology, Department of Health Science \& Technology, Aalborg University, Aalborg, Denmark

Manuscript II: (page $77-97$ )

In vivo targeting of antigen to ten different receptors on dendritic cells induced differential humoral responses.

Pugholm $\mathrm{LH}^{1,2}$, Varming, $\mathrm{K}^{1}$ \& Agger, $\mathrm{R}^{2}$

${ }^{1}$ Department of Clinical Immunology, Aalborg Hospital, Aalborg, Denmark

${ }^{2}$ Laboratory of Immunology, Department of Health Science \& Technology, Aalborg University, Aalborg, Denmark 
Augmented $\mathrm{T}$ cell activation by targeting antigen to dendritic cells. A comparison of ten different targets.

Pugholm, Lotte $\mathrm{H}^{\mathrm{a}, \mathrm{b}}$, Varming, Kim ${ }^{\mathrm{a}}$ \& Agger, Ralf ${ }^{\mathrm{b}}$

${ }^{a}$ Department of Clinical Immunology, Aalborg University Hospital, Urbansgade 32, 9000 Aalborg, Denmark

baboratory of Immunology, Department of Health Science \& Technology, Aalborg University, Frederik Bajers Vej 3B, 9220 Aalborg, Denmark

Correspondence:

Lotte Hatting Pugholm

Department of Clinical Immunology

Aalborg University Hospital

Urbansgade 32

9000 Aalborg

Denmark

E-mail: lohap@rn.dk

Phone: +4599321674

Fax: +4596452144 


\section{Abstract}

Targeting of antigen (Ag) to DCs may increase the efficiency of immunization procedures and holds promise for the development of more effective vaccines. With this end in mind, it is important to identify structures optimal for Ag-targeting.

In this study, a method for screening target receptors for Ag-delivery to murine DCs was established. The antibody-mediated delivery of Ag to ten different target receptors on DCs was analyzed by measuring the production of IFN- $\gamma$ and IL-4 in crude spleen cell cultures by ELISPOT.

Targeting of Ag to CD11c, CD36, CD205 and Clec7A led to positive IFN- $\gamma$ responses compared to the non-targeted isotype control. In contrast, Ag-delivery to CD206, CD209, Clec6A, Clec9A, Siglec H and PDC-TREM did only elicit positive IFN-y in a small fraction of repeated experiments. CD36 and CD205 did also produce positive IL-4 responses in a number of repeated experiments, while no positive responses were obtained by the nontargeted isotype control. PDC-TREM has not previously been assayed as a potential target receptor. Even though this target only elicited positive IFN-y responses in 1 out of 4 mice and IL-4 responses in 1 out of 3 mice, a role of PDC-TREM as an endocytic receptor mediating Ag presentation for $\mathrm{T}$ cells cannot be ruled out. Future studies will clarify whether PDC-TREM might function as an endocytic receptor mediating Ag presentation for T cells.

The assay described here allows simultaneous analysis of a large number of potential target structures, facilitates direct comparison between the different targets regarding strength and character of the T cell responses induced by the targeted DCs and is useful as a first-line screening of potential target structures on murine DCs.

Keywords: Dendritic cells, targeting, C-type lectins, PDC-TREM, ELISPOT.

Abbreviations: cDCs: Conventional dendritic cells, pDCs: Plasmacytoid dendritic cells, TREM: Triggering receptor expressed on myeloid cells. 


\section{Introduction}

DCs capture and process Ag and may potently activate $\mathrm{T}$ cells that recognize antigenic peptides presented in complex with MHC molecules on the DC surface. Furthermore, DCs can control the outcome of the Ag presentation and influence the expansion and differentiation of the activated cells [1]. Thus, DCs play an important role in shaping the resulting immune response, e.g. determining the nature of $T$ helper responses or inducing tolerance rather than the production of effector cells [2;3]. In recent years, it has been demonstrated by several groups, that targeting of Ag to surface receptors expressed on DCs may enhance Ag-specific immune responses [4;5]. These results have incited great interest in elucidating the potential of DC-targeting in the development of human vaccines. New vaccines targeting DCs might not only be more potent, but could potentially be engineered to generate immune responses of a desired type by directly stimulating the targeted DCs [4].

Several different target receptors have been advocated for this purpose e.g. DEC205, DCSIGN and CLEC9A [2;6-9], but more DC surface molecules deserve examination for their usefulness for Ag-delivery. Furthermore, to promote progress in the area, it is important to directly compare the results of targeting different receptors. In this study, a simple assay for in vitro screening and comparison of potential vaccine targets on murine DCs was developed. The assay is based on rat anti-mouse monoclonal antibodies (mAb), which are used as both targeting devices (the variable parts of the molecule) and as Ag (epitopes on the rat immunoglobulin that are immunogenic in the mouse). The assay is performed on crude spleen cell suspensions, and the results of targeting DCs with different antibodies are evaluated by ELISPOT analysis of the induced cytokine production. In the present paper, the $\mathrm{T}$ cell responses following Ag-delivery to 8 different target structures - CD11c, CD36, CD205, CD206, CD209, Clec6A, Clec7A and Clec9A - expressed on conventional DCs (cDCs) were investigated. Furthermore, two receptors, primarily expressed on plasmacytoid DCs (pDCs) were included in the study: Siglec $\mathrm{H}$ and PDC-TREM.

PDC-TREM has, to own knowledge, not been studied as a potential targeting receptor before, and while the other target receptors have previously been investigated separately by other groups, the present study is the first to simultaneously compare many potential target receptors. 


\section{Materials and Methods}

Mice

All murine experiments were performed on female C57BL/6J mice (Taconic Europe, Ejby, DK), conducted at the animal facility at the Department of Pathology, Aalborg Hospital and carried out according to the national guidelines and regulations. All experimental procedures were approved by the Animal Experiments Inspectorate in Denmark (approval \# 2008561-1508).

\section{Antibodies for targeting}

The following mAb were used for in vitro stimulation of splenocytes: CD11c $(223 \mathrm{H} 7$, rat IgG2a, MBL, Woburn, USA), CD36 (No.72-1, rat IgG2a, eBioscience, San Diego, USA), CD205 (205yekta, rat IgG2a, eBio), CD206 (MR5D3, rat IgG2a, Acris, Herford, Germany), CD209 (LWC06-PE, rat IgG2a, eBio), Clec6A (D2.11E4, rat IgG2a, Serotec, Oxford, UK), Clec7A (2A11, rat IgG2b, Serotec), Clec9A (700517, rat IgG2a, R\&D, Minneapolis, USA), Siglec-H (eBio440c, rat IgG2b, eBio), PDC-TREM (4A6, rat IgG2a, Biolegend, San Diego, USA), Two isotype control Abs were included as non-targeting controls: rat IgG2a,k (eBR2a, eBio) and rat IgG2b,k (eB149/10H5, eBio). When available, antibodies were acquired as functional grade (azide free and low endotoxin). If not available as functional grade, the buffer was changed to sterile PBS with low endotoxin (sPBS, Gibco, Life technologies, Paisly, UK) by ultrafiltration three times using Amicon Ultra- 0.5 centrifugal filter devices with a molecular weight cutoff of 30kDa (Millipore, Billerica, USA).

\section{Immunization}

Mice were immunized subcutaneously with a functional grade non-targeting isotype control monoclonal rat antibody of either isotype IgG2a or IgG2b (Biolegend). Three injections were administered with 3-week intervals. The first dose consisted of $25 \mu \mathrm{g}$ of $\mathrm{Ag}$ emulsified in Freund's complete adjuvant (Sigma-Aldrich, St. Louis, USA); whereas the following two vaccinations were performed with $10 \mu \mathrm{g} \mathrm{Ag}$ in Freund's incomplete adjuvant (Sigma Aldrich). The efficiency of the immunization was confirmed by measuring the presence of anti-rat lgG in mouse serum by ELISA. 
Isolation of splenocytes

Splenocytes were isolated according to Inaba et al. [10] with minor modifications. Following digestion in 400U/ml Collagenase D (Roche, Basel, Germany), undigested material was aspirated into a syringe and ejected through a $26 \mathrm{G}$ needle. Splenocytes were centrifuged and red blood cells were removed using the ACK lysis buffer as described in [11]. The cells were subsequently counted in trypan blue and subjected to further isolation procedures as described below or adjusted to $1 \times 10^{7}$ cells $/ \mathrm{ml}$ in DC2 medium consisting of RPMI 1640 (Gibco) supplemented with 1\% penicillin/streptomycin (Ampliqon, Odense, DK) and $2 \%$ mouse serum (Gentaur, Kampenhout, Belgium) and used in the ELISPOT assay.

\section{Isolation of $C D 11 c^{+} D C s$}

Splenocytes were isolated as described above, however, following passage through the 26G needle the mononuclear cells were isolated by density gradient centrifugation (Lymhoprep, Axis-shield, Oslo, Norway), resuspended in sPBS with 0.1\% BSA (SigmaAldrich) and 2mM EDTA (Merck, Darmstadt, Germany), counted and subjected to negative

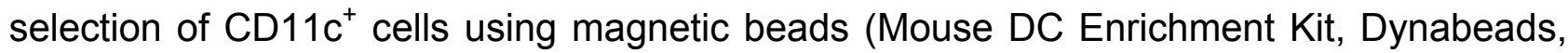
Life Technologies) according to the manufacturer's instructions. The isolated untouched cells were counted in trypan blue and adjusted to $1 \times 10^{7}$ cells $/ \mathrm{ml}$ in PBS containing $0.5 \%$ BSA (Sigma-Aldrich) and $0.09 \% \mathrm{NaN}_{3}$ (PBS/BSA/Az) and used for flow cytometry.

\section{Flow cytometry}

The following Abs were used for flow cytometry: CD8a APC, CD11c FITC, CD80 PE and CD86 APC (all BD Pharmingen, San Diego, USA). In addition, cells were stained with fluorochrome-conjugated Abs of the same hybridomas as used for targeting. Cells were resuspended in PBS/BSA/Az, stained with the relevant antibodies, washed in PBS/BSA/Az and resuspended in 1\% paraformaldehyde followed by flow cytometry using a FACSCanto flow cytometer (BD Biosciences). 


\section{IFN- $y$ and IL-4 ELISPOT}

ELISPOT analysis was performed on crude splenocytes cultured with mAb specific for each of the selected target receptors. Spleen donors were mice immunized with a nontargeted control antibody.

96-well Multiscreen IP plates (Millipore) were coated overnight at $4^{\circ} \mathrm{C}$ with IFN-y or IL-4 capture antibody (Mabtech, Stockholm, Sweden) at $15 \mu \mathrm{g} / \mathrm{ml}$ in sPBS. Plates were washed in sPBS and blocked in RPMI with 10\% mouse serum (Gentaur) for at least 2 hours at $37^{\circ} \mathrm{C}$. After several washes, $10^{6}$ splenocytes $(100 \mu \mathrm{l})$ were transferred to each well and monoclonal target antibodies were added at final concentrations of $10 \mu \mathrm{g} / \mathrm{ml}$ or $1 \mu \mathrm{g} / \mathrm{ml}$. Non-targeted rat IgG2a or IgG2b (eBio) were included as controls. As a positive control, concanavalin A (Sigma-Aldrich) was added to wells containing splenocytes at a final concentration of $1 \mu \mathrm{g} / \mathrm{ml}$. All experiments were performed in triplicates. Cells were cultured in IFN-y and IL-4 plates at $37^{\circ} \mathrm{C}$ and with $5 \% \mathrm{CO}_{2}$ for 20 or 42 hours, respectively. For detection of cytokines, plates were incubated with $100 \mu \mathrm{l}$ of $1 \mu \mathrm{g} / \mathrm{ml}$ biotinylated anti-IFN-Y or anti-IL-4 (Mabtech) in PBS with 0.5\% FCS (Gibco) for two hours, washed and incubated with $100 \mu$ streptavidin-alkaline phosphatase (Mabtech) for 60 minutes followed by another wash and addition of $100 \mu \mathrm{l}$ BCIP/NBT substrate (Mabtech). The number of cytokine-producing cells was determined using a ImmunoSpot S5 UV analyzer (CTL, Cleveland, USA).

\section{Generation of bone marrow-derived DCs}

The procedure for generating bone marrow-derived DCs (BM-DCs) was modified from [12]. Mice were sacrificed by cervical dislocation. The femur and tibia were removed and freed of muscles and tendons. The bones were placed in $70 \%$ ethanol for $120 \mathrm{~s}$ and subsequently washed in SPBS. The marrow was flushed with $5 \mathrm{ml} \mathrm{sPBS}$ using a syringe fitted with a $25 \mathrm{G}$ needle. Visible cell clusters were broken up by pipetting and the cell suspension was centrifuged for $5 \mathrm{~min}$ at $300 \mathrm{xg}$ at RT and resuspended in DC10 medium consisting of RPMI 1640 (Gibco) with 1\% penicillin/streptomycin (Ampliqon), $50 \mu \mathrm{M} 2-$ mercaptoethanol and $10 \%$ foetal calf serum (FCS, Gibco). The cell suspension was adjusted to $2 \times 10^{6}$ cells $/ \mathrm{ml}$ in DC10 with $40 \mathrm{ng} / \mathrm{ml}$ recombinant murine GM-CSF (Peprotech, Rocky Hill, USA) and $1 \mathrm{ng} / \mathrm{ml}$ recombinant murine IL-4 (Peprotech) and seeded in bacteriological Petri dishes (Falcon, $\mathrm{BD}$ Biosicences) and placed in a $\mathrm{CO}_{2}$ - 
incubator at $37^{\circ} \mathrm{C}$. At day 3 fresh DC10 containing GM-CSF and IL-4 was added to each dish. At day 5 and 7 the medium was partially replaced by collecting half the medium from each dish. The collected medium was centrifuged (5 min at $300 x g$ at RT) and the pellet was resuspended in fresh cytokine-supplemented DC10 and returned to the each dish. At day 10 the cells were harvested by pipetting, washed and counted in trypan blue. The BMDCs subjected to surface-marker analysis (see flow cytometry), or used for the internalization assay and for microscopy.

\section{Antibody internalization assay}

BM-DCs were incubated with the mAbs targeting CD11c, CD36, CD205, CD209, PDCTREM, or Siglec $\mathrm{H}$ on ice for 30 minutes. Tubes with non-targeting isotype control mAbs were included to correct for non-specific binding. After washing in ice-cold PBS/BSA, half of the cells were kept on ice to prevent internalization, whereas the other half was placed at $37^{\circ} \mathrm{C}$ to induce internalization of the bound Abs. After 30 or $60 \mathrm{~min}$ at either $37^{\circ} \mathrm{C}$ or $4^{\circ} \mathrm{C}$, cells were put on ice for $15 \mathrm{~min}$ to stop internalization and washed in ice-cold PBS/BSA/Az. A fraction of the cells were used for preparation of cytospin slides using a Shandon cytospin-centrifuge (Bie\&Berntsen). Cytopsin slides were left to dry for $30 \mathrm{~min}$ and subsequently frozen for later use. The rest of the cells incubated on ice for 30 min with either PE-conjugated mouse anti-rat IgG2a or FITC-conjugated mouse anti-rat IgG2b (both BD Biosciences). Unbound Abs were washed away and cells were fixed in $1 \%$ paraformaldehyde and analysed on the FACSCanto flow cytometer (BD Biosciences). Mean fluorescens intensities (MFI) were corrected for non-specific binding by subtracting the MFI obtained by the isotype control. The corrected values were used for calculating the percentage of internalized $\mathrm{Abs}\left(\mathrm{MFI} 4^{\circ} \mathrm{C}-\mathrm{MFI} 37^{\circ} \mathrm{C}\right) / \mathrm{MFI} 4^{\circ} \mathrm{C} \times 100$.

\section{Confocal laser scanning microscopy of cytospin slides}

Cytospin of BM-DC suspensions were fixed in acetone for $10 \mathrm{~min}$, rehydrated in PBS and stained with Alexa Flour 488-conjugated goat anti-rat IgG (Jackson Immunresearch, West Grove, USA) for 60 min. Following four times washing in PBS, slides were stained with APC-conjugated rat anti-mouse MHC II (I-A/I-E, M5/114.15.2, eBioscience) for 45 min. Rat $\lg \mathrm{G} 2 \mathrm{~b}, \mathrm{k}$ APC (eBioscience) were used as isotype control. Slides were then washed 4 
times in PBS and mounted with DAKO mounting media. Images were acquired on a Leica TCS Sp5 confocal laser scanning microscope connected to an OS-9 computer.

Data analysis

ELISPOT analysis was performed using ImmunoSpot 4.0.19 software (CTL). Flow cytometric analysis was performed using FlowJo, version 7.6.5 (TreeStar, Ashland, USA). Graphs and statistical analysis were compiled using the GraphPad Prism 5.04 software (GraphPad Software, San Diego, USA). The raw data obtained from the ELISPOT assays was subjected to the quality control recommended by Moodie et al. [13] [14]. Data sets that met the criteria were then subjected to statistical analysis as advocated by the same group using a web tool found at http://www.scharp.org/zoe/runDFR. 


\section{Results}

\section{Targeting of Ag to DCs in spleen cell cultures evokes stronger T cell responses}

A very simple cell culture system was established, in which DC-targeting or non-targeting monoclonal rat antibodies were added to crude spleen cells from mice immunized with a rat isotype control antibody. The effect of delivering $\mathrm{Ag}$ to the ten target receptors was tested using two $\mathrm{Ag}$ concentrations $(10 \mu \mathrm{g} / \mathrm{ml}$ or $1 \mu \mathrm{g} / \mathrm{ml})$ and the number of cells producing IFN-y or IL-4 was determined using the ELISPOT technique. Spleen cell donors were immunized with either isotype $\lg G 2 a$ or $\lg G 2 b$, depending on the isotype of the targeting antibodies. The efficacy of the immunization was confirmed by measuring the presence of mouse anti-rat IgG by ELISA (data not shown).

The ELISPOT raw data, based on uncorrected spot counts, are shown in figure $1 \mathrm{~A}$. Raw data was subjected to a comprehensive quality control based on the intra-replicate variation as well as response detection. The data that passed the variance filter was subsequently subjected to statistical analysis using the distribution-free resampling (DFR) method in order to investigate whether the mean spot counts obtained with Ags was significantly different from the background (wells containing splenocytes and medium without $\mathrm{Ag}$ ). The DFR(eq) tests a null hypothesis of equal background and experimental well means using a permutation test with Westfall-Young Stepdown max T adjustment for multiple testing in order to control the family-wise error rate. In addition to the statistical criteria for positive responses, the limit of detection of the assay was estimated and included in the response definition criterion.

The IFN- $\gamma$ responses obtained by Ag-delivery to the different target structures are presented in figure $1 \mathrm{~B}$. Both positive and negative responses are shown and the number of positive responses out of the total number of repeated experiments is provided in the table. The responses obtained varied among the repeated experiments but at the highest Ag concentration CD11c (4/5), CD36 (5/7), CD205 (4/7) and Clec7A (7/7) elicited a high fraction of positive responses compared to the non-targeting control (1/7). Antigen-delivery to CD206, Clec6A, Clec9A and PDC-TREM at $10 \mu \mathrm{g} / \mathrm{ml}$ only elicited high IFN- $\gamma$ responses in 1 or 2 of the repeated experiments, while CD209 and Siglec $\mathrm{H}$ did not elicit any positive IFN- $\gamma$ responses. Targeting of Clec7A at $1 \mu \mathrm{g} / \mathrm{ml}$ also elicited high IFN- $\gamma$ responses in all repeated experiments $(6 / 6)$ compared to the non-targeting control $(0 / 6)$. The other target 
Abs only elicited 0 or 1 positive response at this Ag concentration. Regarding induction of IL-4, only few experiments with both the targeting Abs and the non-targeted control elicited spot counts that were significantly higher than the background spot counts at any of the two Ag concentrations (Figure 1C). However, targeting Ag to CD36 and CD205 at 10 $\mu \mathrm{g} / \mathrm{ml}$ did produce positive IL-4 responses in 3/7 and 2/7 cases, respectively, whereas the nontargeting control produced no positive responses (0/7).

\section{Differential expression of the ten target receptors on DC subsets}

The expression of the ten target receptors on splenic CD $11 \mathrm{c}^{+} \mathrm{DCs}$ was analysed by flow cytometry. The analysis demonstrated differential expression of the targets on $\mathrm{CD} \mathrm{a}^{+}$or CD8 $\alpha^{-}$DCs (Figure 2). CD36 were present at high levels on both CD8 $\alpha^{+}$and CD8 $\alpha^{-}$DCs. CD205 was highly expressed by $\mathrm{CD} \mathrm{\alpha}^{+} \mathrm{DCs}$, while Clec9A displayed intermediate expression by this subset. In contrast, CD206, CD209, Clec6A, PDC-TREM and Siglec H were expressed at low levels on the $C D 8 \alpha^{+} \mathrm{DCs}$. The CD8 $\alpha^{-} \mathrm{DC}$ subset expressed low to intermediate levels of CD206, CD209, Clec6A, Clec9A, PDC-TREM and Siglec H. Clec7A was expressed on a small subset of $\mathrm{CD} 11 \mathrm{c}^{+}, \mathrm{CD}^{-} \mathrm{a}^{-} \mathrm{DCs}$, but could not be detected on the CD8 $\alpha^{+}$DCs.

\section{Antibody binding and receptor internalization}

The in vitro screening assay identified several potential target receptors that upon $\mathrm{Ag}$ delivery induced the production of IFN-Y. As receptor endocytosis is considered a prerequisite for $\mathrm{Ag}$ presentation, we examined the level of $\mathrm{Ab}$ internalization using immature BM-DCs. First, the surface expression of the ten receptors was examined by flow cytometry. This demonstrated expression of CD11c, CD36, CD205 and CD209 but not CD206, Clec6A, Clec7A and Clec9A (Figure 3A). Additionally, the cells exhibited low expression of two markers, Siglec $H$ and PDC-TREM, normally expressed on plasmacytoid DCs. The next step was to determine the efficiency by which the different target Abs induce receptor internalization. Bone marrow-derived DCs were treated at the immature stage with selected monoclonal target Abs and the level of Abs remaining at the cell surface after different culture periods was determined by flow cytometry (Figure 3B). Targeting CD36 resulted in the most comprehensive internalization of approximately $39 \%$ (33\%-45\%) and 53\% (33\%-79\%) after 30 or $60 \mathrm{~min}$, respectively, while the CD205 
antibody induced receptor internalization at 28\% (19\%-52\%) after $30 \mathrm{~min}$ and $33 \%$ (19\%$56 \%)$ after $60 \mathrm{~min}$ of culture. Approximately $8 \%(6 \%-11 \%)$ to $15 \%(13 \%-18 \%)$ of the CD11c Abs disappeared from the cell surface after 30 or $60 \mathrm{~min}$, respectively. The expression of CD209, PDC-TREM and Siglec $\mathrm{H}$ was too weak to perform analysis of receptor internalization.

Receptor internalization was also investigated by confocal laser scanning microscopy of cytospin slides of BM-DCs that had been incubated with target Abs at either $4^{\circ} \mathrm{C}$ or $37^{\circ} \mathrm{C}$ for $30 \mathrm{~min}$ (Figure $3 \mathrm{C}$ ). Nuclei were stained with DAPI and BM-DCs were visualized by staining with APC-conjugated rat anti-mouse MHC II. Target Abs (both surface bound and internalized) were visualized by staining with Alexa Flour 488-conjugated goat anti-rat IgG (Figure $3 C$ ). The results showed a difference in Alexa Flour 488 staining between cells cultured at $37^{\circ} \mathrm{C}$ and cells cultured at $4^{\circ} \mathrm{C}$. A variable green staining in the form of evenly distributed, small green spots in the plane of the membrane was seen on many cells in all preparations, indicating the presence of rat mAb on the cell membrane. In contrast, larger, brightly stained dots inside the cell perimeter in the plane of the nucleus were preferentially seen in cells incubated at $37^{\circ} \mathrm{C}$, supporting the notion that the target Abs is actually internalized in these cells. 


\section{Discussion}

Targeting Ags to DCs has been shown to induce strong immune responses with smaller amounts of antigen than needed without targeting [15]. Several different DC surface molecules have been targeted, and there are indications, that the choice of molecular target affects the quality of the resulting immune response [15-19]. Consequently, with a view to identifying optimal targets for vaccines, it is of interest to investigate a multitude of different targets, preferentially in setups that allow direct comparison of the induced immune responses.

In this study a simple assay for screening of candidate vaccine target receptors on murine DCs was developed. It allows simultaneous analysis of several potential target receptors and direct comparison of the $\mathrm{T}$ cell responses induced by targeting Ag to these receptors. The assay is based on rat mAbs functioning as both targeting devices and Ags and it utilizes, as a source of both DCs and responding T cells, crude cultures of splenocytes isolated from mice immunized with non-targeting isotype control Abs.

Ten different target receptors were included in the screening assay and the effect of $\mathrm{Ag}$ delivery was determined for two Ag concentrations. A response definition criterion was applied to the raw data in order to define positive responses. The targeting Abs that elicited high IFN-y responses in repeated experiments were CD11C, CD36, CD205 and Clec7A. CD36, CD205 and Clec7A did also induce positive IL-4 responses in a fraction of the repeated experiments. The responses obtained by the other target structures were only positive in a small number of the repeated experiments. In general, very few experiments in the IL-4 assay turned out as positive responses by the DFR (eq) test, which may partly be due to a low signal-to-noise ratio in this assay. Thus, future experiments should focus on the goal of reducing background spot counts and/or increasing the signalto-noise ratio in the IL-4 assay.

To the best of our knowledge, PDC-TREM has not previously been investigated as a target receptor for Ag-delivery to DCs and even though this target only elicited positive IFN-Y responses in 1 out of 4 mice and IL-4 responses in 1 out of 3 mice, a role of PDCTREM as an endocytic receptor mediating Ag presentation for T cells cannot be ruled out. The efficiency of PDC-TREM as a target for receptor-mediated Ag internalization needs to be clarified by future studies, for instance by in vivo-targeting. 
The differences in the responses obtained by the targeting Abs and the non-targeting Abs, especially in the IFN- $\gamma$ assay, indicate that the responses are elicited by a specific interaction between the target receptor and the targeting Abs. However, when the mAbs used for targeting are full-length Abs, containing the Fc portion, the uptake of Ag after targeting DC surface molecules may partly be due to FcR binding rather than specific binding via the $\mathrm{mAb}$ variable regions, which is not the purpose of DC targeting. The present study used a non-targeting isotype control mAb which controls for FcR uptake of monomeric Ig, but not polymeric Ig, and the results showed that FcR-dependent uptake of targeted $\mathrm{Ag}$ is of little importance for the immune response and that the mAb binding was specific. Other groups have also investigated the importance of FcR-mediated uptake in this kind of experiments. Two studies showed that targeting with intact antibodies also induced equally strong humoral responses in FcR $\mathrm{Y}$-chain deficient mice upon injection of a targeting $\mathrm{mAb}$ indicating that the $\mathrm{Fc}$ portion of the targeting $\mathrm{mAb}$ plays no role in the enhancement of immune responses [20;21]. Furthermore, Corbett et al. demonstrated strong Ig responses with the use of $F\left(a b^{\prime}\right) 2$ fragments, confirming that Ag-delivery was due to specific rather than FcR or complement-mediated binding [20].

As the assay employed in this study is based on Ag-delivery via mAbs, the outcome of this process depends on inherent properties of the individual targeting Abs. Features like the affinity and the specificity of the mAb for the target receptor as well as the particular epitope recognized by the antibody may be important for the efficacy of the Ag-delivery. The assay entails a risk of rejecting good candidates only on the basis of inappropriate properties of target antibodies and not on the fact that these candidates are inefficient as target receptors. Nevertheless, the potential target receptors identified by this screening assay is likely good candidates for DC-directed vaccines. The potential receptors can subsequently be subjected to in-depth studies investigating the underlying mechanisms that determine the outcome of the targeted-delivery of $\mathrm{Ag}$ (e.g. amount of $\mathrm{Ag}$ delivered, trafficking route, presentation on $\mathrm{MHC}$ I and/or II) as well as to in vivo targeting studies.

$\mathrm{T}$ cell activation requires that the $\mathrm{Ag}$ (in this case an $\mathrm{Ab}$ ) is taken up by the cell expressing the target receptor and subsequently presented as peptides on the cell surface in complex with MHC molecules. The efficiency of targeting $\mathrm{Ag}$ to specific receptors is probably not directly related to the expression levels of these receptors but may, to a greater extent, 
dependent on the ability of the specific receptor to function as an efficient endocytic receptor. In addition, the general distribution of the target receptor on different cell types may also be important as different DC subsets possess specialized functions. The present

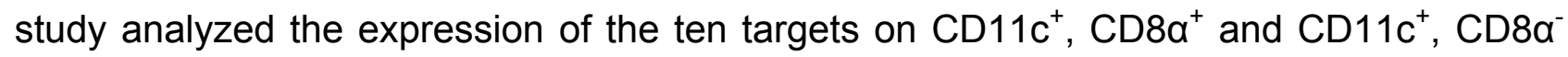
splenic DCs and found no obvious correlation between the expression pattern of the receptor on the two DC subsets and the ability to induce IFN- $\gamma$ production in $\mathrm{T}$ cells following targeting of $\mathrm{Ag}$ to that specific receptor. We found high expression of CD11c and CD36 on both subsets, and weak expression of Clec7A on a fraction of the CD11 ${ }^{+}, \mathrm{CD}^{-} \mathrm{a}^{-}$ DC subsets. Still, all three targets elicited positive IFN-y responses. In contrast, two other receptors, CD205 and Clec9A, displayed high expression on CD8 ${ }^{+}$DCs, but low expression on CD8 $\alpha^{-}$DCs and only one of these two targets, CD205, elicited repeated IFN- $\mathrm{Y}$ responses. Overall these results indicate that efficient induction of an IFN- $\mathrm{Y}$ response may be more receptor-dependent than subset-dependent. The level of receptor internalization was analyzed for the target receptors that are expression on BM-DCs. Analysis of the level of receptor internalization demonstrated that targeting of CD36 induced internalization of more Abs than CD205 and CD11c. In addition, CD205 appeared more efficient at mediating receptor internalization compared to CD11c. Receptor internalization was confirmed by confocal microscopy showing a difference in Alexa Flour 488 staining between cells cultured at $37^{\circ} \mathrm{C}$ and cells cultured at $4^{\circ} \mathrm{C}$.

As the screening assay was performed on crude spleen cell suspensions, it is at this stage not know which cell type(s) within the splenic population that are responsible for presenting $\mathrm{Ag}$ to $\mathrm{T}$ cells. Future studies may therefore favour investigations on pure DC and $\mathrm{T}$ cell suspensions. Still, the screening assay provides information about the relative efficiency of unique target receptors expressed by different DC subsets. 


\section{Acknowledgements}

The authors thank the animal technicians at the animal facility of Department of Pathology, Aalborg Hospital for competent handling of the mice, and laboratory technician Brita Holst Jensen for technical assistance during the study.

\section{Conflict of interest}

The authors declare no financial or commercial conflict of interest. 


\section{References}

1. Banchereau,J., Briere,F., Caux,C., Davoust,J., Lebecque,S., Liu,Y.J., Pulendran,B., and Palucka,K., Immunobiology of dendritic cells. Annu.Rev Immunol 2000. 18: $767-811$.

2. Lahoud,M.H., Ahmet,F., Kitsoulis,S., Wan,S.S., Vremec,D., Lee,C.N., Phipson,B., Shi,W., Smyth,G.K., Lew,A.M., Kato,Y., Mueller,S.N., Davey,G.M., Heath,W.R., Shortman,K., and Caminschi,I., Targeting Antigen to Mouse Dendritic Cells via Clec9A Induces Potent CD4 T Cell Responses Biased toward a Follicular Helper Phenotype. The Journal of Immunology 2011. 187: 842-850.

3. Shortman,K., Lahoud,M.H., and Caminschi,I., Improving vaccines by targeting antigens to dendritic cells. Exp.Mol.Med. 2009. 41: 61-66.

4. Tacken,P.J. and Figdor,C.G., Targeted antigen delivery and activation of dendritic cells in vivo: Steps towards cost effective vaccines. Seminars in Immunology 2011. 23: $12-20$.

5. Caminschi,I., Maraskovsky,E., and Heath,W.R., Targeting Dendritic Cells in vivo for Cancer Therapy. Front Immunol 2012. 3: 13.

6. Idoyaga,J., Lubkin,A., Fiorese,C., Lahoud,M.H., Caminschi,I., Huang,Y., Rodriguez,A., Clausen,B.E., Park,C.G., Trumpfheller,C., and Steinman,R.M., Comparable T helper 1 (Th1) and CD8 T-cell immunity by targeting HIV gag p24 to 
CD8 dendritic cells within antibodies to Langerin, DEC205, and Clec9A. Proc.Natl.Acad.Sci.U.S.A 2011. 108: 2384-2389.

7. Mahnke,K., Qian,Y., Fondel,S., Brueck,J., Becker,C., and Enk,A.H., Targeting of antigens to activated dendritic cells in vivo cures metastatic melanoma in mice. Cancer Res 2005. 65: 7007-7012.

8. Joffre,O.P., Sancho,D., Zelenay,S., Keller,A.M., and Reis E Sousa, Efficient and versatile manipulation of the peripheral CD4+ T-cell compartment by antigen targeting to DNGR-1/CLEC9A. Eur.J.Immunol 2010. 40: 1255-1265.

9. Tacken,P.J., de Vries,I.J., Gijzen,K., Joosten,B., Wu,D., Rother,R.P., Faas,S.J., Punt,C.J., Torensma,R., Adema,G.J., and Figdor,C.G., Effective induction of naive and recall T-cell responses by targeting antigen to human dendritic cells via a humanized anti-DC-SIGN antibody. Blood 2005. 106: 1278-1285.

10. Inaba,K., Swiggard,W.J., Steinman,R.M., Romani,N., Schuler,G., and Brinster,C., Isolation of Dendritic Cells. Current Protocols in Immunology. John Wiley \& Sons, Inc., 2001.

11. Kruisbeek,A.M., Isolation of mouse mononuclear cells. Curr.Protoc.Immunol 2001. Chapter 3: Unit. 
12. Petersen, Toldbod, Holtz, Hokland, Bolund, and Agger, Strain-Specific Variations in the Development of Dendritic Cells in Murine Bone-Marrow Cultures. Scandinavian Journal of Immunology 2000. 51: 586-594.

13. Moodie,Z., Price,L., Gouttefangeas,C., Mander,A., Janetzki,S., Lower,M., Welters,M.J., Ottensmeier,C., van der Burg,S.H., and Britten,C.M., Response definition criteria for ELISPOT assays revisited. Cancer Immunol Immunother. 2010. 59: $1489-1501$.

14. Moodie,Z., Price,L., Janetzki,S., and Britten,C.M., Response determination criteria for ELISPOT: toward a standard that can be applied across laboratories. Methods Mol.Biol. 2012. 792: 185-196.

15. Kreutz,M., Tacken,P.J., and Figdor,C.G., Targeting dendritic cells: why bother? Blood 2013.

16. den Haan,J.M., Lehar,S.M., and Bevan,M.J., CD8(+) but not CD8(-) dendritic cells cross-prime cytotoxic T cells in vivo. J.Exp.Med. 2000. 192: 1685-1696.

17. Pooley,J.L., Heath,W.R., and Shortman,K., Cutting edge: intravenous soluble antigen is presented to CD4 T cells by CD8- dendritic cells, but cross-presented to CD8 T cells by CD8+ dendritic cells. J.Immunol 2001. 166: 5327-5330.

18. Mahnke,K., Guo,M., Lee,S., Sepulveda,H., Swain,S.L., Nussenzweig,M., and Steinman,R.M., The dendritic cell receptor for endocytosis, DEC-205, can recycle 
and enhance antigen presentation via major histocompatibility complex class IIpositive lysosomal compartments. J.Cell Biol. 2000. 151: 673-684.

19. Caminschi,I., Lahoud,M.H., and Shortman,K., Enhancing immune responses by targeting antigen to DC. Eur.J.Immunol. 2009. 39: 931-938.

20. Corbett,A.J., Caminschi,I., McKenzie,B.S., Brady,J.L., Wright,M.D., Mottram,P.L., Hogarth,P.M., Hodder,A.N., Zhan,Y., Tarlinton,D.M., Shortman,K., and Lew,A.M., Antigen delivery via two molecules on the CD8- dendritic cell subset induces humoral immunity in the absence of conventional "danger". Eur.J.Immunol 2005. 35: 28152825.

21. Caminschi,I., Proietto,A.I., Ahmet,F., Kitsoulis,S., Shin,T.J., Lo,J.C., Rizzitelli,A., Wu,L., Vremec,D., van Dommelen,S.L., Campbell,I.K., Maraskovsky,E., Braley,H., Davey,G.M., Mottram,P., van,d., V, Jensen,K., Lew,A.M., Wright,M.D., Heath,W.R., Shortman,K., and Lahoud,M.H., The dendritic cell subtype-restricted C-type lectin Clec9A is a target for vaccine enhancement. Blood 2008. 112: 32643273. 


\section{Figure legends}

Figure 1. T-cell responses following Ag-delivery to specific DC receptors.

Splenocytes from mice immunized with isotype control antibody were cultured with $\mathrm{mAb}$ specific for the receptors indicated at final concentrations of either $10 \mu \mathrm{g} / \mathrm{ml}$ (gray) or 1 $\mu \mathrm{g} / \mathrm{ml}$ (black). T cell activation was measured in IFN-y and IL-4 ELISPOT assays. As controls, splenocytes were cultured with non-targeted isotype control antibodies. Raw data is illustrated as mean +/- SEM from three-eight independent experiments (A). Raw data was tested for the intra-replicate variation and replicates passing this test were subjected to a distribution-free resampling (DFR) method testing for difference from background spot counts. Data is corrected for the background spot count level and the IFN- $Y$ responses were presented in (B) and IL-4 responses in (C). Red data points specify triplicates that were not significantly different from the background spot counts. Black data points specify positive target responses and gray data points specify positive non-targeting responses, all were determined by the DFR(eq) test. LOD are indicated with a dotted line.

The number of positive responses determined by the DFR(eq) and with spot counts above LOD was accepted as positive responses. The numbers of positive responses out of the total number of repeated experiments are shown in the two tables to the right.

Figure 2. Flow cytometric analysis of the expression of the ten target receptors on spleen DCs.

Splenocytes were harvested from unimmunized mice, $\mathrm{CD}_{11 \mathrm{c}^{+}}$cells were isolated using magnetic beads and cell suspensions were stained with mAb against CD11c FITC, CD8 $\alpha$ APC and each of the target receptors (PE or PerCP-Cy5.5 conjugated). A) Gating of splenocytes. B) Gating of DC subsets within the splenocyte population. C) Expression of

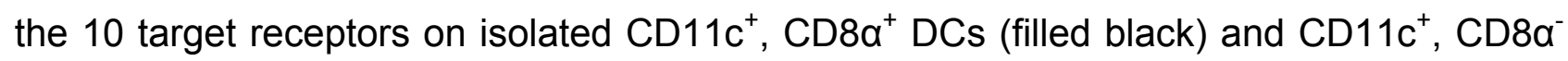
DCs (filled gray). Results obtained with isotype controls are shown with a black line. Data presented were derived from a single experiment and are representative of three independent experiments. 
Figure 3. Antibody binding and receptor internalization.

A) Bone marrow-derived DCs were stained for phenotypic markers (CD11C FITC, CD80 PE, CD86 APC and CD8a APC) and with antibodies for each of the 10 target receptors (tinted blue). Isotype controls are included (black line). Data presented are from a single experiment and are representative of three independent experiments. B) Bone marrowderived DCs were treated at the immature stage with selected monoclonal target Abs and the level of receptor internalization after different culture periods was determined by flow cytometry. Data is illustrated as mean +/- SD of three to five repeated experiments. C) Cytospin slides from BM-DC suspensions subjected to $30 \mathrm{~min}$ of receptor internalization at either $4^{\circ} \mathrm{C}$ or $37^{\circ} \mathrm{C}$ were stained with Alexa Flour 488-conjugated goat anti-rat IgG and APC-conjugated rat anti-mouse MHC ॥ and examined by confocal laser scanning microscopy. Six individual cells are shown at the level of the nucleus (the position of which is indicated by the dark area). Data are representative of 2 independent experiments. White bars correspond to $10 \mu \mathrm{m}$. 
Figure 1.

$1 \mathrm{~A}$
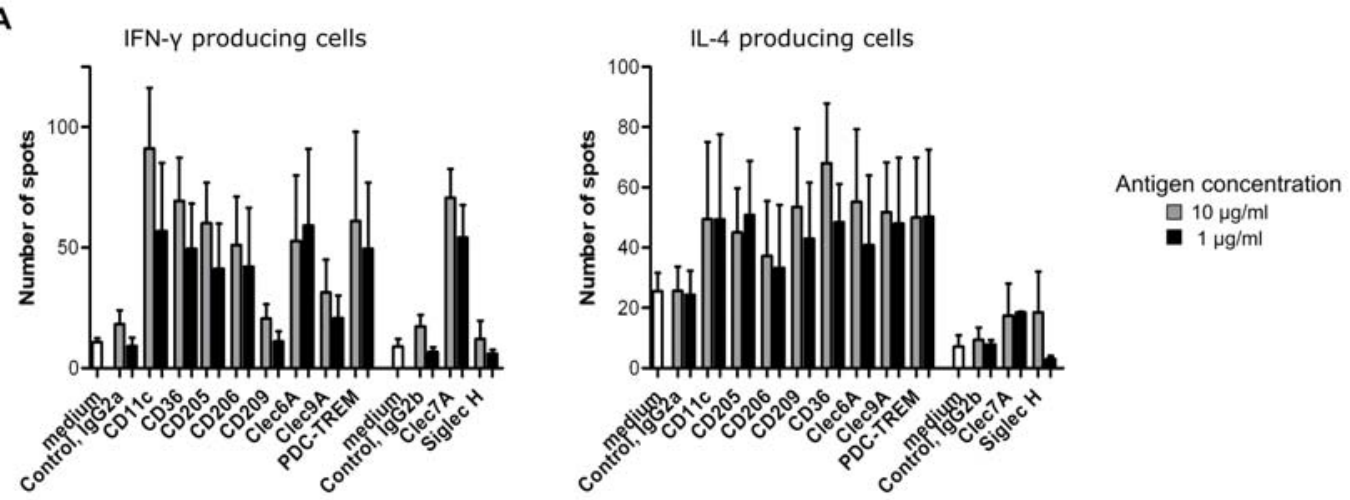

1B
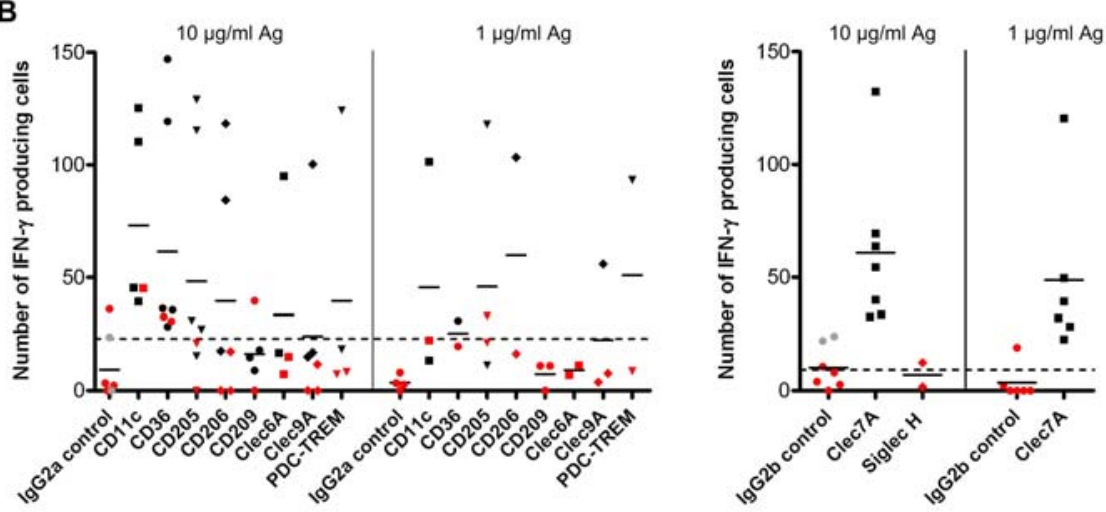

\begin{tabular}{|c|c|c|}
\hline Targets & $\begin{array}{l}\text { IFN-y. } \\
10 \mu g / m \mid\end{array}$ & $\begin{array}{l}\text { IFN-r. } \\
1 \mathrm{gg} / \mathrm{ml}\end{array}$ \\
\hline $\lg G 2 a$ control & $1 / 7$ & $0 / 4$ \\
\hline CD11c & $4 / 5$ & $1 / 3$ \\
\hline CD36 & $5 / 7$ & $1 / 2$ \\
\hline CD205 & $4 / 7$ & $1 / 4$ \\
\hline CD206 & 216 & $1 / 2$ \\
\hline $\mathrm{CD} 209$ & $0 / 5$ & $0 / 3$ \\
\hline Clec $B A$ & $1 / 4$ & $0 / 2$ \\
\hline Clec9A & $1 / 6$ & $1 / 3$ \\
\hline PDC-TREM & $1 / 4$ & $1 / 2$ \\
\hline $\lg \mathrm{G} 2 \mathrm{~b}$ control & $2 / 7$ & $0 / 6$ \\
\hline Clec7A & $7 / 7$ & $6 / 6$ \\
\hline Siglec H & $0 / 2$ & \\
\hline
\end{tabular}

1C
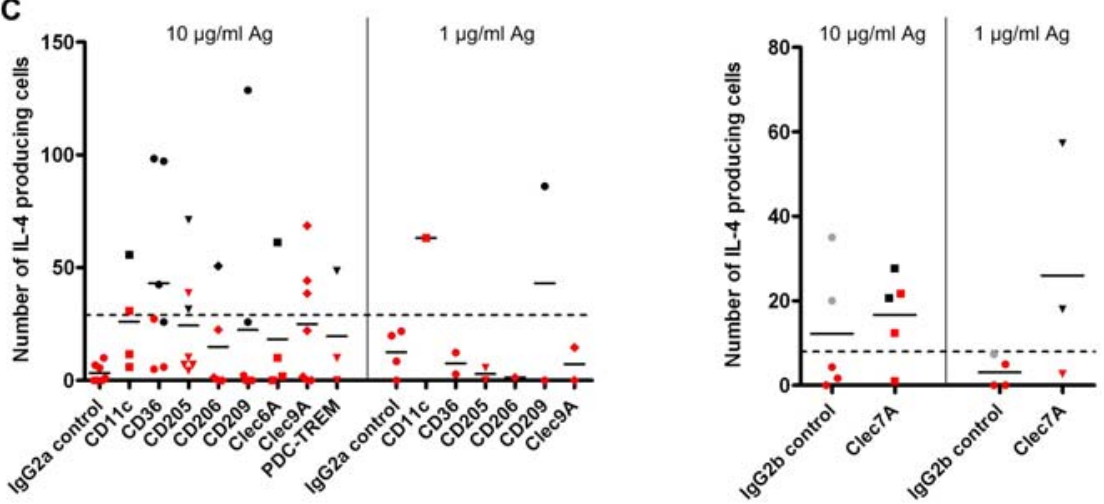

\begin{tabular}{|l|l|l|}
\hline Targets & $\begin{array}{l}\text { IL-4, } \\
10 \mu / \mathrm{ml}\end{array}$ & $\begin{array}{l}\text { IL-4, } \\
1 \mu \mathrm{g} / \mathrm{ml}\end{array}$ \\
\hline IgG2a control & $0 / 7$ & $0 / 4$ \\
\hline CD11c & $1 / 4$ & $0 / 1$ \\
\hline CD36 & $3 / 7$ & $0 / 2$ \\
\hline CD205 & $2 / 7$ & $0 / 2$ \\
\hline CD206 & $1 / 5$ & $0 / 1$ \\
\hline CD209 & $1 / 7$ & $1 / 2$ \\
\hline Clec6A & $1 / 4$ & \\
\hline Clec9A & $0 / 7$ & $0 / 2$ \\
\hline PDC-TREM & $1 / 3$ & \\
\hline IgG2b control & $2 / 5$ & $0 / 4$ \\
\hline Clec7A & $2 / 5$ & $2 / 3$ \\
\hline
\end{tabular}


Figure 2.

A.
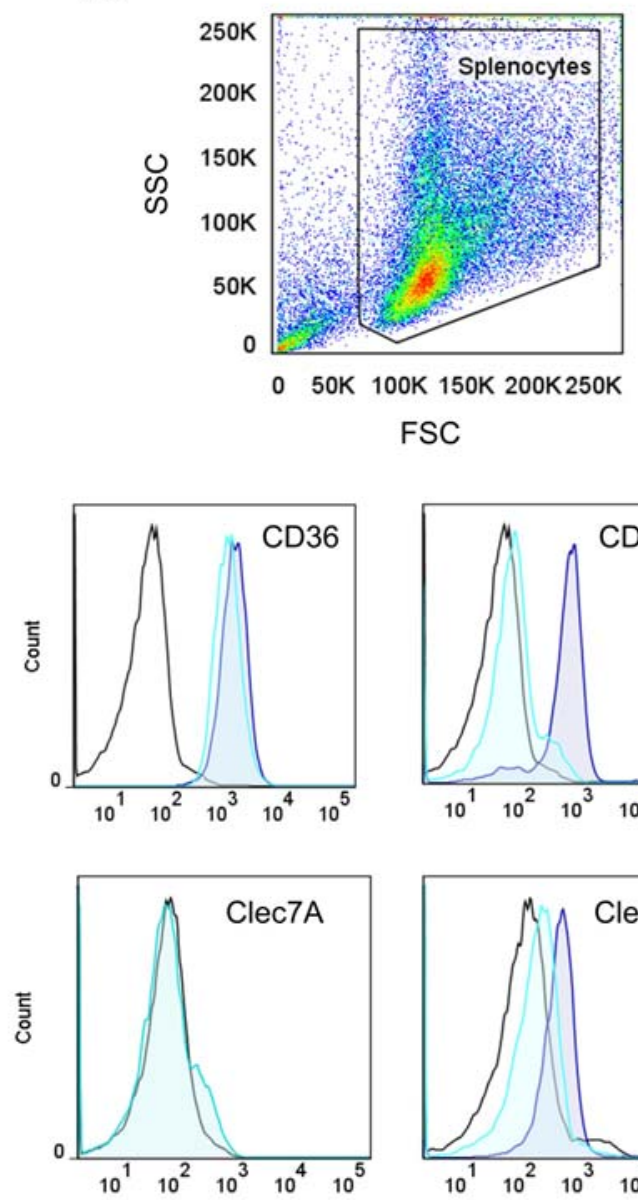

B.
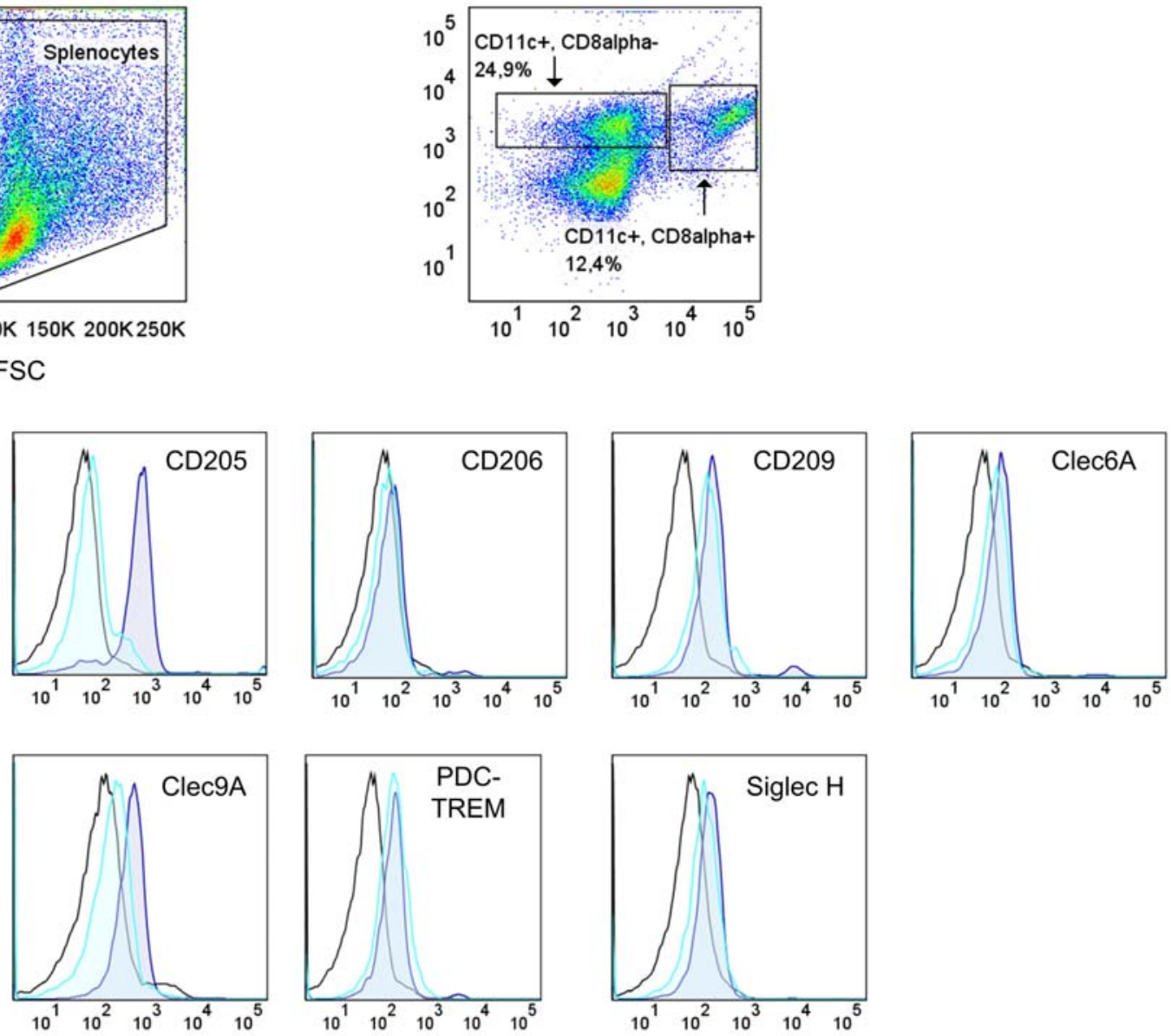

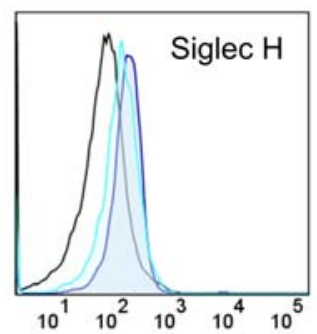


Figure 3.

3A
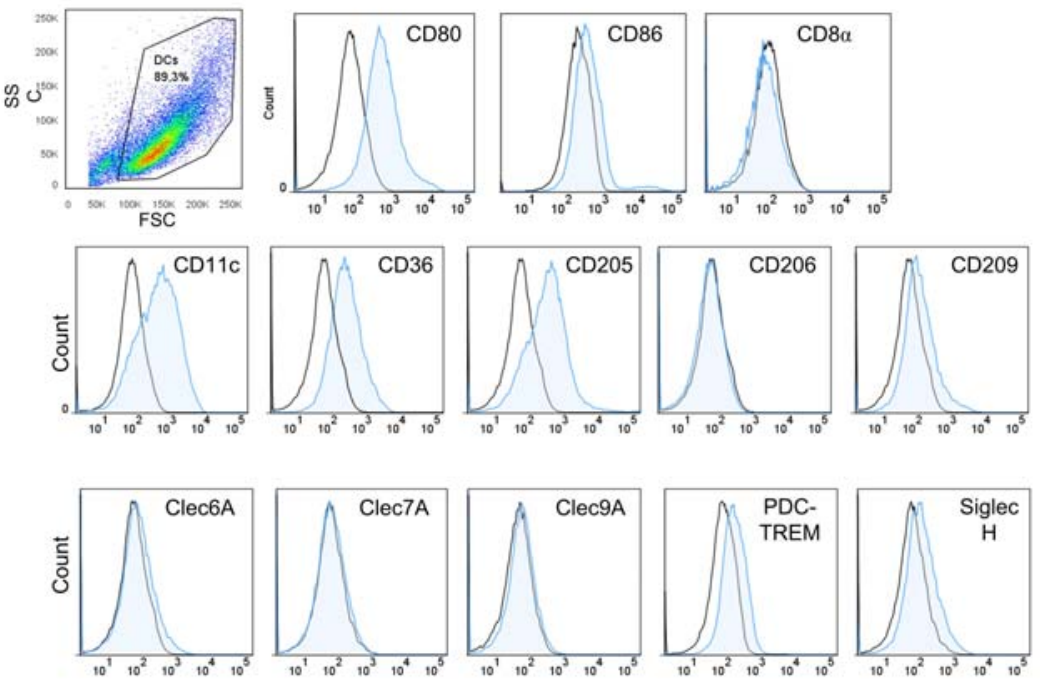

$3 C$
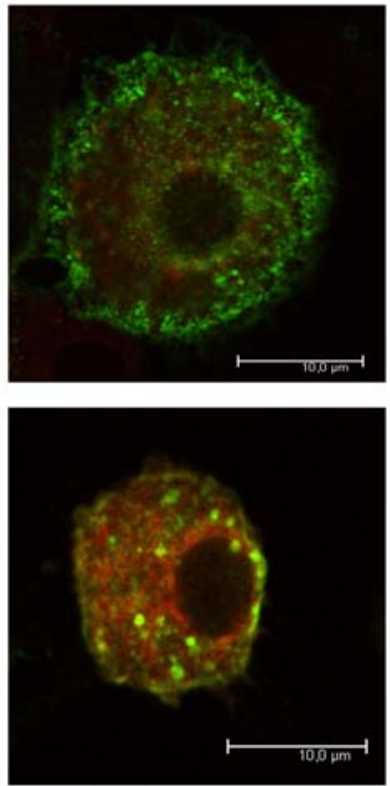

CD11c
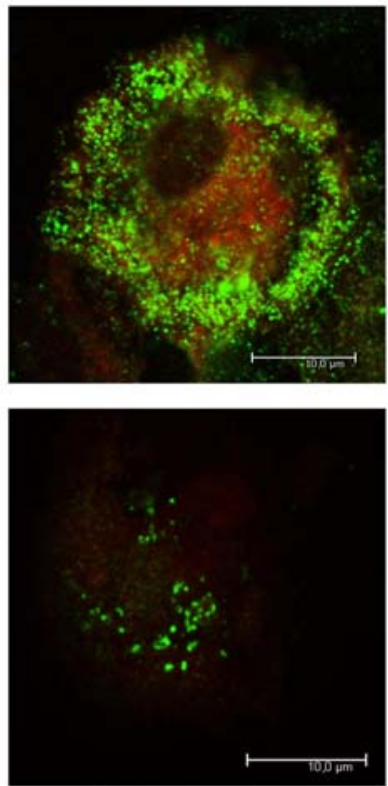

CD36

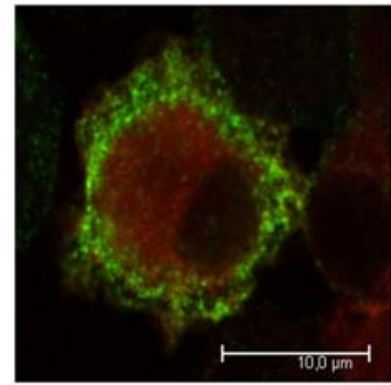

$4^{\circ} \mathrm{C}$

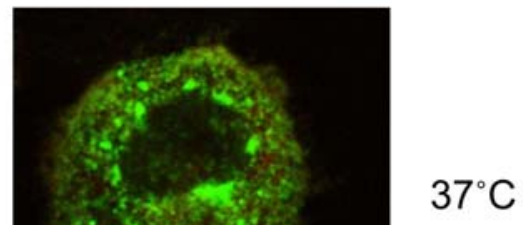

$37^{\circ} \mathrm{C}$ 
Manuscript II:

Antibody responses induced by targeting antigen to ten different receptors on dendritic cells in vivo.

Pugholm LH ${ }^{1,2}$, Varming, $K^{1} \&$ Agger, $\mathrm{R}^{2}$

${ }^{1}$ Department of Clinical Immunology, Aalborg Hospital, Aalborg, Denmark

${ }^{2}$ Laboratory of Immunology, Department of Health Science \& Technology, Aalborg University, Aalborg, Denmark

Correspondence:

Lotte Hatting Pugholm

Department of Clinical Immunology

Aalborg Hospital

Reberbansgade

9100 Aalborg

Denmark

Phone: +4599321674

E-mail: lohap@rn.dk

Keywords:

Dendritic cells, C-type lectins, Humoral responses, PDC-TREM, ELISPOT.

\section{Abbreviations:}

DCs: Dendritic cells

pDCs: Plasmacytoid dendritic cells

Ags: Antigens

S.c: Subcutaneous

CLRs: C-type lectin receptors 


\section{Abstract}

The superior capacity of dendritic cells (DCs) to induce and control adaptive immune responses has kindled hopes that it may be possible, by targeting antigens (Ags) to DCs, to induce potent and adjustable immune responses that could be clinically favourable in various human disorders. Monoclonal antibodies (mAbs) directed at DC surface receptors can be employed for targeted delivery of disease-specific Ags to DCs.

The results presented here demonstrate, that Ag-delivery by the means of mAbs to murine DCs in vivo in the absence of adjuvant may indeed mediate much stronger humoral responses than obtained with non-targeted $\mathrm{Ag}$. In addition, the results demonstrated that the efficacy of targeting Ags to specific receptors via mAbs depends on inherent properties of the targeting $A b$, emphasizing the importance of testing different mAbs of the same specificity in order to identify the ones best suited for antibody-based. With the panel of targeting mAbs used in the present study, considerable differences in antibody responses were found between the ten different target receptors. The targets that elicited strong antibody responses were PDC-TREM, CD11c, CD36, CD205, Clec6A and Clec7A. Targeting Ags to CD206, CD209, Clec9A and Siglec H showed responses comparable to the ones elicited by the non-targeted controls.

The IgG subclass composition of the antibody responses induced by Ag-delivery to the different receptors was also determined. All responses were dominated by IgG1. However, following delivery to Clec7A robust amounts of IgG2a were produced, indicating the presence of a manifest Th1 component in the immune responses of these mice. 


\section{Introduction}

Targeting Ag to DCs in vivo is an effective way of enhancing immunization. Several studies have demonstrated that targeting Ags to various target structures on DCs may augment both $\mathrm{T}$ cell responses and humoral immunity (1-15). Since the vast majority of studies have only investigated targeting to one particular target structure it is, however, not clear whether targeting the same Ag to different structures, or to different epitopes on the same target structure, will result in markedly different immune responses. It is, therefore, clearly of interest to compare the results obtained after targeting different molecules on the DC surface.

In this study, the humoral responses induced by in vivo targeting DCs using mAbs specific for CD11c, CD36, CD205, CD206, CD209, Clec6A, Clec7A, Clec9A, Siglec-H and PDCTREM were compared. The results demonstrate that Ag-delivery to different targets on DCs in vivo give rise to humoral responses that differ in strength and IgG subclass composition. Targeting Ag to CD205, Clec6A, CLEC7A, CD36, CD11c and PDC-TREM induced very strong antibody responses compared to the non-targeted controls. To the best of our knowledge, PDC-TREM has not previously been investigated as a potential DC target receptor. The results presented here indicate that this receptor might function as an endocytic receptor mediating Ag presentation and inducing humoral immune responses. It may therefore be an interesting candidate for further investigation. 


\section{Materials and Methods}

Mice

All murine experiments were performed on female C57BL/6J mice (Taconic Europe, Ejby, DK) and conducted at the animal facility of the Department of Pathology, Aalborg Hospital. All experimental procedures were approved by the Animal Experiments Inspectorate in Denmark (approval \# 2008561-1508) and carried out according to the national guidelines and regulations.

\section{Antibodies for targeting}

The following mAbs were used for in vivo targeting of DCs. CD11c $(223 \mathrm{H} 7$, rat IgG2a, MBL, Woburn, USA), CD36 (No.72-1, rat IgG2a, eBioscience, San Diego, USA), CD36 (MF3, rat IgG2a, Serotec, Oxford, UK), CD205 (205yekta, rat IgG2a, eBio), CD205 (NLDC-145, rat IgG2a, Biolegend, San Diego, USA), CD206 (MR5D3, rat IgG2a, Acris, Herford, Germany), CD209 (LWC06-PE, rat IgG2a, eBio), Clec6A (D2.11E4, rat IgG2a, Serotec), Clec7A (2A11, rat IgG2b, Serotec), Clec7A (218820, rat IgG2a, R\&D, Minneapolis, USA), Clec9A (700517, rat IgG2a, R\&D), Siglec-H (eBio440c, rat IgG2b, eBio) and PDC-TREM (4A6, rat lgG2a, Biolegend). Two isotype control Abs were included as non-targeting controls: rat IgG2a,k (eBR2a, eBio) and rat IgG2b,k (eB149/10H5, eBio). In experiments with only one specific Ab per target receptor, the Abs chosen for targeting CD36, CD205 and Clec7A were No.72-1, 205yekta, and 2A11, respectively. When available, Abs were acquired azide free and low endotoxin (functional grade). If not available as functional grade, the buffer was changed to sterile PBS with low endotoxin (sPBS, Gibco, Life technologies, Paisly, UK) by ultrafiltration three times using Amicon Ultra-0.5 centrifugal filter devices with a molecular weight cutoff of $30 \mathrm{kDa}$ (Millipore, Billerica, USA). The concentration of the Abs was measured using NanoDrop ND-1000 (Thermo Scientific, Wilmington, USA).

\section{Immunization and blood sampling}

Mice were immunized subcutaneously at the scruff of the neck with $5 \mu \mathrm{g}$ of monoclonal rat Ab specific for each of the ten target receptors. Four mice were included in each group. The mAbs were diluted in sPBS to a concentration of $50 \mu \mathrm{g} / \mathrm{ml}$. Mice were immunized at 
day 0 and again at day 28. As controls, mice were immunized with the non-targeted isotype-matched control $\mathrm{Ab}$.

Blood samples were drawn from the cheek of the mice using Goldenrod animal lancets (MEDIpoint, Mineola, USA). Serum samples were collected at days 0, 14, 28, 42, 56, 70, and 84 and frozen for later use.

\section{ELISA analyses}

To measure mouse anti-rat IgG Abs, 96-wells microtiter plates (Nunc, Thermo Scientific, Rockford, USA) were coated with $0.1 \mu \mathrm{g} / \mathrm{ml}$ rat IgG (Jackson ImmunoResearch, West Grove, USA) overnight at $4^{\circ} \mathrm{C}$. The plates were subsequently washed 3 times in PBS containing $0.05 \%$ Tween 20 (Biochemicals, USA) (PBST). Similar washing procedures were performed between each step. Plates were blocked in $100 \mu$ PBST for 1 hour. Dilutions of serum in PBST were added and incubated for 2 hours at RT. Plates were then incubated with biotin-conjugated polyclonal rabbit anti-mouse Ig (Dako, Glostrup, DK) (1:50.000) for 2 hour at RT, washed and incubated with streptavidin-alkaline phosphates (AP) (Dako) for 1 hour at RT. Plates were subsequently washed 3 times in PBST, two times in 1x Tropix Assay buffer (Applied Biosystems, Bedford, USA) and mouse anti-rat antibodies were detected by addition of $100 \mu$ Tropix CSPD (Applied Biosystems) for 30 min. Plates were read on a FLUOstar OPTIMA (BMG Labtech, Ortenberg, Germany).

The IgG subclasss of the Ab response was determined by subclass specific secondary Abs conjugated to biotin (Goat anti-mouse $\operatorname{lgG} 1(2.5 \mu \mathrm{g} / \mathrm{ml}$ ) or $\operatorname{lgG} 2 \mathrm{a}(5 \mu \mathrm{g} / \mathrm{ml})$, Antibodies-online, Aachen, Germany).

The two subclass-specific secondary Abs were absorbed with rat IgG as detailed below to reduce unspecific binding in the assay. The subclass ELISAs were carried out as described above except that plates were blocked with PBST containing $1 \mathrm{mg} / \mathrm{ml}$ BSA for 1 hour at RT.

A measure of the concentrations of mouse anti-rat IgG Abs in the serum of the immunized mice was obtained by comparing the values obtained with the serum samples with standard curves. Dilution series of known concentration of mouse IgG (ChromPure mouse IgG, Jackson Immunoresearch), mouse IgG1 (Mab1.1, Serotec) or mouse IgG2a (Mab9.2, Loke Diagnostics) were coated directly unto the plastic surface of the ELISA plates 
overnight at $4^{\circ} \mathrm{C}$. These wells were subsequently treated as described above, but during the serum incubation, these wells contained PBST instead.

The limit of detection of the three assays was $0.0002 \mu \mathrm{g} \mathrm{eq} / \mathrm{ml}, 0.0018 \mu \mathrm{g} \mathrm{eq} / \mathrm{ml}$, and $0.0006 \mu \mathrm{g} \mathrm{eq} / \mathrm{ml}$ respectively. Intra-assay coefficients of variability was determined from the calculated concentrations and were $<10 \%$.

The standard curve-fitting was performed by the OPTIMA software (BMG Labtech, Germany) or by KaleidaGraph 3.5 (Synergy Software, Reading, PA) using the fourparameter log-logistic (4PL) curve-fitting method. The equation of the fitted standard curve was used to quantify the level of mouse anti-rat IgG in the serum samples. The Ab levels in the serum samples were correlated to a concentration of $x \mu \mathrm{g} / \mathrm{ml}$ of a given standard and subsequently expressed as $\mathrm{x} \mu \mathrm{g}$ equivalents $/ \mathrm{ml}$. The pre-immunization level was calculated from the values obtained from the pre-bleed samples and specified as mean + 2xSD. Graphs were compiled by GraphPad Prism 5.04 software (GraphPad Software, San Diego, CA) or Genesis 1.7.6 (IGB TU Graz, Austria).

Absorption of secondary antibodies to reduce unspecific binding in ELISA

$1 \mathrm{mg} / \mathrm{ml}$ ChromePure Rat IgG (Jackson ImmunoResearch, PA, USA) was diluted in 1000 $\mu$ l coupling buffer $\left(0.2 \mathrm{M} \mathrm{NaHCO}_{3}, 0.5 \mathrm{M} \mathrm{NaCl} \mathrm{pH} 8.3\right)$ and coupled to a $1 \mathrm{ml}$ HiTrap NHSactivated HP column (GE Healthcare, Uppsala, Sweden) according to the manufacturer's instructions. Buffers used for coupling were coupling buffer, blocking buffer $(0.5 \mathrm{M}$

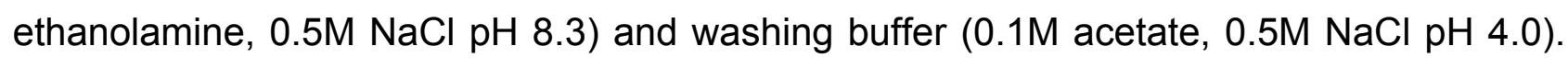
The efficiency of the coupling procedure was measured by comparing the $A_{280 n m}$ values of the Ab solution before and after the coupling, giving a coupling percent of $95,4 \%$.

Goat anti-mouse IgG1 (Biotin) (Antibodies-online, Atlanta, USA) and Goat anti-mouse IgG2a antibody (Biotin) (Antibodies-online, Atlanta, USA) were purified on the HiTrap NHS column coupled with rat IgG (coupling procedure explained above) with the HPLC technique (ÄKTApurifier, GE Healthcare). The Abs were diluted 1:10 in PBS to a final concentration of $1 \mathrm{mg} / \mathrm{ml}$ and sterile filtered $(0.22 \mu \mathrm{m}) .500 \mu \mathrm{l}$ of $\mathrm{Ab}$ was loaded on the HPLC-system and flow rate was set at $1 \mathrm{ml} / \mathrm{min}$. Fractions of $500 \mu /$ tube were collected through the whole procedure. PBS pH 7.2 was used as running buffer and bound material was eluted with $0.1 \mathrm{M}$ glycin $\mathrm{pH} 2.5$. The flow through from the column was collected. To check that the binding capacity of the column was not exceeded, the flow through fractions 
were pooled and run over the column once more. Data showed that the column had a binding capacity that exceeded the $A b$ amount loaded. The concentrations of the purified Abs were measured on Nanodrop ND-1000 (Thermo Scientific). 


\section{Results}

Targeting antigen to DCs in vivo induces potent humoral responses

Mice were immunized with monoclonal target Abs twice (day 0 and day 28). Blood samples were collected with 2 weeks intervals from day 14 to day 84 . The Ab responses induced by the different target Abs were determined by ELISA. To allow comparison of the levels of antibody produced by individual mice, all measurements were recalculated into concentrations by means of standard curves prepared by dilution of known concentrations of total mouse IgG, monoclonal lgG1 or monoclonal lgG2.

The total IgG responses are shown in Figure 1. The concentration of anti-rat lgG in the pre-bleed sera of the mice was very low $(0.36 \mu \mathrm{g} \mathrm{eq} / \mathrm{ml})$, and immunizations with nontargeted control antibodies, whether rat IgG2a, kappa or IgG2b, kappa, induced only negligible $A b$ responses during the course of the experiments. Immunizing with mAbs targeting the 10 different target structures induced very different levels of antibody production. Delivering Ag to PDC-TREM, CD11c, CD36, CD205, Clec6A and Clec7A elicited very strong antibody responses compared to the non-targeted control (indicated with a dotted line). In contrast, targeting of Ag to CD206, CD209, Clec9A and Siglec H did not facilitate effective humoral responses.

For the six groups of mice that had been immunized with an Ab generating clear-cut antirat IgG responses, the contributions of two IgG subclasses $\lg G 1$ and $\lg G 2 a$, to the responses were also determined. As seen in Figure 2, interesting differences were seen between the antibody responses induced by the selected targets. All six target receptors elicited production of IgG1, but targeting of CD11C, CD36 and CD205 elicited very strong IgG1 responses while Clec6A, Clec7A and PDC-TREM induced intermediate levels of $\lg$ 1. Regarding the production of $\lg G 2 a$, the Abs targeting Clec7A clearly induced substantial amounts of $\lg \mathrm{G} 2 \mathrm{a}$, while this subclass was basically not detectable in the responses generated by CD11c, CD36, CD205, Clec6A and PDC-TREM.

The immune responses induced by different antibodies reacting with the same target, may vary considerably.

As demonstrated, targeting of Ag to DCs in vivo can elicit strong humoral responses for several of the target receptors. The efficiency of a target in facilitating an immune 
response may depend not only on the target itself but also on inherent properties of the particular antibody used for Ag-delivery. Consequently, humoral responses following Agdelivery to CD36, CD205 and Clec7A were determined using antibodies from two different hybridomas directed at the same receptor. In all three instances the humoral responses induced varied considerably between the two mAbs (Figure 3).

Delivering $\mathrm{Ag}$ to $\mathrm{CD} 36$, the mAb No. 72-1 is more efficient than MF3, regarding induction of anti-rat IgG Abs. No.72-1 demonstrated increasing concentrations following the second injection at day 28 until day 56 after which the Ig concentration displays a minor decline. MF3, on the other hand, demonstrated low but continuously increasing concentrations from day 14 to 84 .

The induction of anti-rat $\lg G$ responses following the first injection was nearly identical for the two Abs directed at CD205, but upon the second injection, they elicited very different levels of Abs. Re-immunizing with 205yekta created a pronounced increase in $A b$ concentration, while NLDC-145 only induced a minor increase in production of Abs.

The two Abs targeting Clec7A also differed with respect to the anti-rat IgG responses generated. Thus, 2A11 generated high Ab concentrations following the second injection while the $A b$ levels were unaffected by the second injection of the $A b 218820$. 


\section{Discussion}

We have previously analyzed cellular immune responses following Ag-delivery to ten different receptors expressed on DCs in murine spleen cell cultures in vitro (Pugholm et al., in prep). The results showed that targeting DC using mAbs may induce Ag-specific $T$ cell activation but the results obtained with in vitro DC cultures are unlikely to reliably reflect the situation in vivo. In the present study we investigated the humoral immune responses elicited by in vivo targeting $\mathrm{Ag}$ in the form of rat mAbs to murine $\mathrm{DCs}$ using mAbs specific for CD205, CD206, CD209, Clec6A, Clec7A, Clec9A, CD36, CD11c, Siglec$\mathrm{H}$ and PDC-TREM.

The $A b$ responses in serum of the immunized mice were followed by ELISA. Measures of the content of total $\lg$, IgG1 and $\lg G 2 a$ of the $A b$ responses were determined for each sample by reference to dilutions of immunoglobulin standards included in the ELISA. Due to differences between the serum immunoglobulin and the immunoglobulin standards in the way they present themselves in the ELISA wells (bound to the rat IgG coating the wells versus coated directly onto the wells) and in antigenic nature (e.g. polyclonal serum IgG1 versus an IgG1 mAb used as standard), the measure of total IgG, IgG1 or IgG2a Abs in the serum is useful in comparison between serum samples, but cannot be expected to represent the exact concentrations. To reflect this fact, the measure of concentration is expressed as $\mu \mathrm{g}$ equivalents $/ \mathrm{ml}$.

The Ag-delivery to DCs in vivo mediated strong humoral responses for several of the ten targets, but the IgG levels induced by the efficient target receptors were very different. Targeting of PDC-TREM, CD11C, CD36, CD205, Clec6A and Clec7A displayed superior ability to induce antibody responses compared to the other targets and the non-targeted controls (Figure 1). The potent induction of IgG by Ag-delivery to Clec7A obtained in the present study is in agreement with the findings of Carter et al. (15), who demonstrated an OVA-specific antibody response after injection of OVA-anti-Clec7A. In contrast, Carter et al. did not observe OVA-specific responses when Ag was targeted to CD205. In our study CD205 did elicit potent humoral responses, which is consistent with the findings of other studies $(1,2,7,16,17)$. However, in all of these studies an adjuvant was co-administered. Another receptor mediating strong antibody responses in the present study was CD11c. In 2000 Wang et al. demonstrated adjuvant-independent induction of high levels of Ag- 
specific IgG upon targeting Ag to CD11C (18) and later in 2009 Wei et al. obtained strong antibody responses with a fusion protein (scFvCD11c-Her2) but only when injected in combination with an adjuvant (14). Thus, studies on CD11c agree that Ag-delivery to CD11c is effective in inducing humoral responses, but disagree upon the necessity of DCactivating agents. The multi-ligand scavenger receptor, CD36, proved also to be an effective receptor for Ag-delivery as we observed strong antibody responses following Agdelivery to this receptor. The targeting potential of CD36 has only been addressed by one other group, who showed high levels of OVA-specific antibodies in mice primed with OVAanti-CD36 (12). The humoral responses observed by targeting CD36 were in both studies obtained without adding adjuvants.

Targeting of Ag to PDC-TREM did also induce high concentrations of Ag-specific lgG indicating that this receptor might function as an endocytic receptor mediating $\mathrm{Ag}$ presentation and inducing humoral immune responses.

Antigen-delivery to CD209, Clec9A and Siglec H did not generate humoral responses as they induced IgG responses comparable to the level obtained by the non-targeted control. CD206 induced a very modest $A b$ response, not detectable until by the end of the experiment (Figure 1). Our results regarding CD209 are at variance with the findings by Corbett et al. who investigated the humoral response induced by targeted delivery of Ags to CIRE (CD209) and demonstrated high levels of Ag-specific IgG (1). Similarly, the finding that Ag-delivery to Clec9A did not induce any Ab response is in disagreement with the findings of Lahoud et al. $(7,8)$. In the case of CD209, our study and the study published by Corbett et al. employed Abs from different hybridomas (LWC06 vs 5H10) (1). The same applies to Clec9A, in which case we use the anti-Clec9A Ab 700517, whereas the studies of Lahoud et al. were performed with the anti-Clec9A Ab 10B4 (7,8). The discrepancies found between our results and results obtained by other groups may be caused by the use of different Abs. Tacken et al. described that intracellular routing of targeted Ags depends on the particular epitope recognized by the targeting Abs. They showed that Abs directed at the carbohydrate recognition domain of CD209 induced a clathrin-dependent internalization and mainly channelled Ags into late endosomal compartments, whereas the uptake of Abs directed at the neck region of the receptor was clathrin-independent and shuttle Ags into early endosomal compartments rich in MHC class I molecules (6). This diversity in intracellular routing may have immense impact on the processing and 
presentation of Ags. Furthermore, it is probable that some antibodies/epitopes will not trigger internalization, which may be the explanation for the fact that the outcome of targeting Ags to different receptors in the present study was contradictive to the findings of other groups. Alternatively, some Abs employed in this study may recognize epitopes that require maturation of $\mathrm{DCs}$ for effective immune activation, while other Abs may induce maturation of the DCs following interaction with its target structure.

The fact that the fate of the Ags is dependent on the particular epitope is also evident from the results of the present study, where different Abs, reacting with the same target receptor, in all cases initiated quite different antibody responses (Figure 3). These different capabilities to induce humoral responses probably rely primarily on inherent variations between the Abs, such as the affinity and the epitope recognition, which emphasize one of the disadvantages of investigating the targeting efficiency of potential target receptors using Abs as targeting devices. However, it also highlights the importance of testing different mAbs of the same specificity in order to identify the ones best suited for Ab-based vaccines.

The IgG subclass composition of the $A b$ responses was determined. Ag-delivery to CD11c, CD36, CD205, Clec6a, Clec7A and PDC-TREM elicited IgG1 responses, but CD11c, CD36 and CD205 appeared superior in generating such Th2 responses compared to the others. In contrast to the high induction of IgG1, the production of IgG2a appeared to be more restricted. Clec7A demonstrated strong IgG2a responses compared to CD11C, CD36, CD205, Clec6A and PDC-TREM (Figure 2) indicating the presence of Th1 responses in mice immunized with anti-Clec7A.

Any targeting procedure using mAbs as targeting device will depend on a number of features, of which some are related to the receptor that is targeted, whereas others are related to the specific antibody used. One factor related to the particular target receptor, is the distribution of the receptor on different cell types. A broad expression might lead to targeting of $\mathrm{Ag}$ to irrelevant cell populations with a potential reduction of the desired response, whereas a very specific expression of a target receptor on DCs is likely to result in prolonged Ag presentation by DCs, which have been described as being a crucial factor for immune responses (7). However, the results obtained in the present study were not supportive of this notion, as strong antibody responses were elicited by Ag-delivery to 
Clec7A and CD36 displaying broad expression patterns but also by CD11c, CD205 and PDC-TREM which displays a more strict expression patterns.

In conclusion, Ag-delivery to PDC-TREM, CD11c, CD36, CD205, Clec6A and Clec7A mediated strong humoral responses. The effect of in vivo targeting of Ag to PDC-TREM has not previously been reported but the results presented in this study indicates that PDC-TREM could potentially be an interesting target structure for Ag-delivery, and it reveals somewhat surprisingly, that this receptor, preferentially expressed on pDCs, may induce $A b$ responses that are comparable to those obtained when targeting $\mathrm{Ag}$ to receptors on cDCs. 
Conflict of interest

None.

\section{Acknowledgements}

The authors thank the animal technicians at the animal facility of Department of Pathology, Aalborg Hospital for competent handling of the mice, and laboratory technician Brita Holst Jensen for technical assistance during the study. 


\section{Reference List}

1. Corbett, A. J., I. Caminschi, B. S. McKenzie, J. L. Brady, M. D. Wright, P. L. Mottram, P. M. Hogarth, A. N. Hodder, Y. Zhan, D. M. Tarlinton, K. Shortman, and A. M. Lew. 2005. Antigen delivery via two molecules on the CD8- dendritic cell subset induces humoral immunity in the absence of conventional "danger". Eur. J. Immunol 35: 2815-2825.

2. Cheong, C., J. H. Choi, L. Vitale, L. Z. He, C. Trumpfheller, L. Bozzacco, Y. Do, G. Nchinda, S. H. Park, D. B. Dandamudi, E. Shrestha, M. Pack, H. W. Lee, T. Keler, R. M. Steinman, and C. G. Park. 2010. Improved cellular and humoral immune responses in vivo following targeting of HIV Gag to dendritic cells within human anti-human DEC205 monoclonal antibody. Blood 116: 3828-3838.

3. Idoyaga, J., A. Lubkin, C. Fiorese, M. H. Lahoud, I. Caminschi, Y. Huang, A. Rodriguez, B. E. Clausen, C. G. Park, C. Trumpfheller, and R. M. Steinman. 2011. Comparable T helper 1 (Th1) and CD8 T-cell immunity by targeting HIV gag p24 to CD8 dendritic cells within antibodies to Langerin, DEC205, and Clec9A. Proc. Natl. Acad. Sci. U. S. A 108: 2384-2389.

4. Mahnke, K., Y. Qian, S. Fondel, J. Brueck, C. Becker, and A. H. Enk. 2005. Targeting of antigens to activated dendritic cells in vivo cures metastatic melanoma in mice. Cancer Res 65: 7007-7012.

5. Bonifaz, L. C., D. P. Bonnyay, A. Charalambous, D. I. Darguste, S. Fujii, H. Soares, M. K. Brimnes, B. Moltedo, T. M. Moran, and R. M. Steinman. 2004. In vivo targeting of antigens to maturing dendritic cells via the DEC-205 receptor improves T cell vaccination. J. Exp. Med. 199: 815-824.

6. Tacken, P. J., W. Ginter, L. Berod, L. J. Cruz, B. Joosten, T. Sparwasser, C. G. Figdor, and A. Cambi. 2011. Targeting DC-SIGN via its neck region leads to prolonged antigen residence in early endosomes, delayed lysosomal degradation, and cross-presentation. Blood 118: 4111-4119.

7. Lahoud, M. H., F. Ahmet, S. Kitsoulis, S. S. Wan, D. Vremec, C. N. Lee, B. Phipson, W. Shi, G. K. Smyth, A. M. Lew, Y. Kato, S. N. Mueller, G. M. Davey, W. R. Heath, K. Shortman, and I. Caminschi. 2011. Targeting Antigen to Mouse Dendritic Cells via Clec9A Induces Potent CD4 T Cell Responses Biased toward a Follicular Helper Phenotype. The Journal of Immunology 187: 842-850.

8. Caminschi, I., A. I. Proietto, F. Ahmet, S. Kitsoulis, T. J. Shin, J. C. Lo, A. Rizzitelli, L. Wu, D. Vremec, S. L. van Dommelen, I. K. Campbell, E. Maraskovsky, H. Braley, G. M. Davey, P. Mottram, d. van, V, K. Jensen, A. M. Lew, M. D. Wright, W. R. Heath, K. Shortman, and M. H. Lahoud. 2008. The dendritic cell subtype-restricted C-type lectin Clec9A is a target for vaccine enhancement. Blood 112: 3264-3273.

9. Sancho, D., D. Mourao-Sa, O. P. Joffre, O. Schulz, N. C. Rogers, D. J. Pennington, J. R. Carlyle, and Reis E Sousa. 2008. Tumor therapy in mice via 
antigen targeting to a novel, DC-restricted C-type lectin. J. Clin. Invest 118: 2098-2110.

10. Joffre, O. P., D. Sancho, S. Zelenay, A. M. Keller, and Reis E Sousa. 2010. Efficient and versatile manipulation of the peripheral CD4+ T-cell compartment by antigen targeting to DNGR-1/CLEC9A. Eur. J. Immunol 40: 1255-1265.

11. Zhang, J., A. Raper, N. Sugita, R. Hingorani, M. Salio, M. J. Palmowski, V. Cerundolo, and P. R. Crocker. 2006. Characterization of Siglec-H as a novel endocytic receptor expressed on murine plasmacytoid dendritic cell precursors. Blood 107: 3600-3608.

12. Tagliani, E., P. Guermonprez, J. Sepulveda, M. Lopez-Bravo, C. Ardavin, S. Amigorena, F. Benvenuti, and O. R. Burrone. 2008. Selection of an antibody library identifies a pathway to induce immunity by targeting CD36 on steadystate CD8 alpha+ dendritic cells. J. Immunol 180: 3201-3209.

13. Castro, F., A. Tutt, A. White, J. Teeling, S. James, R. French, and M. Glennie. 2008. CD11c provides an effective immunotarget for the generation of both CD4 and CD8 T cell responses. Eur. J. Immunol. 38: 2263-2273.

14. Wei, H., S. Wang, D. Zhang, S. Hou, W. Qian, B. Li, H. Guo, G. Kou, J. He, H. Wang, and Y. Guo. 2009. Targeted Delivery of Tumor Antigens to Activated Dendritic Cells via CD11c Molecules Induces Potent Antitumor Immunity in Mice. Clinical Cancer Research 15: 4612-4621.

15. Carter, R. W., C. Thompson, D. M. Reid, S. Y. Wong, and D. F. Tough. 2006. Preferential induction of CD4+ $T$ cell responses through in vivo targeting of antigen to dendritic cell-associated C-type lectin-1. J. Immunol 177: 2276-2284.

16. Boscardin, S. B., J. C. Hafalla, R. F. Masilamani, A. O. Kamphorst, H. A. Zebroski, U. Rai, A. Morrot, F. Zavala, R. M. Steinman, R. S. Nussenzweig, and M. C. Nussenzweig. 2006. Antigen targeting to dendritic cells elicits long-lived T cell help for antibody responses. J. Exp. Med. 203: 599-606.

17. Wang, B., N. Zaidi, L. Z. He, L. Zhang, J. M. Kuroiwa, T. Keler, and R. M. Steinman. 2012. Targeting of the non-mutated tumor antigen HER2/neu to mature dendritic cells induces an integrated immune response that protects against breast cancer in mice. Breast Cancer Res 14: R39.

18. Wang, H., M. N. Griffiths, D. R. Burton, and P. Ghazal. 2000. Rapid antibody responses by low-dose, single-step, dendritic cell-targeted immunization. Proceedings of the National Academy of Sciences 97: 847-852. 


\section{Figure legends}

Figure 1. Humoral responses following in vivo targeting.

Mice were immunized with mAbs against the selected target receptors (4 mice in each group). In addition, two groups of mice were immunized with a non-targeting isotypematched mAb. Mice were immunized on day 0 and day 28 and blood samples were drawn at the time points indicated at the top of the diagram.

1A) Serum samples were analyzed for the presence of anti-rat IgG antibodies by ELISA. The values obtained were recalculated into a measure of concentration (expressed as $\mu \mathrm{g}$ equivalents $/ \mathrm{ml}$ ) using a standard curve obtained with known concentrations of murine lgG. Data are presented as the mean value of the 3-4 mice present in each group. The prebleed level (mean $+2 x S D)$ is indicated as a dotted line

1B) The anti-rat antibody responses of all mice in the experiment are illustrated using a cluster diagram. The concentration range is specified at the bottom of the diagram. The diagram shows the variation between the mice in each group and provides an overview of responders (orange/red) and non-responders (yellow). Pre-bleed values (mean $+2 x S D$, $0.36 \mu \mathrm{g} \mathrm{eq} / \mathrm{ml}$ ) are shown in the top row. Gray indicate missing sample.

\section{Figure 2. Isotype distribution in the antibody responses induced by targeting}

Serum samples were analyzed for the presence of anti-rat Abs of the subclasses IgG1 and IgG2a by ELISA. The values obtained were recalculated into a measure of concentration (expressed as $\mu \mathrm{g}$ equivalents/ml) using a standard curve obtained with known concentrations of murine monoclonal $\lg G 1$ or $\lg G 2 a$. Data are presented as the mean value of the 3-4 mice present in each group. The pre-bleed level (mean $+2 \times S D)$ is indicated as a dotted line and was $0.7 \mu \mathrm{g} \mathrm{eq} / \mathrm{ml}$ for $\operatorname{lgG} 1$ and $0.6 \mu \mathrm{g} \mathrm{eq} / \mathrm{ml}$ for $\operatorname{lgG} 2 \mathrm{a}$

\section{Figure 3. In vivo targeting the same DC surface markers with two different mAbs.}

Six groups of mice ( $N=4$ per group) were immunized with different mAbs for each of the following targets; CD36, CD205 and Clec7A. Immunization was performed at day 0 and day 28 with $5 \mu \mathrm{g}$ antibody. Blood samples were drawn at the indicated time points and the concentration of the mouse anti-rat antibodies (total $\lg G$ ) was determined. 


\begin{abstract}
A) The concentration of mouse anti-rat Abs is illustrated for every mouse in a cluster diagram. The concentration range is specified at the bottom of the diagram. The diagram shows the variation between the mice in each group and the difference in responses between the different mAbs. B) shows the time course of the IgG responses obtained by the different mAbs. Each data point presents the mean value for each group. The prebleed level (mean + 2xSD, $0.36 \mu \mathrm{g} \mathrm{eq} / \mathrm{ml}$ ) is indicated as a dotted line. Results are given as $\mu \mathrm{g}$ equivalents $/ \mathrm{ml}$.
\end{abstract}


Figure 1.

mAbs of isotype lgG2a

mAbs of isotype IgG2b

$1 \mathrm{~A}$.

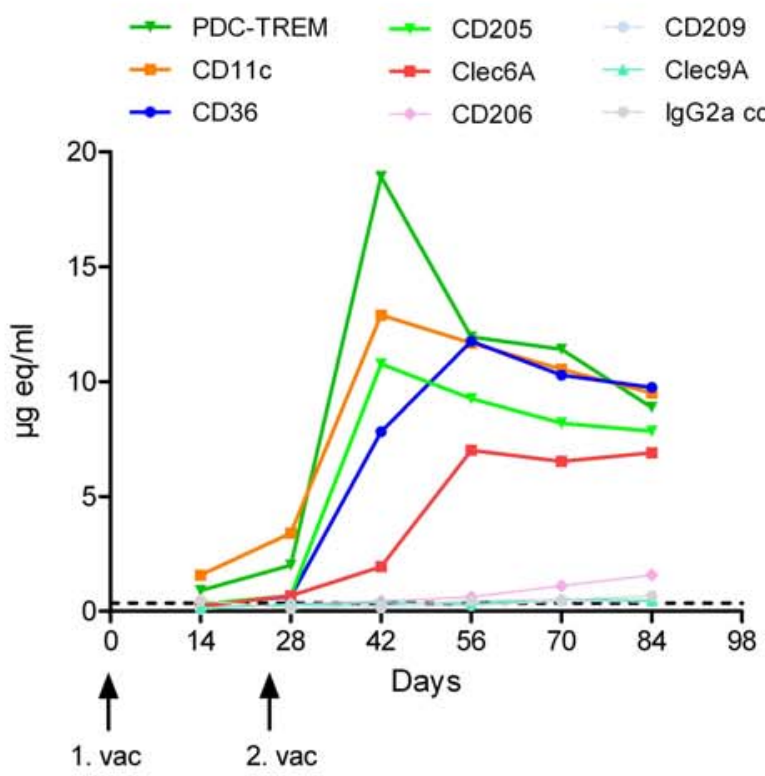

$1 B$.

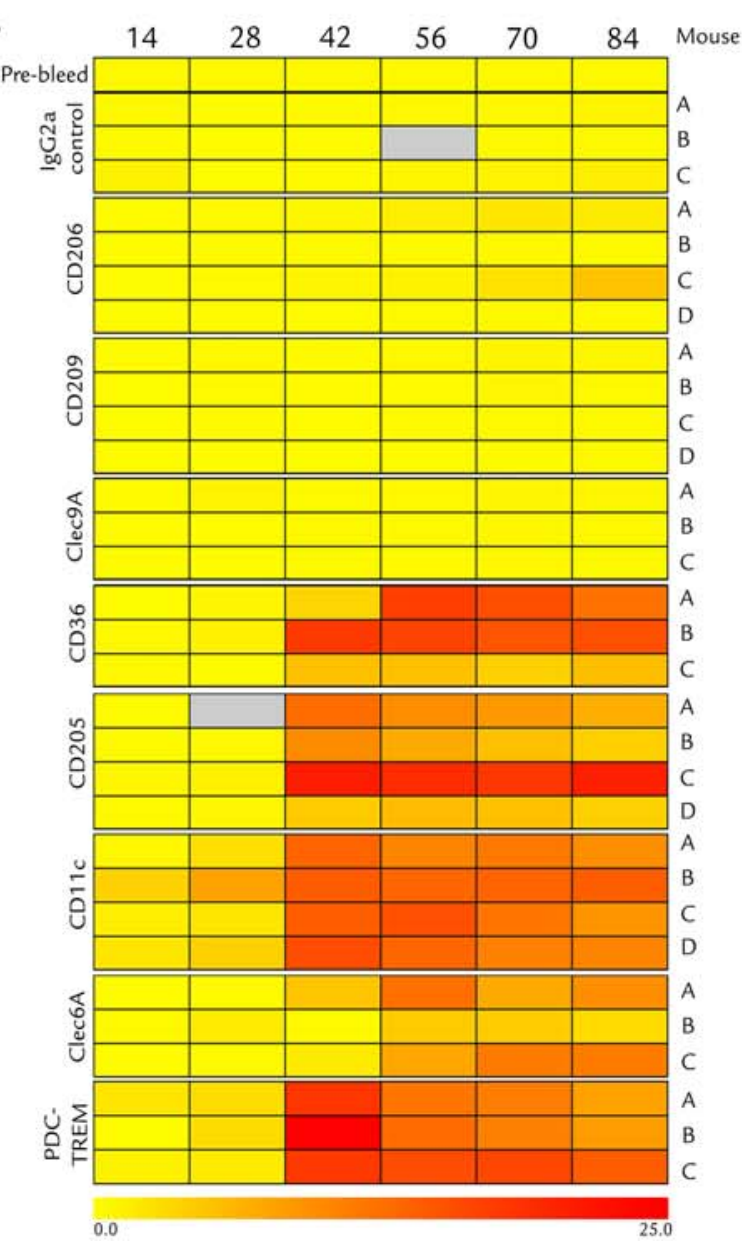


Figure 2.

$\lg \mathrm{G} 1$

IgG2a
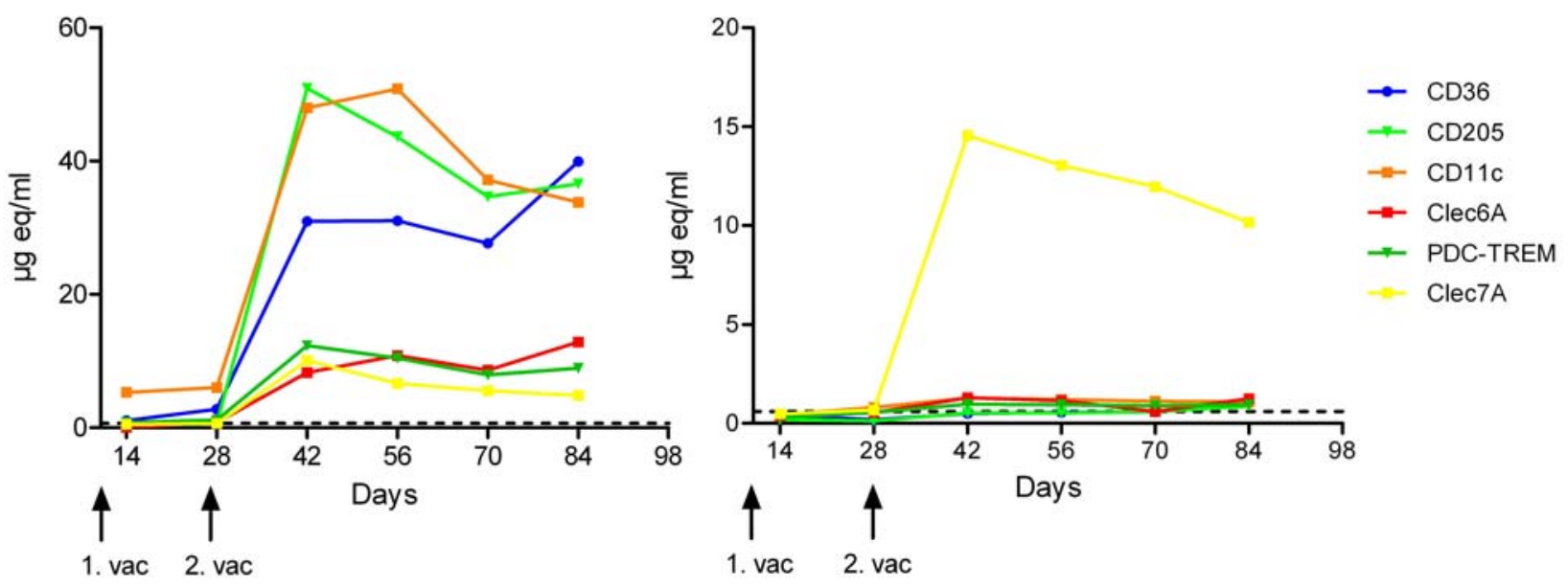
Figure 3.

$3 A$.

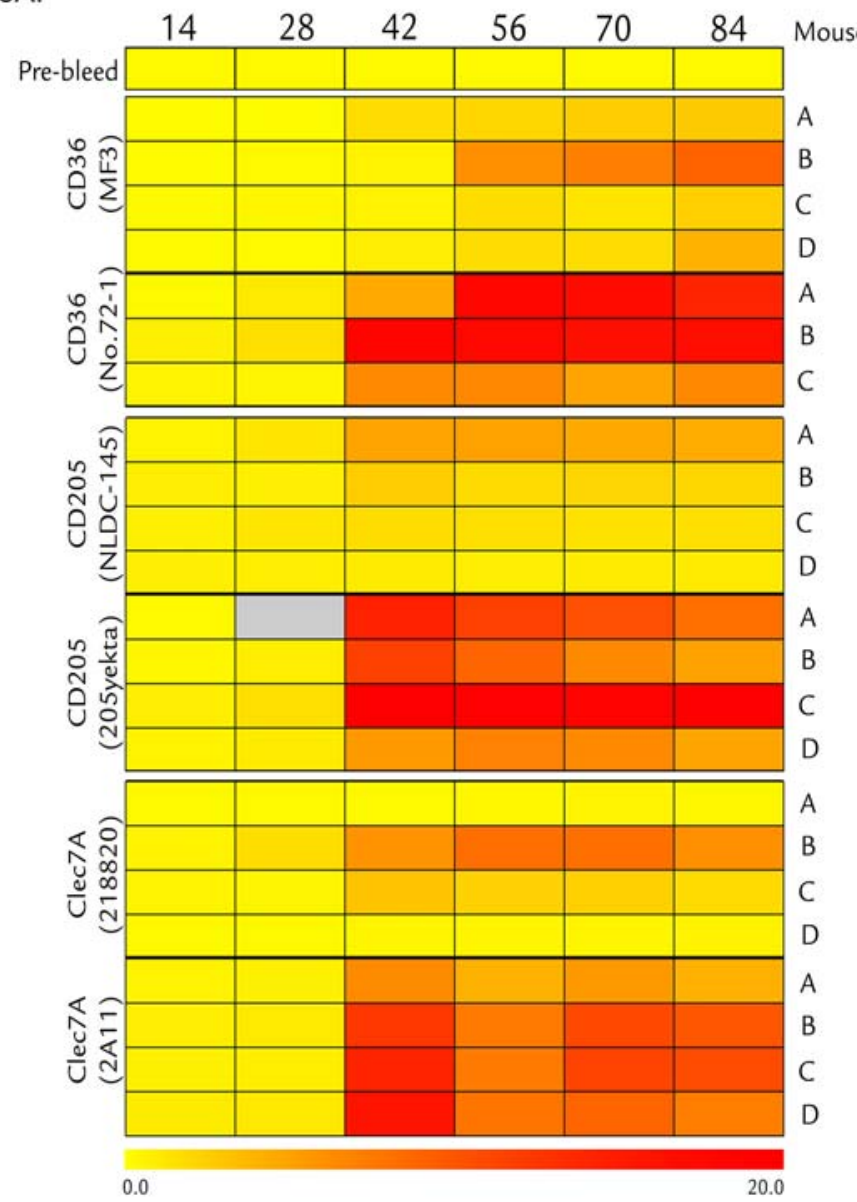

3B.
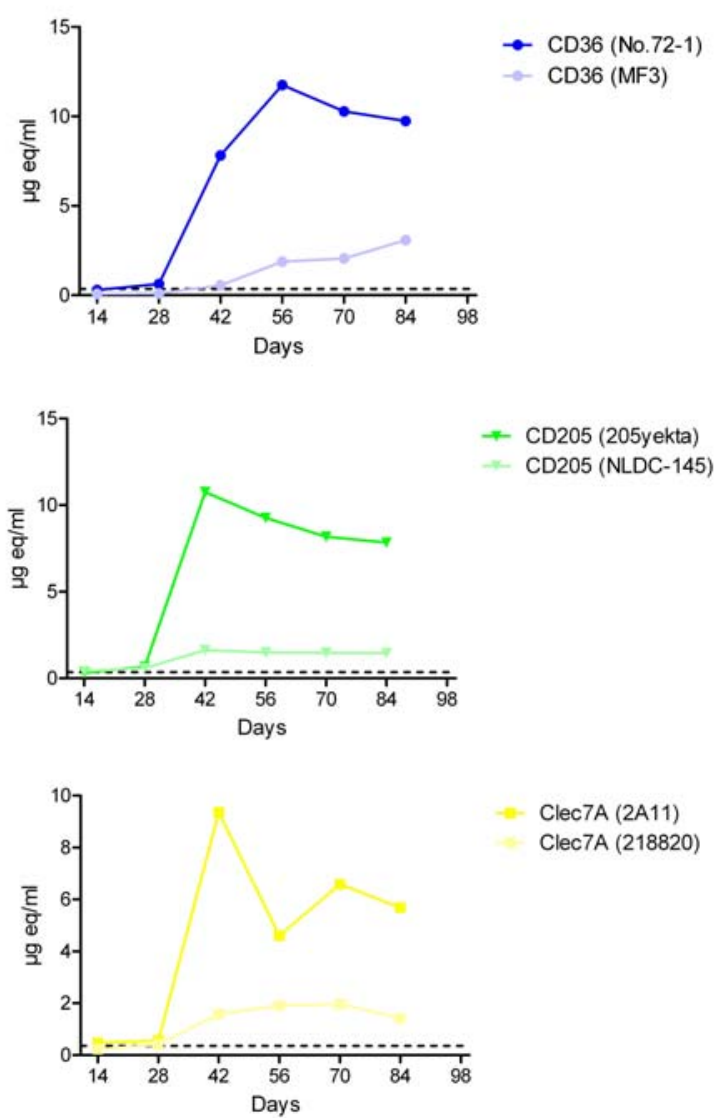


\section{Additional data not included in manuscript 1:}

Confirmation of immunization of mice with isotype-control non-targeting $A b$ in Freund's Adjuvant

\section{Detection of mouse anti-rat antibodies by ELISA}

Two weeks following the third vaccination, peripheral blood was collected from the cheek of the mice using Goldenrod animal lancets (MEDIpoint, Mineola, USA). Serum was collected and frozen for later use. ELISA plates (Nunc, Thermo Scientific, Rockford, USA) were coated with $10 \mu \mathrm{g} / \mathrm{ml}$ rat IgG (Jackson ImmunoResearch, West Grove, USA) in PBS with $0.05 \%$ tween 20 (PBS-T) overnight at $4^{\circ} \mathrm{C}$. Plates were washed 3 times in PBS-T and blocked in PBS-T for 1 hour at RT. Similar washing procedures were performed between each step. Blocking solution was removed and $100 \mu \mathrm{l}$ of diluted serum was added in duplicates. Following 2 hours incubation, $100 \mu \mathrm{AP}$-conjugated $\mathrm{F}(\mathrm{ab})_{2}$ fragment rat antimouse IgG (Jackson ImmunoResearch) was added to each well and incubated 1 hour. After 3 washes in PBS-T, $100 \mu \mathrm{l}$ mg/ml PNPP ( $p$-nitrophenyl phosphate; Pierce, Thermo Scientific) was added and colour developed for 20-30 minutes. The reaction was stopped by addition of $50 \mu \mathrm{l} 2.5 \mathrm{~N} \mathrm{NaOH}$ and absorbance at $405 \mathrm{~nm}$ was determined. Serum from blood drawn before immunization served as reference.

\section{Results \& Discussion}

C57BL/6 mice were immunized with a monoclonal rat antibody of either isotype lgG2a or IgG2b. Immunization was confirmed by measuring the presence of mouse anti-rat IgG by ELISA (figure I). Serum samples were drawn two weeks after the third vaccination.

The results showed a high anti-rat response in all mice from both groups compared to the pre-immunization samples, confirming that the immunization procedure was efficient. The lower OD value obtained with 1:100 dilution compared to the 1:316 dilution indicate that the lowest dilution contains to high amounts of $\mathrm{Ag}$ (in this case mouse anti-rat $\mathrm{Abs}$ ) resulting in a suppressed OD value. This phenomenon is called HOOK effect and can be circumvented by making higher dilutions or a dilution series. The HOOK effect is usually only a problem in quantitative assays as high protein concentrations will still produce positive ELISA results, however, with suppressed OD values. In this assay we searched for a "yes/no" answer and did not need specific Ab levels. 


\section{Mouse anti-rat IgG detected in immunized mice}

A

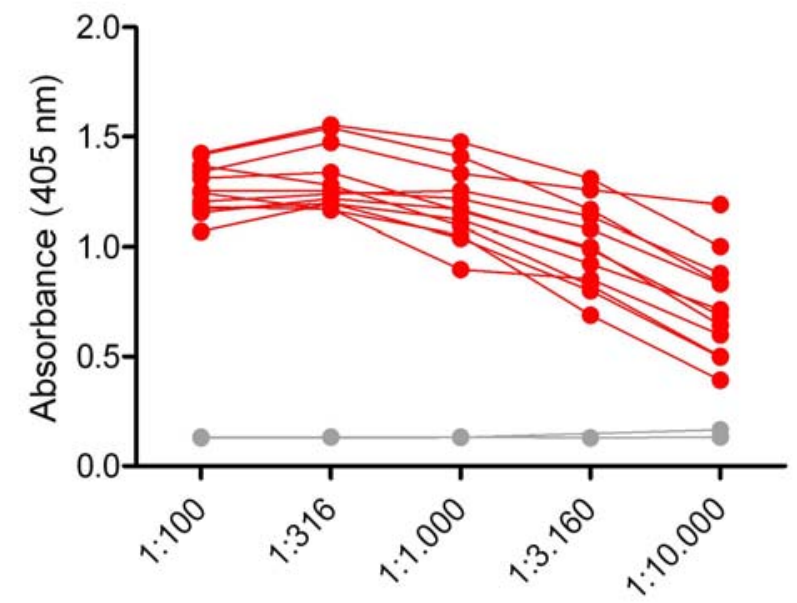

Dilution of serum
B

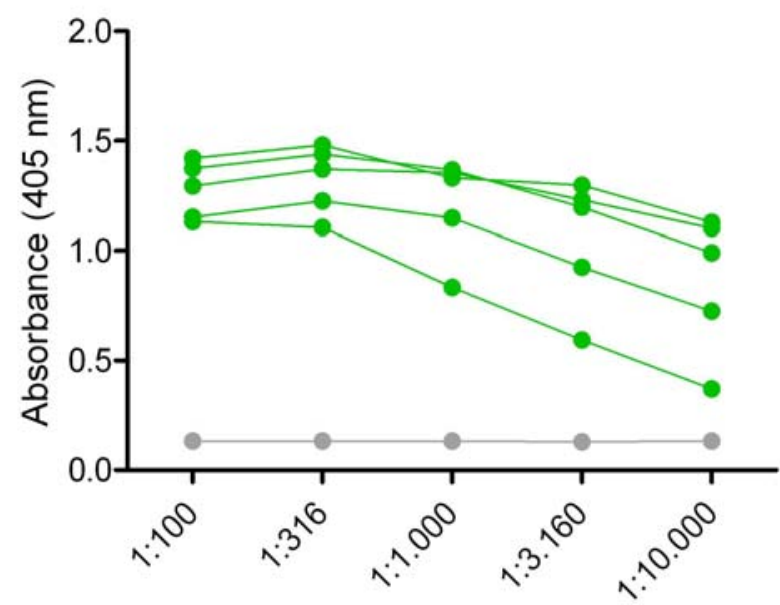

Dilution of serum

Figure I. Mouse anti-rat antibodies in immunized mice.

The antibody levels in mice immunized with a non-targeting control antibody of isotype lgG2a (A) or IgG2b (B). Gray circles specify serum samples from blood drawn before immunization.

\section{Antigen-delivery to bone marrow-derived DCs}

\section{Generation of bone marrow-derived DCs}

The procedure for generating bone marrow-derived DCs (BM-DCs) were modified from (207). Mice were sacrificed by cervical dislocation. The femur and tibia were removed and freed of muscles and tendons. The bones were placed in $70 \%$ ethanol for $120 \mathrm{~s}$ and subsequently washed in sPBS. The marrow was flushed with $5 \mathrm{ml}$ sPBS using a syringe fitted with a 25G needle. Visible cell clusters were broken up by pipetting and the cell suspension was centrifuged for $5 \mathrm{~min}$ at $300 \mathrm{xg}$ at RT and resuspended in DC10 medium consisting of RPMI 1640 (Gibco) with 1\% penicillin/streptomycin (Ampliqon), 50 нM 2mercaptoethanol and $10 \%$ foetal calf serum (FCS, Gibco). The cell suspension was adjusted to $2 \times 10^{6}$ cells $/ \mathrm{ml}$ in DC10 with $40 \mathrm{ng} / \mathrm{ml}$ recombinant murine GM-CSF (Peprotech, Rocky Hill, USA) and $1 \mathrm{ng} / \mathrm{ml}$ recombinant murine IL-4 (Peprotech) and seeded in bacteriological Petri dishes (Falcon, BD Biosicences) and placed in a $\mathrm{CO}_{2}-$ 
incubator at $37^{\circ} \mathrm{C}$. At day 3 fresh DC10 containing GM-CSF and IL-4 was added to each dish. At day 5 and 7 the medium was partially replaced by collecting half the medium from each dish. The collected medium was centrifuged ( $5 \mathrm{~min}$ at $300 \mathrm{xg}$ at RT) and the pellet was resuspended in fresh cytokine-supplemented DC10 and returned to the each dish. At day 10 the cells were harvested by pipetting, washed and counted in trypan blue. The cells were then seeded in tissue-culture grade 12-well plates (Nunc) with $10 \mu \mathrm{g} / \mathrm{ml}$ of the monoclonal target antibodies and placed in a $\mathrm{CO}_{2}$-incubator at $37^{\circ} \mathrm{C}$ for 1 hour. As controls, DCs treated with a non-targeting isotype control antibody as well as untreated DCs were included. Subsequently, unbound antibodies were washed away and cells were resuspended in DC10 containing $20 \mathrm{ng} / \mathrm{ml} \mathrm{GM-CSF,} 1 \mathrm{ng} / \mathrm{ml} \mathrm{IL-} 4$ and $10 \mathrm{ng} / \mathrm{ml}$ LPS (Sigma, E. coli $0111: 34$ ) and placed in a $\mathrm{CO}_{2}$-incubator at $37^{\circ} \mathrm{C}$ overnight. At day 11 cells were again harvested by pipetting, washed, counted and resuspended in DC2. The antibody-treated BM-DCs were now ready for co-culture with T cells.

\section{Isolation of $T$ cells}

Splenocyte suspensions were prepared as described above from mice immunized with a non-targeting isotype control antibody. Following filtration, the cell suspensions were subjected to density gradient centrifugation using Lymphoprep (Axis-Shield, Oslo, Norway) and the mononuclear cells were harvested in sterile PBS with $0.1 \%$ BSA (Sigma-Aldrich) and $2 \mathrm{mM}$ EDTA (Merck). Cells were counted and $T$ cells isolated by negative selection using magnetic beads (Dynal Mouse T Cell Negative Isolation Kit, Dynabeads, Life Technologies) according to the manufacturer's instructions. Briefly, $1 \times 10^{8} \mathrm{cells} / \mathrm{ml}$ were mixed with the antibody cocktail containing mAb against mouse CD45R (B220), CD11b (Mac1), Ter-119 and CD16/32 and incubated for $20 \mathrm{~min}$ at $4^{\circ} \mathrm{C}$ followed by washing and incubation with Dynabeads for $15 \mathrm{~min}$ at $4^{\circ} \mathrm{C}$ while rotating. The cell suspension was subsequently placed in a magnet for 2 min. The supernatant, containing the T cells, was removed and centrifuged. The pellet was washed in RPMI 1640 (Gibco) and counted in trypan blue. The cell concentration was adjusted to $2 \times 10^{6} \mathrm{cells} / \mathrm{ml}$ in DC2 medium. The T cells were now ready for co-culture with the antibody-treated DCs. 


\section{IFN- $y$ and IL-4 ELISPOT}

ELISPOT analysis was performed on antibody-treated BM-DCs co-cultured with T cells isolated from mice immunized with a non-targeted control antibody.

96-well Multiscreen IP plates (Millipore) were coated overnight at $4^{\circ} \mathrm{C}$ with IFN-y or IL-4 (Mabtech, Nacka Strand, Sweden) capture antibody $(15 \mu \mathrm{g} / \mathrm{ml})$ in sPBS. Plates were washed three times in sPBS and blocked in sPBS with $10 \%$ mouse serum (Gentaur) for at least 2 hours at $37^{\circ} \mathrm{C}$, followed by another three washes in sPBS. Dilutions of antibodytreated BM-DCs $\left(4 \times 10^{4}-2 \times 10^{4}\right)$ were plated and co-cultured with $2 \times 10^{5} \mathrm{~T}$ cells. Cells were cultured in IFN- $y$ and IL-4 plates at $37^{\circ} \mathrm{C}$ and with $5 \% \mathrm{CO}_{2}$ for 20 or 42 hours, respectively. Cytokine production was detected with $100 \mu \mathrm{l}$ of $1 \mu \mathrm{g} / \mathrm{ml}$ biotinylated anti-IFNY or anti-IL-4 (Mabtech) in PBS with 0.5\% FCS (Gibco) for two hours followed by 3 times washing and addition of $100 \mu \mathrm{l}$ streptavidin-alkaline phosphatase (Mabtech). After 60 minutes of incubation, plates were washed in sPBS and $100 \mu \mathrm{l} \mathrm{BCIP/NBT}$ substrate (Mabtech) was added and the plates developed for 10-20 minutes. The number of cytokine-producing cells was determined using a ImmunoSpot S5 UV analyzer (CTL, Cleveland, USA).

\section{Results \& Discussion}

Bone marrow-derived DCs were treated at the immature stage with selected monoclonal target antibodies followed by addition of a maturation stimulus using LPS. The antibodytreated DCs were then co-cultured with T cells isolated from an immunized mouse and the production of IFN- $y$ or IL-4 was examined in an ELISPOT assay. No notable IL-4 production was obtained for any of the targets (data not shown). The IFN- $\gamma$ response is shown in figure II. 

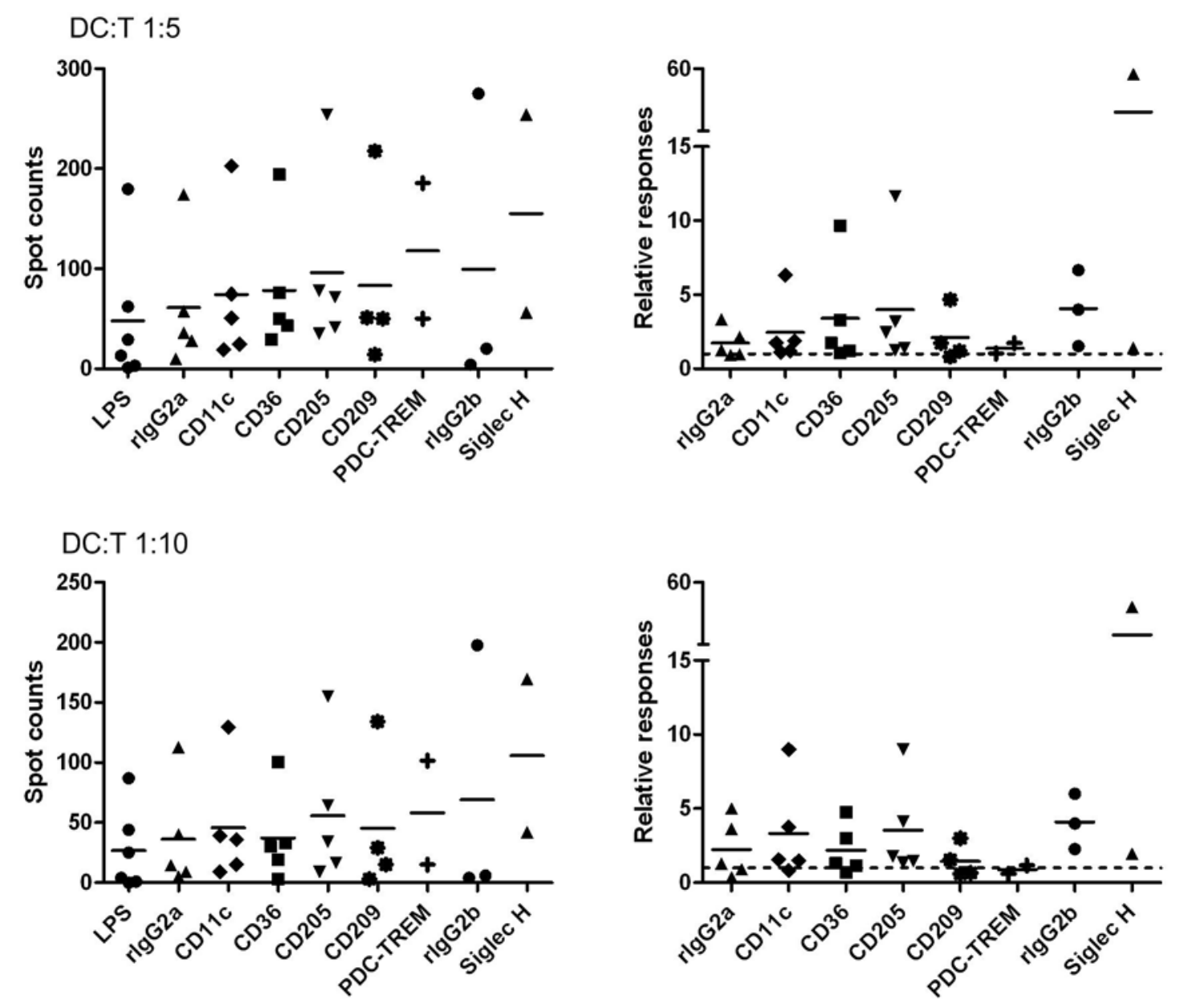

\section{Figure II. IFN-y production induced by Ag-treated BM-DCs.}

BM-DCs were treated with $\mathrm{mAb}$ - targeting or a non-targeting isotype-matched control - for 1 hour. Unbound antibodies were washed away and DCs were matured with LPS overnight. Antibody-treated DCs $\left(4 \times 10^{4}\right.$ or $2 \times 10^{4}$ cells/well) were plated in duplicates and cultured with $\mathrm{T}$ cells $\left(2 \times 10^{5}\right.$ cells/well), isolated from an immunized mouse, for 20 hours. The production of IFN- $y$ in the co-culture was determined by ELISPOT. As controls, untreated DCs (without Ag, with LPS) were included in the assay. Data presented to the left is uncorrected spot counts (raw data) with a solid line indicating the mean of repeated experiments. Data presented in the column to the right shows relative responses (Spot count [Ag-treated LPS-matured DCs] / spot count [untreated (no Ag) LPS-matured DCs]. Mean for each target is indicated with a solid line and the ratio of 1 is indicated with a dotted line.

Repeated experiments displayed pronounced variation in background cytokine-production induced by untreated (no Ag) LPS-matured DCs indicating that the mice varied in their reactivity towards LPS or other substances present in culture media (e.g. from FCS). This high background-reactivity may mask an eventual effect of targeting Ag to DCs and as 
such it may be beneficial to omit the use of LPS and instead use other maturation factors. The large variability in spot count levels among repeated experiments emphasizes the need for more experiments prior to a conclusion concerning the ability of Ag-treated DCs to activate $T$ cells. However, due to time limitations it was not possible to include more experiments before the deadline of this thesis. 


\section{Discussion}

The overall goal in this thesis was to investigate a number of receptors on DCs for their potential as future targets for DC-directed vaccines.

The major aim in the first part of the thesis was to establish a screening assay by which it was possible to evaluate the targeting efficiency of a panel of target receptors simultaneously. The assay was designed to be a quick and simple way of evaluating the targeting efficiency of selected targets and ten different potential target receptors were investigated for their ability to present antigenic peptides on $\mathrm{MHC}$ molecules and lead to $\mathrm{T}$ cell activation. The results demonstrated that targeting of $\mathrm{Ag}$ to CD11c, CD36, CD205 and Clec7A led to positive IFN-y responses compared to the non-targeted isotype control. Regarding induction of IL-4, CD36 and CD205 did also produce positive IL-4 responses, while no positive responses were obtained by the non-targeted isotype control.

Antigen-delivery to the other targets did only lead to positive IFN-y and IL-4 in few of the repeated experiments.

In the first setup, the screening of targets were performed by targeting Ag to the DC subsets present in crude spleen cell suspension, but this suspension also contained other APCs, and these cells may have been involved in the Ag presentation and $\mathrm{T}$ cell activation. As such, the next step was to investigate the immuno-stimulatory effect of targeting Ag to the ten receptors using pure DC cultures. Bone marrow-derived DCs were treated with targeting mAbs against receptors that were expressed by the BM-DCs, and subsequently tested for their ability to induce cytokine-production in T cells. In spite of substantial optimization of the assay, cytokine-production induced by the untreated (no Ag) LPS-matured DCs was not avoided giving substantial background cytokine-production. Due to the high cytokine-production induced by LPS-matured DCs, a conclusion about the DC-mediated $T$ cell activation obtained with either the targeted or the non-targeted antibodies was not possible. This unspecific cytokine-production may be reduced if DCs are matured with others factors like a cytokine cocktail or other TLR ligands, e.g. poly I:C. Alternatively, the assay may be performed without maturation of the DCs.

The ability to detect a significant difference in the levels of $T$ cell activation between targeted vs non-targeted Ag may be related to the Ag concentration used for treating the 
DCs (Figure 5). At high Ag concentrations (B) the effect of targeting $\mathrm{Ag}$ is not appreciated but by reducing the $\mathrm{Ag}$ concentration $(\mathrm{A})$ the potency of targeting $\mathrm{Ag}$ directly to $\mathrm{DCs}$ becomes clear. Thus, a more pronounced difference in the ability to induce cytokineproducing $\mathrm{T}$ cells may have been achieved by reducing the concentration of the $\mathrm{Ag}$.

\section{Response}

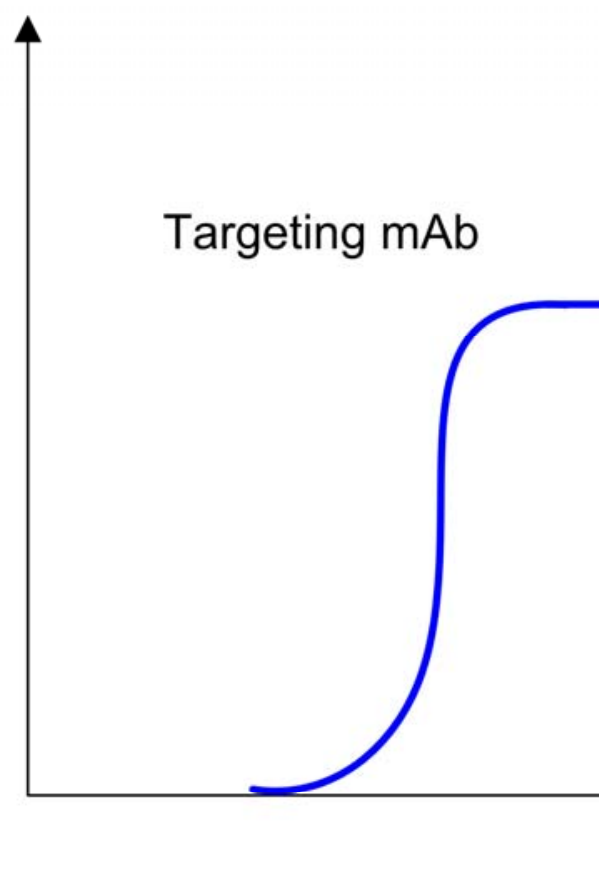

$\mathrm{mAb}$
A
B

Figure 5. Theoretical dose-response curve indicating the relation between the Ag concentration and the effect of specific delivery of $\mathrm{Ag}$. The targeting $\mathrm{mAb}$ is more potent than the non-targeting $\mathrm{mAb}$, but at high $\mathrm{Ag}$ concentrations this difference is not observed.

Obviously, both advantages and drawbacks are present when these kinds of in vitro assays are used as a means of investigating potential target receptors, compared to in vivo targeting studies. The major advantage in the in vitro screening assay is the capability to analyze a large number of target receptors simultaneously using only a very small number of mice. Investigation of the same number of potential receptors by in vivo targeting studies would require a substantially larger number of mice. In spite of this major advantage, the in vitro screening assay is unlikely to reliably reflect the situation in vivo and the assay were therefore primarily designed for a first-line evaluation of target 
receptors that must be examined in detail in subsequent studies, e.g. in vivo targeting studies.

The major goal in the second part of this project was to examine the immune responses induced by targeting $\mathrm{Ag}$ to DCs in vivo in mice. Mice were immunized with one of the ten selected target receptors (1 group per target, 10 groups in all, 4 mice per group) or with the non-targeting isotype-matched control antibodies (2 groups, IgG2a or lgG2b). Blood samples were collected at 2-weeks intervals from day 14 to day 84 and serum samples were assayed for the presence of anti-rat antibodies. The results demonstrated that Agdelivery to DCs in vivo mediated strong humoral responses for several of the ten targets, but these anti-rat antibody responses differed substantially between the targets. The targets that elicited strong antibody responses were CD11C, CD36, CD205, Clec6A, Clec7A and PDC-TREM The levels of the two subclasses, IgG1 and IgG2a, were also determined, and the results demonstrated overall production of IgG1 but with high IgG1 levels obtained after Ag-delivery to CD11c, CD36 and CD205. The production of IgG2a was more restricted, showing high IgG2a responses following Ag-delivery to Clec7A. As the subclasses produced during an immune response depends on the cytokines secreted by $\mathrm{T}$ helper cells, isotype-switching are a reflection of the $\mathrm{T}$ cell polarization obtained in vivo. Thus, the high production of IgG2a mediated by Clec7A indicates the presence of Th1 responses in these in vivo-targeted mice.

The in vivo targeting study was performed in the absence of adjuvant. Numerous other studies have obtained enhanced humoral responses to targeted Ags, but the majority of these studies administered the targeting antibody in combination with a DC-activating agent or adjuvant $(31,62,98,150,164)$. The present study demonstrated enhanced antibody production in the absence of adjuvant. Corbett et al. also demonstrated strong humoral responses following Ag-delivery to CIRE (mouse CD209) and FIRE (F4/80-like receptor) two receptors expressed on CD8 $\alpha^{-}$DCs - without adding an adjuvant, whereas delivery of $\mathrm{Ag}$ to CD205 on $\mathrm{CD} \mathrm{a}^{+} \mathrm{DCs}$ were unable to induce antibody responses unless an adjuvant was co-administered. They suggested that targeting of $\mathrm{Ag}$ to certain $\mathrm{DC}$ subsets can circumvent the need for additional DC activation signals (62). However, later studies by the same group demonstrated that Ag-delivery to Clec9A, which is expressed by the $\mathrm{CD} \mathrm{a}^{+} \mathrm{DC}$ subset, mediated strong humoral responses without adjuvant, indicating that the subtype of DC targeted is not the determining factor. Instead, Shortman et al. 
proposed that the nature of the targeted receptor determines whether the response requires additional DC activation agents (190). The present study found enhanced antibody production mediated by several target receptors expressed by different DC subsets in the absence of adjuvant, which support the notion of Shortman et al. However, we are not able to completely exclude inadvertent exposure to DC activating agents, like trace amounts of endotoxin in the mAbs or introduction of pathogenic components upon vaccination. Further studies on the direct effect of the targeted receptor on the maturation state of DCs as well as studies using MyD88\%, TRIF $\%$ gene-deficient mice are necessary for elucidation of the importance, or not, of DC maturation. Nevertheless, avoiding the side effects of adjuvants may be an important step in developing suitable vaccines for human immunotherapy (190).

Comparing the results obtained in the in vitro study with the results obtained in the in vivo study, it is clear that there are both similar but also divergent results. The two studies agree upon the targeting efficiency of the different targets, as targets like CD11C, CD36, CD205 and Clec7A elicit immune responses in both studies. However, the two studies does not completely agree on the direction of the immune response - Th1/IFN-Y vs Th2/IL4 - induced by targeting $\mathrm{Ag}$ to the effective receptors. The in vitro screening assay demonstrated potent IFN-Y production by CD11C, CD36, CD205 and Clec7A indicating that targeting of $\mathrm{Ag}$ to these receptors elicited Th1 responses. In contrast, the in vivo targeting study demonstrated an IgG subclass production following immunization with CD11C, CD36 and CD205 that indicated an overall Th2 response in the vaccinated mice. Regarding Clec7A, the two studies agreed upon the presence of Th1 responses.

The exact reason for this discrepancy between the two studies is not entirely clear, but it may be related to the use of adjuvant. The spleen cell suspensions used in the in vitro assay were extracted from mice immunized with a non-targeting isotype control antibody in Freund's adjuvant. The magnitude and type of Th response to an $\mathrm{Ag}$ can be greatly modulated through the use of adjuvants (208). Immunization in the presence of Freund's complete adjuvant (CFA) has been shown to initiate Th1-biased responses $(209,210)$. In addition, studies have shown that primary and recall Ag-specific Th2 responses can be inhibited, if the $\mathrm{Ag}$ was injected together with an adjuvant that induced Th1-biased responses (211). Thus, the discrepancy observed between the in vitro and the in vivo 
studies may be caused by a predetermined capacity of the Ag-specific $\mathrm{T}$ cells (and perhaps also the splenic DCs) used in the in vitro study to induce Th1 types of cytokines, which can not be converted during the subsequent recall in vitro stimulation. The results obtained in the in vivo study is unbiased regarding the direction of the immune response induced by targeting Ag to the different receptors and may provide a more "pure" response compared to the responses obtained in the presence of adjuvant. The advantages of using one approach over the other depend on the desired immunological outcome. Some vaccines may benefit from the polarizing effect of an adjuvant, e.g. induction of Th1 type responses promoting activation of cytotoxic $\mathrm{T}$ cells, whereas others may function well without. Another explanation for the divergent results obtained in the two studies may be that each study reaches different DCs. The in vivo-targeting study reaches several types of DCs, including the ones in peripheral tissues, and not only the DC subsets residing in the spleen as for the in vitro screening assay. It is likely that different DC subsets will lead to induction of different responses. In support of this hypothesis, Matzinger argue that it is possible that the ultimate control of the nature of the immune response lies within the tissues, in which the response occurs, and that tissue-derived signals may educate APCs in order to control the effector class of the immune response (212). Thus, the discrepancy between the studies may also be related to targeting of DC subsets located in different tissues.

The $\mathrm{T}$ cell stimulatory efficiency of targeting Ag to DCs through antibodies are depending on a number of features, of which some are related to the specific target receptor, while others are related to the particular targeting antibody.

Factors, related to the specific target receptor that may be of importance for the targeting efficiency are:

i) The expression level of the receptor on DCs.

It is possible that the expression levels of the target receptors on DCs are important for the targeting-efficiency and that high expression levels of a target receptor is an advantage. However, the results obtained here demonstrated no obvious correlation between the expression level of the receptor and the ability to activate $\mathrm{T}$ cells following targeting of $\mathrm{Ag}$ to that specific receptor. Other studies have also shown that the expression level of the 
particular receptor is not important for the immunogenicity of the Ag cargo (166), indicating that low expressed receptors may be just as effective as high expressed receptors.

ii) The distribution of the target receptor on different cell populations.

Lahoud et al. described that when the expression of a target receptor is restricted to few cell types, targeting of Ag to that receptor led to prolonged Ag presentation by DCs and that this was crucial for priming of $\mathrm{T}$ cells. In contrast, a broad expression pattern on several cell types could lead to Ag uptake in irrelevant cells and potentially reduce the effect of Ag-delivery (150). However, the results obtained in this project were not supportive of this finding, as both strong antibody responses and potent IFN- $\gamma$ production were elicited by Ag-delivery to Clec7A and CD11c. While the expression of CD11c is restricted to DCs, Clec7A displays a broader distribution. Clec7A was originally identified as a DC-specific marker, however, in later studies its expression was demonstrated on several other cells types, including macrophages, monocytes and neutrophils $(98,155)$. Hence, Clec7A displays a broad expression pattern compared to CD11c but still both were observed as strong inducers of immune responses.

iii) The expression of the target receptor on specific DC subsets.

The nature of the immune responses induced by Ag-targeted DCs may be determined by the specialized functions of the different DC subsets. However, this association was not clearly reflected in the results obtained in the present study. We observed both IFN-Y and IL-4 responses following Ag-delivery to receptors primarily expressed on CD8 $\alpha^{+}(C D 205)$, receptors expressed on both $C D 8 \alpha^{+}$and $C D 8 \alpha^{-}$DCs (CD36) and receptors expressed on CD8 $\alpha^{-}$DCs (Clec7A). Additionally, the present study demonstrated no correlation between the target expression on specific DCs subsets, $C D 8 \alpha^{+}$or CD8 $\alpha^{-} \mathrm{DCs}$, and the ability to induce antibody production. The target receptors that proved most efficient at inducing humoral responses is found on several DC subsets, including pDCs (PDC-TREM).

Monoclonal antibodies has proven efficient as targeting devices for Ag-delivery to DCs and the screening assay developed in this study did identify potential vaccine targets. However, we demonstrated that the outcome of targeting Ag to DCs via mAb depend on inherent properties of the particular antibody. As such, the assays employed in this thesis entail a risk of rejecting good candidates only on the basis of inappropriate properties of target antibodies and not on the fact that these candidates are inefficient as target receptors. Nevertheless, the potential target receptors identified by these studies are very 
likely good candidates for DC-directed vaccines. Notably, the relation between targeting efficiency and antibody properties like binding affinity and epitope recognition, emphasize the importance of testing different mAbs directed against the same potential target receptor in order to identify the ones best suited for antibody-based vaccines.

Targeting Ag to specific receptors may elicit different kinds of immune responses making the application of DC-directed vaccines diverse. It may be possible to design vaccines that, based on the target receptor and/or the DC subset that is targeted, induce immune responses of desired nature: i) immune activation, activation of $\mathrm{T}$ helper cells or cytotoxic T cells, e.g. tumor-specific $T$ cell activation in cases of cancer immunotherapy, ii) immune deviation in allergy or iii) immune regulation, induction of regulatory T cells or anergy, e.g. in cases of autoimmune diseases. 


\section{Future perspectives}

\section{Murine study}

In this study the targeting efficiency of a panel of different receptors expressed on DCs was investigated both in vitro and in vivo. Several target receptors proved efficient and may be objects for future studies.

In order to elaborate on the nature of the immune responses induced by the different targets, I would like to perform the following studies in the nearer future:

1) Investigation of the level of anti-rat antibodies in the in vivo-targeted mice at time points beyond day 84 , which provide information on the duration of the humoral responses initiated by the antibody-targeted DCs. Therefore, the lgG levels in serum from blood samples collected at day 150 - 200 will be determined in the near future.

2) Investigation of the cellular responses induced by in vivo-targeted DCs by recall in vitro stimulation using the ELISPOT assay. This requires optimization of the ELISPOT assay in a way that enables the detection of low-frequent Ag-specific T cells. Another approach for measuring the presence of $\mathrm{T}$ cell activation may be to determine proliferation of memory $\mathrm{CD}^{+}$and $\mathrm{CD}^{+} \mathrm{T}$ cells in recall stimulation with Ag-treated DCs. One problem with the ELISPOT recall assay is the inability to detect activation of low-frequent Ag-specific $\mathrm{T}$ cells, which might be overcome in a proliferative assay, in which activated low-frequent Ag-specific T cells will expand. For several reasons, it is likely that the proliferation assay is more adequate for analyzing the $\mathrm{T}$ cell activation elicited by targeting of $\mathrm{Ag}$ to different receptor on DCs in vivo: 1) Low-frequent Ag-specific T cells are easier detected by a proliferation assay than by merely measuring the activation of these cells, 2) Proliferation assays may allow for concurrent analysis of $\mathrm{T}$ cell surface markers providing information on whether $\mathrm{CD}^{+}$and/or $\mathrm{CD}^{+}{ }^{\mathrm{T}}$ cell are activated by the DCs. Regardless of which of the two assays that are employed, such investigation could provide information about the type of $\mathrm{T}$ cell response (Th1 vs Th2 or helper T cell vs cytotoxic T cell) the Ag-targeted DCs induces.

Additionally, further studies on the effect of targeting Ag to DCs via CD11c will be initiated.

1) The route of $\mathrm{Ag}$ administration as well as the micro-milieu of the specific tissues at the time of administration is of importance for the development of active immunity and may be 
involved in determining the immunological outcome of the Ag encounter (209). As such, immunization by different administration routes (i.v., i.p. and s.c.) will be performed in order to determine the optimal route for targeting DCs and for induction of strong immune responses. The readout will be the antibody production determined by ELISA.

2) Targeting of $A g$ to $C D 11 \mathrm{c}$ will be assayed in a murine tumour model. A fusion protein of a tumour Ag (erythropoietin-producing hepatocellular receptor tyrosine kinase class A2, EphA2) and a scFv specific for CD11c will be generated by genetic engineering and used for vaccinating mice. The protective and/or therapeutic effect of this vaccination will be tested using the MCA205 sarcoma cell line that expresses high levels of EphA2.

\section{The human study}

Investigation of targeting of Ag to human DCs was unfortunately not achieved during this project. However, recent initiated collaboration between the group of Ralf Agger and the group of Bjarne Bogen, Institute of Immunology, University of Oslo, provide the opportunity to perform this study. Bogen and co-workers developed a human $\mathrm{T}$ cell clone that can be used to screen large numbers of target receptors for their ability to internalize, process and present Ag on MHC class II molecules (213). The $\mathrm{CD}^{+} \mathrm{T}$ cell clone is specific for mouse Ig $C_{K}$ and restricted by HLA-DR4. Such a $T$ cell clone can be used for analysis of the efficiency of delivery of $A g$ to DCs through mouse anti-human mAb. Using this approach DCs can be generated from healthy donors (tissue type HLA-DR4), which circumvents the obstacles related to limited number of cells from patients. PBMCs will be extracted from buffycoats from healthy donors and DCs will be generated from monocytes using IL-4 and GM-CSF. Following exposure to mouse anti-human monoclonal target antibodies and a maturation stimulus, the DCs will be co-cultured with the $T$ cell clone and assayed for $T$ cell activation and/or expansion. If the $\mathrm{T}$ cell clone is activated, targeting of $\mathrm{Ag}$ to the different receptors did deliver antigenic peptides for presentation on MHC class II. In this way a panel of different target receptors expressed on human DCs can be tested simultaneously and their targeting efficiency can be directly compared. 


\section{Reference List}

1. Banchereau, J., F. Briere, C. Caux, J. Davoust, S. Lebecque, Y. J. Liu, B. Pulendran, and K. Palucka. 2000. Immunobiology of dendritic cells. Annu. Rev Immunol 18: 767-811.

2. Banchereau, J., and R. M. Steinman. 1998. Dendritic cells and the control of immunity. Nature 392: 245-252.

3. Alvarez, D., E. H. Vollmann, and U. H. von Andrian. 2008. Mechanisms and consequences of dendritic cell migration. Immunity 29: 325-342.

4. Steinman, R. M., and Z. A. Cohn. 1973. Identification of a novel cell type in peripheral lymphoid organs of mice. I. Morphology, quantitation, tissue distribution. J. Exp. Med. 137: 1142-1162.

5. Steinman, R. M., D. S. Lustig, and Z. A. Cohn. 1974. Identification of a novel cell type in peripheral lymphoid organs of mice. 3. Functional properties in vivo. J. Exp. Med. 139: 1431-1445.

6. Steinman, R. M., and M. D. Witmer. 1978. Lymphoid dendritic cells are potent stimulators of the primary mixed leukocyte reaction in mice. Proc. Natl. Acad. Sci. U. S. A 75: 5132-5136.

7. Steinman, R. M., D. S. Lustig, and Z. A. Cohn. 1974. Identification of a novel cell type in peripheral lymphoid organs of mice. 3. Functional properties in vivo. J. Exp. Med. 139: 1431-1445.

8. Shortman, K., and Y. J. Liu. 2002. Mouse and human dendritic cell subtypes. Nat Rev Immunol 2: 151-161.

9. Villadangos, J. A., and W. R. Heath. 2005. Life cycle, migration and antigen presenting functions of spleen and lymph node dendritic cells: Limitations of the Langerhans cells paradigm. Seminars in Immunology 17: 262-272.

10. Shortman, K., and S. H. Naik. 2007. Steady-state and inflammatory dendritic-cell development. Nat Rev Immunol 7: 19-30.

11. Steinman, R. M. 1991. The dendritic cell system and its role in immunogenicity. Annu. Rev Immunol 9: 271-296.

12. Zhang, J. G., P. E. Czabotar, A. N. Policheni, I. Caminschi, S. S. Wan, S. Kitsoulis, K. M. Tullett, A. Y. Robin, R. Brammananth, M. F. van Delft, J. Lu, L. A. O'Reilly, E. C. Josefsson, B. T. Kile, W. J. Chin, J. D. Mintern, M. A. Olshina, W. Wong, J. Baum, M. D. Wright, D. C. Huang, N. Mohandas, R. L. Coppel, P. M. Colman, N. A. Nicola, K. Shortman, and M. H. Lahoud. 2012. The dendritic cell receptor Clec9A binds damaged cells via exposed actin filaments. Immunity 36: 646-657. 
13. Matzinger, P. 2002. The Danger Model: A Renewed Sense of Self. Science 296: 301-305.

14. Thery, C., and S. Amigorena. 2001. The cell biology of antigen presentation in dendritic cells. Curr. Opin. Immunol 13: 45-51.

15. Sallusto, F., P. Schaerli, P. Loetscher, C. Schaniel, D. Lenig, C. R. Mackay, S. Qin, and A. Lanzavecchia. 1998. Rapid and coordinated switch in chemokine receptor expression during dendritic cell maturation. Eur. J. Immunol. 28: 2760-2769.

16. Merad, M., M. G. Manz, H. Karsunky, A. Wagers, W. Peters, I. Charo, I. L. Weissman, J. G. Cyster, and E. G. Engleman. 2002. Langerhans cells renew in the skin throughout life under steady-state conditions. Nat Immuno/ 3: 1135-1141.

17. Stumbles, P. A., D. H. Strickland, C. L. Pimm, S. F. Proksch, A. M. Marsh, A. S. McWilliam, A. Bosco, I. Tobagus, J. A. Thomas, S. Napoli, A. E. Proudfoot, T. N. Wells, and P. G. Holt. 2001. Regulation of dendritic cell recruitment into resting and inflamed airway epithelium: use of alternative chemokine receptors as a function of inducing stimulus. J. Immunol 167: 228-234.

18. Dieu, M. C., B. Vanbervliet, A. Vicari, J. M. Bridon, E. Oldham, S. Ait-Yahia, F. Briere, A. Zlotnik, S. Lebecque, and C. Caux. 1998. Selective recruitment of immature and mature dendritic cells by distinct chemokines expressed in different anatomic sites. J. Exp. Med. 188: 373-386.

19. MartIn-Fontecha, A., S. Sebastiani, U. E. Hopken, M. Uguccioni, M. Lipp, A. Lanzavecchia, and F. Sallusto. 2003. Regulation of dendritic cell migration to the draining lymph node: impact on T lymphocyte traffic and priming. J. Exp. Med. 198: 615-621.

20. Sozzani, S., P. Allavena, A. Vecchi, and A. Mantovani. 2000. Chemokines and dendritic cell traffic. J. Clin. Immunol 20: 151-160.

21. Huang, F. P., and G. G. MacPherson. 2001. Continuing education of the immune system--dendritic cells, immune regulation and tolerance. Curr. Mol. Med. 1: 457468.

22. Steinman, R. M., and M. C. Nussenzweig. 2002. Avoiding horror autotoxicus: the importance of dendritic cells in peripheral T cell tolerance. Proc. Natl. Acad. Sci. U. S. A 99: 351-358.

23. Adler, A. J., D. W. Marsh, G. S. Yochum, J. L. Guzzo, A. Nigam, W. G. Nelson, and D. M. Pardoll. 1998. CD4+ T cell tolerance to parenchymal self-antigens requires presentation by bone marrow-derived antigen-presenting cells. J. Exp. Med. 187: 1555-1564.

24. Hawiger, D., K. Inaba, Y. Dorsett, M. Guo, K. Mahnke, M. Rivera, J. V. Ravetch, R. M. Steinman, and M. C. Nussenzweig. 2001. Dendritic cells induce peripheral T cell unresponsiveness under steady state conditions in vivo. J. Exp. Med. 194: 769-779. 
25. Kurts, C., H. Kosaka, F. R. Carbone, J. F. Miller, and W. R. Heath. 1997. Class Irestricted cross-presentation of exogenous self-antigens leads to deletion of autoreactive CD8(+) T cells. J. Exp. Med. 186: 239-245.

26. Bonifaz, L., D. Bonnyay, K. Mahnke, M. Rivera, M. C. Nussenzweig, and R. M. Steinman. 2002. Efficient targeting of protein antigen to the dendritic cell receptor DEC-205 in the steady state leads to antigen presentation on major histocompatibility complex class I products and peripheral CD8+ T cell tolerance. J. Exp. Med. 196: 1627-1638.

27. Dhodapkar, M. V., R. M. Steinman, J. Krasovsky, C. Munz, and N. Bhardwaj. 2001. Antigen-specific inhibition of effector $T$ cell function in humans after injection of immature dendritic cells. J. Exp. Med. 193: 233-238.

28. Jonuleit, H., E. Schmitt, G. Schuler, J. Knop, and A. H. Enk. 2000. Induction of interleukin 10-producing, nonproliferating CD4(+) T cells with regulatory properties by repetitive stimulation with allogeneic immature human dendritic cells. J. Exp. Med. 192: 1213-1222.

29. Mahnke, K., Y. Qian, J. Knop, and A. H. Enk. 2003. Induction of CD4+/CD25+ regulatory $\mathrm{T}$ cells by targeting of antigens to immature dendritic cells. Blood 101: 4862-4869.

30. Hugues, S., A. Boissonnas, S. Amigorena, and L. Fetler. 2006. The dynamics of dendritic cell-T cell interactions in priming and tolerance. Curr. Opin. Immunol 18: 491-495.

31. Boscardin, S. B., J. C. Hafalla, R. F. Masilamani, A. O. Kamphorst, H. A. Zebroski, U. Rai, A. Morrot, F. Zavala, R. M. Steinman, R. S. Nussenzweig, and M. C. Nussenzweig. 2006. Antigen targeting to dendritic cells elicits long-lived T cell help for antibody responses. J. Exp. Med. 203: 599-606.

32. Wu, L., and Y. J. Liu. 2007. Development of dendritic-cell lineages. Immunity 26: 741-750.

33. Serbina, N. V., T. P. Salazar-Mather, C. A. Biron, W. A. Kuziel, and E. G. Pamer. 2003. TNF/iNOS-producing dendritic cells mediate innate immune defense against bacterial infection. Immunity 19: 59-70.

34. Geissmann, F., S. Jung, and D. R. Littman. 2003. Blood monocytes consist of two principal subsets with distinct migratory properties. Immunity. 19: 71-82.

35. Naik, S. H., D. Metcalf, N. A. van, I. Wicks, L. Wu, M. O'Keeffe, and K. Shortman. 2006. Intrasplenic steady-state dendritic cell precursors that are distinct from monocytes. Nat Immunol 7: 663-671.

36. Kushwah, R., and J. Hu. 2011. Complexity of dendritic cell subsets and their function in the host immune system. Immunology 133: 409-419. 
37. Liu, K., and M. C. Nussenzweig. 2010. Origin and development of dendritic cells. Immunological Reviews 234: 45-54.

38. Inaba, K., M. Inaba, M. Deguchi, K. Hagi, R. Yasumizu, S. Ikehara, S. Muramatsu, and R. M. Steinman. 1993. Granulocytes, macrophages, and dendritic cells arise from a common major histocompatibility complex class II-negative progenitor in mouse bone marrow. Proc. Natl. Acad. Sci. U. S. A 90: 3038-3042.

39. D'Amico, A., and L. Wu. 2003. The early progenitors of mouse dendritic cells and plasmacytoid predendritic cells are within the bone marrow hemopoietic precursors expressing Flt3. J. Exp. Med. 198: 293-303.

40. Manz, M. G., D. Traver, T. Miyamoto, I. L. Weissman, and K. Akashi. 2001. Dendritic cell potentials of early lymphoid and myeloid progenitors. Blood 97: 33333341.

41. McKenna, H. J., K. L. Stocking, R. E. Miller, K. Brasel, S. T. De, E. Maraskovsky, C. R. Maliszewski, D. H. Lynch, J. Smith, B. Pulendran, E. R. Roux, M. Teepe, S. D. Lyman, and J. J. Peschon. 2000. Mice lacking flt3 ligand have deficient hematopoiesis affecting hematopoietic progenitor cells, dendritic cells, and natural killer cells. Blood 95: 3489-3497.

42. Brasel, K., S. T. De, J. L. Smith, and C. R. Maliszewski. 2000. Generation of murine dendritic cells from flt3-ligand-supplemented bone marrow cultures. Blood 96: 30293039.

43. Kamath, A. T., J. Pooley, M. A. O'Keeffe, D. Vremec, Y. Zhan, A. M. Lew, A. D'Amico, L. Wu, D. F. Tough, and K. Shortman. 2000. The development, maturation, and turnover rate of mouse spleen dendritic cell populations. $J$. Immunol 165: 6762-6770.

44. Liu, K., C. Waskow, X. Liu, K. Yao, J. Hoh, and M. Nussenzweig. 2007. Origin of dendritic cells in peripheral lymphoid organs of mice. Nat Immunol 8: 578-583.

45. Brown, K. A., P. Bedford, M. Macey, D. A. McCarthy, F. Leroy, A. J. Vora, A. J. Stagg, D. C. Dumonde, and S. C. Knight. 1997. Human blood dendritic cells: binding to vascular endothelium and expression of adhesion molecules. Clin. Exp. Immunol 107: 601-607.

46. O'Keeffe, M., H. Hochrein, D. Vremec, B. Scott, P. Hertzog, L. Tatarczuch, and K. Shortman. 2003. Dendritic cell precursor populations of mouse blood: identification of the murine homologues of human blood plasmacytoid pre-DC2 and CD11c+ DC1 precursors. Blood 101: 1453-1459.

47. Penna, G., M. Vulcano, S. Sozzani, and L. Adorini. 2002. Differential migration behavior and chemokine production by myeloid and plasmacytoid dendritic cells. Human Immunology 63: 1164-1171. 
48. Strioga, M., V. Schijns, D. J. Powell, Jr., V. Pasukoniene, N. Dobrovolskiene, and J. Michalek. 2012. Dendritic cells and their role in tumor immunosurveillance. Innate. Immun.

49. Barchet, W., M. Cella, and M. Colonna. 2005. Plasmacytoid dendritic cells--virus experts of innate immunity. Semin. Immunol 17: 253-261.

50. Colonna, M., G. Trinchieri, and Y. J. Liu. 2004. Plasmacytoid dendritic cells in immunity. Nat Immunol 5: 1219-1226.

51. Penna, G., S. Sozzani, and L. Adorini. 2001. Cutting edge: selective usage of chemokine receptors by plasmacytoid dendritic cells. J. Immunol 167: 1862-1866.

52. Austyn, J. M., J. W. Kupiec-Weglinski, D. F. Hankins, and P. J. Morris. 1988. Migration patterns of dendritic cells in the mouse. Homing to T cell-dependent areas of spleen, and binding within marginal zone. J. Exp. Med. 167: 646-651.

53. Vremec, D., J. Pooley, H. Hochrein, L. Wu, and K. Shortman. 2000. CD4 and CD8 expression by dendritic cell subtypes in mouse thymus and spleen. J. Immunol 164: 2978-2986.

54. den Haan, J. M., S. M. Lehar, and M. J. Bevan. 2000. CD8(+) but not CD8(-) dendritic cells cross-prime cytotoxic T cells in vivo. J. Exp. Med. 192: 1685-1696.

55. Pulendran, B., J. L. Smith, G. Caspary, K. Brasel, D. Pettit, E. Maraskovsky, and C. R. Maliszewski. 1999. Distinct dendritic cell subsets differentially regulate the class of immune response in vivo. Proc. Natl. Acad. Sci. U. S. A 96: 1036-1041.

56. Pooley, J. L., W. R. Heath, and K. Shortman. 2001. Cutting edge: intravenous soluble antigen is presented to CD4 T cells by CD8- dendritic cells, but crosspresented to CD8 T cells by CD8+ dendritic cells. J. Immunol 166: 5327-5330.

57. Sathe, P., and K. Shortman. 2008. The steady-state development of splenic dendritic cells. Mucosal. Immunol 1: 425-431.

58. De, S. T., B. Pajak, E. Muraille, L. Lespagnard, E. Heinen, B. P. De, J. Urbain, O. Leo, and M. Moser. 1996. Regulation of dendritic cell numbers and maturation by lipopolysaccharide in vivo. J. Exp. Med. 184: 1413-1424.

59. De, S. T., E. Butz, J. Smith, R. Maldonado-Lopez, B. Pajak, M. Moser, and C. Maliszewski. 2001. CD8alpha(-) and CD8alpha(+) subclasses of dendritic cells undergo phenotypic and functional maturation in vitro and in vivo. J. Leukoc. Biol. 69: 951-958.

60. Maldonado-Lopez, R., S. T. De, B. Pajak, C. Heirman, K. Thielemans, O. Leo, J. Urbain, C. R. Maliszewski, and M. Moser. 1999. Role of CD8alpha+ and CD8alphadendritic cells in the induction of primary immune responses in vivo. J. Leukoc. Biol. 66: 242-246. 
61. Shortman, K., and W. R. Heath. 2010. The CD8+ dendritic cell subset. Immunol Rev 234: 18-31.

62. Corbett, A. J., I. Caminschi, B. S. McKenzie, J. L. Brady, M. D. Wright, P. L. Mottram, P. M. Hogarth, A. N. Hodder, Y. Zhan, D. M. Tarlinton, K. Shortman, and A. M. Lew. 2005. Antigen delivery via two molecules on the CD8- dendritic cell subset induces humoral immunity in the absence of conventional "danger". Eur. J. Immunol 35: 2815-2825.

63. Watarai, H., E. Sekine, S. Inoue, R. Nakagawa, T. Kaisho, and M. Taniguchi. 2008. PDC-TREM, a plasmacytoid dendritic cell-specific receptor, is responsible for augmented production of type I interferon. Proc. Natl. Acad. Sci. U. S. A 105: 29932998.

64. Yoneyama, H., K. Matsuno, Y. Zhang, T. Nishiwaki, M. Kitabatake, S. Ueha, S. Narumi, S. Morikawa, T. Ezaki, B. Lu, C. Gerard, S. Ishikawa, and K. Matsushima. 2004. Evidence for recruitment of plasmacytoid dendritic cell precursors to inflamed lymph nodes through high endothelial venules. Int. Immunol 16: 915-928.

65. Swiecki, M., Y. Wang, W. Vermi, S. Gilfillan, R. D. Schreiber, and M. Colonna. 2011. Type I interferon negatively controls plasmacytoid dendritic cell numbers in vivo. J. Exp. Med. 208: 2367-2374.

66. Gilliet, M., W. Cao, and Y. J. Liu. 2008. Plasmacytoid dendritic cells: sensing nucleic acids in viral infection and autoimmune diseases. Nat Rev Immunol 8: 594606.

67. Trinchieri, G. 2010. Type I interferon: friend or foe? J. Exp. Med. 207: 2053-2063.

68. Martin, P., G. M. Del Hoyo, F. Anjuere, C. F. Arias, H. H. Vargas, L. Fernandez, V. Parrillas, and C. Ardavin. 2002. Characterization of a new subpopulation of mouse CD8alpha+ B220+ dendritic cells endowed with type 1 interferon production capacity and tolerogenic potential. Blood 100: 383-390.

69. Moseman, E. A., X. Liang, A. J. Dawson, A. Panoskaltsis-Mortari, A. M. Krieg, Y. J. Liu, B. R. Blazar, and W. Chen. 2004. Human plasmacytoid dendritic cells activated by $\mathrm{CpG}$ oligodeoxynucleotides induce the generation of CD4+CD25+ regulatory $\mathrm{T}$ cells. J. Immunol 173: 4433-4442.

70. Salio, M., M. J. Palmowski, A. Atzberger, I. F. Hermans, and V. Cerundolo. 2004. CpG-matured murine plasmacytoid dendritic cells are capable of in vivo priming of functional CD8 $\mathrm{T}$ cell responses to endogenous but not exogenous antigens. J. Exp. Med. 199: 567-579.

71. Krug, A., R. Veeraswamy, A. Pekosz, O. Kanagawa, E. R. Unanue, M. Colonna, and M. Cella. 2003. Interferon-producing cells fail to induce proliferation of naive $T$ cells but can promote expansion and $\mathrm{T}$ helper 1 differentiation of antigenexperienced unpolarized T cells. J. Exp. Med. 197: 899-906. 
72. Schlecht, G., S. Garcia, N. Escriou, A. A. Freitas, C. Leclerc, and G. Dadaglio. 2004. Murine plasmacytoid dendritic cells induce effector/memory CD8+ T-cell responses in vivo after viral stimulation. Blood 104: 1808-1815.

73. Takagi, H., T. Fukaya, K. Eizumi, Y. Sato, K. Sato, A. Shibazaki, H. Otsuka, A. Hijikata, T. Watanabe, O. Ohara, T. Kaisho, B. Malissen, and K. Sato. 2011. Plasmacytoid Dendritic Cells Are Crucial for the Initiation of Inflammation and T Cell Immunity In-áVivo. Immunity 35: 958-971.

74. Villadangos, J. A., and L. Young. 2008. Antigen-Presentation Properties of Plasmacytoid Dendritic Cells. Immunity 29: 352-361.

75. Boonstra, A., C. Asselin-Paturel, M. Gilliet, C. Crain, G. Trinchieri, Y. J. Liu, and A. O'Garra. 2003. Flexibility of mouse classical and plasmacytoid-derived dendritic cells in directing $\mathrm{T}$ helper type 1 and 2 cell development: dependency on antigen dose and differential toll-like receptor ligation. J. Exp. Med. 197: 101-109.

76. Tacken, P. J., and C. G. Figdor. 2011. Targeted antigen delivery and activation of dendritic cells in vivo: Steps towards cost effective vaccines. Seminars in Immunology 23: 12-20.

77. Figdor, C. G., Y. van Kooyk, and G. J. Adema. 2002. C-type lectin receptors on dendritic cells and langerhans cells. Nat Rev Immunol 2: 77-84.

78. Mellman, I., and R. M. Steinman. 2001. Dendritic cells: specialized and regulated antigen processing machines. Cell 106: 255-258.

79. Mahnke, K., J. Knop, and A. H. Enk. 2003. Induction of tolerogenic DCs: 'you are what you eat'. Trends Immunol 24: 646-651.

80. Cambi, A., and C. G. Figdor. 2003. Dual function of C-type lectin-like receptors in the immune system. Curr. Opin. Cell Biol. 15: 539-546.

81. van, K. Y. 2008. C-type lectins on dendritic cells: key modulators for the induction of immune responses. Biochem. Soc. Trans. 36: 1478-1481.

82. Murphy K. 2011. Janeways Immunobiology. 78.

83. Ravetch, J. V., and S. Bolland. 2001. IgG Fc receptors. Annu. Rev Immunol 19: 275-290.

84. Daeron, M. 1997. Fc receptor biology. Annu. Rev Immunol 15: 203-234.

85. Murphy K. 2011. Janeways Immunobiology. 78.

86. Peiser, L., S. Mukhopadhyay, and S. Gordon. 2002. Scavenger receptors in innate immunity. Curr. Opin. Immunol 14: 123-128. 
87. Burgdorf, S., A. Kautz, V. Bohnert, P. A. Knolle, and C. Kurts. 2007. Distinct pathways of antigen uptake and intracellular routing in CD4 and CD8 T cell activation. Science 316: 612-616.

88. Kim, S. H., A. Visser, C. Cruijsen, A. W. van der Velden, and M. Boes. 2008. Recruitment of Rab27a to phagosomes controls microbial antigen crosspresentation by dendritic cells. Infect. Immun. 76: 5373-5380.

89. Mahnke, K., M. Guo, S. Lee, H. Sepulveda, S. L. Swain, M. Nussenzweig, and R. M. Steinman. 2000. The dendritic cell receptor for endocytosis, DEC-205, can recycle and enhance antigen presentation via major histocompatibility complex class II-positive lysosomal compartments. J. Cell Biol. 151: 673-684.

90. Cambi, A., M. Koopman, and C. G. Figdor. 2005. How C-type lectins detect pathogens. Cell Microbiol. 7: 481-488.

91. Engering, A., T. B. Geijtenbeek, S. J. van Vliet, M. Wijers, L. E. van, N. Demaurex, A. Lanzavecchia, J. Fransen, C. G. Figdor, V. Piguet, and K. Y. van. 2002. The dendritic cell-specific adhesion receptor DC-SIGN internalizes antigen for presentation to T cells. J. Immunol 168: 2118-2126.

92. Kanazawa, N., K. Tashiro, and Y. Miyachi. 2004. Signaling and immune regulatory role of the dendritic cell immunoreceptor (DCIR) family lectins: DCIR, DCAR, dectin2 and BDCA-2. Immunobiology 209: 179-190.

93. Sancho, D., D. Mourao-Sa, O. P. Joffre, O. Schulz, N. C. Rogers, D. J. Pennington, J. R. Carlyle, and Reis E Sousa. 2008. Tumor therapy in mice via antigen targeting to a novel, DC-restricted C-type lectin. J. Clin. Invest 118: 2098-2110.

94. Huysamen, C., and G. D. Brown. 2009. The fungal pattern recognition receptor, Dectin-1, and the associated cluster of C-type lectin-like receptors. FEMS Microbiol. Lett. 290: 121-128.

95. Seeds, R. E., S. Gordon, and J. L. Miller. 2009. Characterisation of myeloid receptor expression and interferon alpha/beta production in murine plasmacytoid dendritic cells by flow cytomtery. Journal of Immunological Methods 350: 106-117.

96. Caminschi, I., A. J. Corbett, C. Zahra, M. Lahoud, K. M. Lucas, M. Sofi, D. Vremec, T. Gramberg, S. Pöhlmann, J. Curtis, E. Handman, S. L. H. van Dommelen, P. Fleming, M. A. Degli-Esposti, K. Shortman, and M. D. Wright. 2006. Functional comparison of mouse CIRE/mouse DC-SIGN and human DC-SIGN. International Immunology 18: 741-753.

97. O'Keeffe, M., H. Hochrein, D. Vremec, I. Caminschi, J. L. Miller, E. M. Anders, L. Wu, M. H. Lahoud, S. Henri, B. Scott, P. Hertzog, L. Tatarczuch, and K. Shortman. 2002. Mouse plasmacytoid cells: long-lived cells, heterogeneous in surface phenotype and function, that differentiate into CD8(+) dendritic cells only after microbial stimulus. J. Exp. Med. 196: 1307-1319. 
98. Carter, R. W., C. Thompson, D. M. Reid, S. Y. Wong, and D. F. Tough. 2006. Preferential induction of CD4+ T cell responses through in vivo targeting of antigen to dendritic cell-associated C-type lectin-1. J. Immunol 177: 2276-2284.

99. Doherty, P. C., and R. M. Zinkernagel. 1975. H-2 compatibility is required for T-cellmediated lysis of target cells infected with lymphocytic choriomeningitis virus. $J$. Exp. Med. 141: 502-507.

100. Tacken, P. J., I. J. de Vries, R. Torensma, and C. G. Figdor. 2007. Dendritic-cell immunotherapy: from ex vivo loading to in vivo targeting. Nat Rev Immunol 7: 790802.

101. Bevan, M. J. 2010. Cross-priming for a secondary cytotoxic response to minor $\mathrm{H}$ antigens with $\mathrm{H}-2$ congenic cells which do not cross-react in the cytotoxic assay. 1976. J. Immunol 185: 1361-1366.

102. Claus, V., A. Jahraus, T. Tjelle, T. Berg, H. Kirschke, H. Faulstich, and G. Griffiths. 1998. Lysosomal enzyme trafficking between phagosomes, endosomes, and lysosomes in $\mathrm{J} 774$ macrophages. Enrichment of cathepsin $\mathrm{H}$ in early endosomes. $\mathrm{J}$. Biol. Chem. 273: 9842-9851.

103. Compeer, E. B., T. W. Flinsenberg, S. G. van der Grein, and M. Boes. 2012. Antigen processing and remodeling of the endosomal pathway: requirements for antigen cross-presentation. Front Immunol 3: 37.

104. Savina, A., C. Jancic, S. Hugues, P. Guermonprez, P. Vargas, I. C. Moura, A. M. Lennon-Dumenil, M. C. Seabra, G. Raposo, and S. Amigorena. 2006. NOX2 controls phagosomal $\mathrm{pH}$ to regulate antigen processing during crosspresentation by dendritic cells. Cell 126: 205-218.

105. Thacker, R. I., and E. M. Janssen. 2012. Cross-presentation of cell-associated antigens by mouse splenic dendritic cell populations. Front Immunol 3: 41.

106. Ackerman, A. L., C. Kyritsis, R. Tampe, and P. Cresswell. 2005. Access of soluble antigens to the endoplasmic reticulum can explain cross-presentation by dendritic cells. Nat Immunol 6: 107-113.

107. Gromme, M., F. G. Uytdehaag, H. Janssen, J. Calafat, R. S. van Binnendijk, M. J. Kenter, A. Tulp, D. Verwoerd, and J. Neefjes. 1999. Recycling MHC class I molecules and endosomal peptide loading. Proc. Natl. Acad. Sci. U. S. A 96: 10326-10331.

108. Shen, L., L. J. Sigal, M. Boes, and K. L. Rock. 2004. Important role of cathepsin S in generating peptides for TAP-independent MHC class I crosspresentation in vivo. Immunity 21: 155-165.

109. Vega, M. A., and J. L. Strominger. 1989. Constitutive endocytosis of HLA class I antigens requires a specific portion of the intracytoplasmic tail that shares structural features with other endocytosed molecules. Proc. Natl. Acad. Sci. U. S. A 86: 26882692. 
110. Ackerman, A. L., C. Kyritsis, R. Tampe, and P. Cresswell. 2003. Early phagosomes in dendritic cells form a cellular compartment sufficient for cross presentation of exogenous antigens. Proc. Natl. Acad. Sci. U. S. A 100: 12889-12894.

111. Burgdorf, S., C. Scholz, A. Kautz, R. Tampe, and C. Kurts. 2008. Spatial and mechanistic separation of cross-presentation and endogenous antigen presentation. Nat Immunol 9: 558-566.

112. Lizee, G., G. Basha, J. Tiong, J. P. Julien, M. Tian, K. E. Biron, and W. A. Jefferies. 2003. Control of dendritic cell cross-presentation by the major histocompatibility complex class I cytoplasmic domain. Nat Immunol 4: 1065-1073.

113. Di, P. T., B. Chatterjee, A. Smed-Sorensen, S. Clayton, A. Palazzo, M. Montes, Y. Xue, I. Mellman, J. Banchereau, and J. E. Connolly. 2008. Direct proteasomeindependent cross-presentation of viral antigen by plasmacytoid dendritic cells on major histocompatibility complex class I. Nat Immunol 9: 551-557.

114. Bernard, A., A. L. Lamy, and I. Alberti. 2002. The two-signal model of T-cell activation after 30 years. Transplantation 73: S31-S35.

115. Boesteanu, A. C., and P. D. Katsikis. 2009. Memory T cells need CD28 costimulation to remember. Semin. Immunol 21: 69-77.

116. Parker, D. C. 1993. T cell-dependent B cell activation. Annu. Rev Immunol 11: 331360.

117. Parker, D. C. 1993. The functions of antigen recognition in T cell-dependent B cell activation. Semin. Immunol 5: 413-420.

118. Murphy K. 2011. Janeways Immunobiology, 8.th edition ed.

119. Schroeder, H. W., Jr., and L. Cavacini. 2010. Structure and function of immunoglobulins. J. Allergy Clin. Immunol 125: S41-S52.

120. Andersen, B. M., and J. R. Ohlfest. 2012. Increasing the efficacy of tumor cell vaccines by enhancing cross priming. Cancer Lett. 325: 155-164.

121. Caminschi, I., E. Maraskovsky, and W. R. Heath. 2012. Targeting Dendritic Cells in vivo for Cancer Therapy. Front Immunol 3: 13.

122. Kato, M., K. J. McDonald, S. Khan, I. L. Ross, S. Vuckovic, K. Chen, D. Munster, K. P. MacDonald, and D. N. Hart. 2006. Expression of human DEC-205 (CD205) multilectin receptor on leukocytes. Int. Immunol 18: 857-869.

123. Kraal, G., M. Breel, M. Janse, and G. Bruin. 1986. Langerhans' cells, veiled cells, and interdigitating cells in the mouse recognized by a monoclonal antibody. J. Exp. Med. 163: 981-997. 
124. Jiang, W., W. J. Swiggard, C. Heufler, M. Peng, A. Mirza, R. M. Steinman, and M. C. Nussenzweig. 1995. The receptor DEC-205 expressed by dendritic cells and thymic epithelial cells is involved in antigen processing. Nature 375: 151-155.

125. Keler, T., L. He, V. Ramakrishna, and B. Champion. 2007. Antibody-targeted vaccines. Oncogene 26: 3758-3767.

126. Cheong, C., J. H. Choi, L. Vitale, L. Z. He, C. Trumpfheller, L. Bozzacco, Y. Do, G. Nchinda, S. H. Park, D. B. Dandamudi, E. Shrestha, M. Pack, H. W. Lee, T. Keler, R. M. Steinman, and C. G. Park. 2010. Improved cellular and humoral immune responses in vivo following targeting of HIV Gag to dendritic cells within human antihuman DEC205 monoclonal antibody. Blood 116: 3828-3838.

127. Idoyaga, J., A. Lubkin, C. Fiorese, M. H. Lahoud, I. Caminschi, Y. Huang, A. Rodriguez, B. E. Clausen, C. G. Park, C. Trumpfheller, and R. M. Steinman. 2011. Comparable T helper 1 (Th1) and CD8 T-cell immunity by targeting HIV gag p24 to CD8 dendritic cells within antibodies to Langerin, DEC205, and Clec9A. Proc. Natl. Acad. Sci. U. S. A 108: 2384-2389.

128. Mahnke, K., Y. Qian, S. Fondel, J. Brueck, C. Becker, and A. H. Enk. 2005. Targeting of antigens to activated dendritic cells in vivo cures metastatic melanoma in mice. Cancer Res 65: 7007-7012.

129. Bonifaz, L. C., D. P. Bonnyay, A. Charalambous, D. I. Darguste, S. Fujii, H. Soares, M. K. Brimnes, B. Moltedo, T. M. Moran, and R. M. Steinman. 2004. In vivo targeting of antigens to maturing dendritic cells via the DEC-205 receptor improves T cell vaccination. J. Exp. Med. 199: 815-824.

130. Wang, B., N. Zaidi, L. Z. He, L. Zhang, J. M. Kuroiwa, T. Keler, and R. M. Steinman. 2012. Targeting of the non-mutated tumor antigen HER2/neu to mature dendritic cells induces an integrated immune response that protects against breast cancer in mice. Breast Cancer Res 14: R39.

131. Curtis, B. M., S. Scharnowske, and A. J. Watson. 1992. Sequence and expression of a membrane-associated C-type lectin that exhibits CD4-independent binding of human immunodeficiency virus envelope glycoprotein gp120. Proc. Natl. Acad. Sci. U. S. A 89: 8356-8360.

132. Park, C. G., K. Takahara, E. Umemoto, Y. Yashima, K. Matsubara, Y. Matsuda, B. E. Clausen, K. Inaba, and R. M. Steinman. 2001. Five mouse homologues of the human dendritic cell C-type lectin, DC-SIGN. Int. Immunol 13: 1283-1290.

133. Gramberg, T., I. Caminschi, A. Wegele, H. Hofmann, and S. Pohlmann. 2006. Evidence that multiple defects in murine DC-SIGN inhibit a functional interaction with pathogens. Virology 345: 482-491.

134. Geijtenbeek, T. B., R. Torensma, S. J. van Vliet, G. C. van Duijnhoven, G. J. Adema, K. Y. van, and C. G. Figdor. 2000. Identification of DC-SIGN, a novel 
dendritic cell-specific ICAM-3 receptor that supports primary immune responses. Cell 100: 575-585.

135. Soilleux, E. J., L. S. Morris, G. Leslie, J. Chehimi, Q. Luo, E. Levroney, J. Trowsdale, L. J. Montaner, R. W. Doms, D. Weissman, N. Coleman, and B. Lee. 2002. Constitutive and induced expression of DC-SIGN on dendritic cell and macrophage subpopulations in situ and in vitro. J. Leukoc. Biol. 71: 445-457.

136. Geijtenbeek, T. B., D. S. Kwon, R. Torensma, S. J. van Vliet, G. C. van Duijnhoven, J. Middel, I. L. Cornelissen, H. S. Nottet, V. N. KewalRamani, D. R. Littman, C. G. Figdor, and K. Y. van. 2000. DC-SIGN, a dendritic cell-specific HIV-1-binding protein that enhances trans-infection of T cells. Cell 100: 587-597.

137. van, K. Y., and T. B. Geijtenbeek. 2003. DC-SIGN: escape mechanism for pathogens. Nat Rev Immunol 3: 697-709.

138. Tacken, P. J., R. Torensma, and C. G. Figdor. 2006. Targeting antigens to dendritic cells in vivo. Immunobiology 211: 599-608.

139. Tacken, P. J., I. J. de Vries, K. Gijzen, B. Joosten, D. Wu, R. P. Rother, S. J. Faas, C. J. Punt, R. Torensma, G. J. Adema, and C. G. Figdor. 2005. Effective induction of naive and recall $\mathrm{T}$-cell responses by targeting antigen to human dendritic cells via a humanized anti-DC-SIGN antibody. Blood 106: 1278-1285.

140. Tacken, P. J., B. Joosten, A. Reddy, D. Wu, A. Eek, P. Laverman, A. KretzRommel, G. J. Adema, R. Torensma, and C. G. Figdor. 2008. No advantage of cellpenetrating peptides over receptor-specific antibodies in targeting antigen to human dendritic cells for cross-presentation. J. Immunol 180: 7687-7696.

141. Tacken, P. J., W. Ginter, L. Berod, L. J. Cruz, B. Joosten, T. Sparwasser, C. G. Figdor, and A. Cambi. 2011. Targeting DC-SIGN via its neck region leads to prolonged antigen residence in early endosomes, delayed lysosomal degradation, and cross-presentation. Blood 118: 4111-4119.

142. Cruz, L. J., P. J. Tacken, J. M. Pots, R. Torensma, S. I. Buschow, and C. G. Figdor. 2012. Comparison of antibodies and carbohydrates to target vaccines to human dendritic cells via DC-SIGN. Biomaterials 33: 4229-4239.

143. Melikov, K., and L. V. Chernomordik. 2005. Arginine-rich cell penetrating peptides: from endosomal uptake to nuclear delivery. Cell Mol. Life Sci. 62: 2739-2749.

144. Richard, J. P., K. Melikov, E. Vives, C. Ramos, B. Verbeure, M. J. Gait, L. V. Chernomordik, and B. Lebleu. 2003. Cell-penetrating peptides. A reevaluation of the mechanism of cellular uptake. J. Biol. Chem. 278: 585-590.

145. Tacken, P. J., B. Joosten, A. Reddy, D. Wu, A. Eek, P. Laverman, A. KretzRommel, G. J. Adema, R. Torensma, and C. G. Figdor. 2008. No advantage of cellpenetrating peptides over receptor-specific antibodies in targeting antigen to human dendritic cells for cross-presentation. J. Immunol 180: 7687-7696. 
146. Tacken, P. J., W. Ginter, L. Berod, L. J. Cruz, B. Joosten, T. Sparwasser, C. G. Figdor, and A. Cambi. 2011. Targeting DC-SIGN via its neck region leads to prolonged antigen residence in early endosomes, delayed lysosomal degradation, and cross-presentation. Blood 118: 4111-4119.

147. Huysamen, C., J. A. Willment, K. M. Dennehy, and G. D. Brown. 2008. CLEC9A is a novel activation C-type lectin-like receptor expressed on BDCA3+ dendritic cells and a subset of monocytes. J. Biol. Chem. 283: 16693-16701.

148. Caminschi, I., A. I. Proietto, F. Ahmet, S. Kitsoulis, T. J. Shin, J. C. Lo, A. Rizzitelli, L. Wu, D. Vremec, S. L. van Dommelen, I. K. Campbell, E. Maraskovsky, H. Braley, G. M. Davey, P. Mottram, d. van, V, K. Jensen, A. M. Lew, M. D. Wright, W. R. Heath, K. Shortman, and M. H. Lahoud. 2008. The dendritic cell subtype-restricted C-type lectin Clec9A is a target for vaccine enhancement. Blood 112: 3264-3273.

149. Joffre, O. P., D. Sancho, S. Zelenay, A. M. Keller, and Reis E Sousa. 2010. Efficient and versatile manipulation of the peripheral CD4+ T-cell compartment by antigen targeting to DNGR-1/CLEC9A. Eur. J. Immunol 40: 1255-1265.

150. Lahoud, M. H., F. Ahmet, S. Kitsoulis, S. S. Wan, D. Vremec, C. N. Lee, B. Phipson, W. Shi, G. K. Smyth, A. M. Lew, Y. Kato, S. N. Mueller, G. M. Davey, W. R. Heath, K. Shortman, and I. Caminschi. 2011. Targeting Antigen to Mouse Dendritic Cells via Clec9A Induces Potent CD4 T Cell Responses Biased toward a Follicular Helper Phenotype. The Journal of Immunology 187: 842-850.

151. Ariizumi, K., G. L. Shen, S. Shikano, S. Xu, R. Ritter, III, T. Kumamoto, D. Edelbaum, A. Morita, P. R. Bergstresser, and A. Takashima. 2000. Identification of a novel, dendritic cell-associated molecule, dectin-1, by subtractive cDNA cloning. J. Biol. Chem. 275: 20157-20167.

152. Brown, G. D., and S. Gordon. 2001. Immune recognition. A new receptor for betaglucans. Nature 413: 36-37.

153. Brown, G. D., J. Herre, D. L. Williams, J. A. Willment, A. S. Marshall, and S. Gordon. 2003. Dectin-1 mediates the biological effects of beta-glucans. J. Exp. Med. 197: 1119-1124.

154. Steele, C., L. Marrero, S. Swain, A. G. Harmsen, M. Zheng, G. D. Brown, S. Gordon, J. E. Shellito, and J. K. Kolls. 2003. Alveolar macrophage-mediated killing of Pneumocystis carinii f. sp. muris involves molecular recognition by the Dectin-1 beta-glucan receptor. J. Exp. Med. 198: 1677-1688.

155. Brown, G. D. 2006. Dectin-1: a signalling non-TLR pattern-recognition receptor. Nat Rev Immunol 6: 33-43.

156. Dennehy, K. M., G. Ferwerda, I. Faro-Trindade, E. Pyz, J. A. Willment, P. R. Taylor, A. Kerrigan, S. V. Tsoni, S. Gordon, F. Meyer-Wentrup, G. J. Adema, B. J. Kullberg, E. Schweighoffer, V. Tybulewicz, H. M. Mora-Montes, N. A. Gow, D. L. Williams, M. G. Netea, and G. D. Brown. 2008. Syk kinase is required for collaborative cytokine 
production induced through Dectin-1 and Toll-like receptors. Eur. J. Immunol 38: 500-506.

157. Taylor, P. R., S. V. Tsoni, J. A. Willment, K. M. Dennehy, M. Rosas, H. Findon, K. Haynes, C. Steele, M. Botto, S. Gordon, and G. D. Brown. 2007. Dectin-1 is required for beta-glucan recognition and control of fungal infection. Nat Immunol 8: 31-38.

158. Reid, D. M., M. Montoya, P. R. Taylor, P. Borrow, S. Gordon, G. D. Brown, and S. Y. Wong. 2004. Expression of the beta-glucan receptor, Dectin-1, on murine leukocytes in situ correlates with its function in pathogen recognition and reveals potential roles in leukocyte interactions. J. Leukoc. Biol. 76: 86-94.

159. Taylor, P. R., G. D. Brown, D. M. Reid, J. A. Willment, L. Martinez-Pomares, S. Gordon, and S. Y. Wong. 2002. The beta-glucan receptor, dectin-1, is predominantly expressed on the surface of cells of the monocyte/macrophage and neutrophil lineages. J. Immunol 169: 3876-3882.

160. Castro, F., A. Tutt, A. White, J. Teeling, S. James, R. French, and M. Glennie. 2008. CD11c provides an effective immunotarget for the generation of both CD4 and CD8 T cell responses. Eur. J. Immunol. 38: 2263-2273.

161. Bilsland, C. A., M. S. Diamond, and T. A. Springer. 1994. The leukocyte integrin p150,95 (CD11c/CD18) as a receptor for iC3b. Activation by a heterologous beta subunit and localization of a ligand recognition site to the I domain. The Journal of Immunology 152: 4582-4589.

162. Stacker, S. A., and T. A. Springer. 1991. Leukocyte integrin P150,95 (CD11c/CD18) functions as an adhesion molecule binding to a counter-receptor on stimulated endothelium. J. Immunol 146: 648-655.

163. Kurts, C. 2008. CD11c: not merely a murine DC marker, but also a useful vaccination target. Eur. J. Immunol 38: 2072-2075.

164. Wei, H., S. Wang, D. Zhang, S. Hou, W. Qian, B. Li, H. Guo, G. Kou, J. He, H. Wang, and Y. Guo. 2009. Targeted Delivery of Tumor Antigens to Activated Dendritic Cells via CD11c Molecules Induces Potent Antitumor Immunity in Mice. Clinical Cancer Research 15: 4612-4621.

165. Metlay, J. P., M. D. Witmer-Pack, R. Agger, M. T. Crowley, D. Lawless, and R. M. Steinman. 1990. The distinct leukocyte integrins of mouse spleen dendritic cells as identified with new hamster monoclonal antibodies. J. Exp. Med. 171: 1753-1771.

166. Wang, H., M. N. Griffiths, D. R. Burton, and P. Ghazal. 2000. Rapid antibody responses by low-dose, single-step, dendritic cell-targeted immunization. Proceedings of the National Academy of Sciences 97: 847-852.

167. Tagliani, E., P. Guermonprez, J. Sepulveda, M. Lopez-Bravo, C. Ardavin, S. Amigorena, F. Benvenuti, and O. R. Burrone. 2008. Selection of an antibody library 
identifies a pathway to induce immunity by targeting CD36 on steady-state CD8 alpha+ dendritic cells. J. Immunol 180: 3201-3209.

168. Martin, C., M. Chevrot, H. Poirier, P. Passilly-Degrace, I. Niot, and P. Besnard. 2011. CD36 as a lipid sensor. Physiol Behav. 105: 36-42.

169. Silverstein, R. L., and M. Febbraio. 2009. CD36, a Scavenger Receptor Involved in Immunity, Metabolism, Angiogenesis, and Behavior. Sci. Signal. 2: re3.

170. Albert, M. L., S. F. Pearce, L. M. Francisco, B. Sauter, P. Roy, R. L. Silverstein, and N. Bhardwaj. 1998. Immature Dendritic Cells Phagocytose Apoptotic Cells via $+{ }_{1}^{1}+15$ and CD36, and Cross-present Antigens to Cytotoxic T Lymphocytes. The Journal of Experimental Medicine 188: 1359-1368.

171. Belz, G. T., D. Vremec, M. Febbraio, L. Corcoran, K. Shortman, F. R. Carbone, and W. R. Heath. 2002. CD36 Is Differentially Expressed by CD8+ Splenic Dendritic Cells But Is Not Required for Cross-Presentation In Vivo. The Journal of Immunology 168: 6066-6070.

172. Blasius, A. L., and M. Colonna. 2006. Sampling and signaling in plasmacytoid dendritic cells: the potential roles of Siglec-H. Trends in Immunology 27: 255-260.

173. Crocker, P. R., and A. Varki. 2001. Siglecs in the immune system. Immunology 103: 137-145.

174. Crocker, P. R., J. C. Paulson, and A. Varki. 2007. Siglecs and their roles in the immune system. Nat Rev Immunol 7: 255-266.

175. Blasius, A. L., M. Cella, J. Maldonado, T. Takai, and M. Colonna. 2006. Siglec-H is an IPC-specific receptor that modulates type I IFN secretion through DAP12. Blood 107: 2474-2476.

176. Zhang, J., A. Raper, N. Sugita, R. Hingorani, M. Salio, M. J. Palmowski, V. Cerundolo, and P. R. Crocker. 2006. Characterization of Siglec-H as a novel endocytic receptor expressed on murine plasmacytoid dendritic cell precursors. Blood 107: 3600-3608.

177. Loschko, J., S. Heink, D. Hackl, D. Dudziak, W. Reindl, T. Korn, and A. B. Krug. 2011. Antigen Targeting to Plasmacytoid Dendritic Cells via Siglec-H Inhibits Th Cell-Dependent Autoimmunity. The Journal of Immunology 187: 6346-6356.

178. Ford, J. W., and D. W. McVicar. 2009. TREM and TREM-like receptors in inflammation and disease. Current Opinion in Immunology 21: 38-46.

179. Shortman, K., M. H. Lahoud, and I. Caminschi. 2009. Improving vaccines by targeting antigens to dendritic cells. Exp. Mol. Med. 41: 61-66.

180. Caminschi, I., and K. Shortman. 2012. Boosting antibody responses by targeting antigens to dendritic cells. Trends Immunol 33: 71-77. 
181. Gamvrellis, A., D. Leong, J. C. Hanley, S. D. Xiang, P. Mottram, and M. Plebanski. 2004. Vaccines that facilitate antigen entry into dendritic cells. Immunol Cell Biol. 82: $506-516$.

182. Rees, A. R., D. Staunton, D. M. Webster, S. J. Searle, A. H. Henry, and J. T. Pedersen. 1994. Antibody design: beyond the natural limits. Trends Biotechnol. 12: 199-206.

183. Brekke, O. H., and I. Sandlie. 2003. Therapeutic antibodies for human diseases at the dawn of the twenty-first century. Nat Rev Drug Discov. 2: 52-62.

184. Narciso, J. E., I. D. Uy, A. B. Cabang, J. F. Chavez, J. L. Pablo, G. P. PadillaConcepcion, and E. A. Padlan. 2011. Analysis of the antibody structure based on high-resolution crystallographic studies. N. Biotechnol. 28: 435-447.

185. Garcia, M. A. 2011. Monoclonal antibodies. Basic features. Neurologia 26: 301-306.

186. Caminschi, I., A. I. Proietto, F. Ahmet, S. Kitsoulis, T. J. Shin, J. C. Lo, A. Rizzitelli, L. Wu, D. Vremec, S. L. van Dommelen, I. K. Campbell, E. Maraskovsky, H. Braley, G. M. Davey, P. Mottram, d. van, V, K. Jensen, A. M. Lew, M. D. Wright, W. R. Heath, K. Shortman, and M. H. Lahoud. 2008. The dendritic cell subtype-restricted C-type lectin Clec9A is a target for vaccine enhancement. Blood 112: 3264-3273.

187. Joffre, O. P., D. Sancho, S. Zelenay, A. M. Keller, and Reis E Sousa. 2010. Efficient and versatile manipulation of the peripheral CD4+ T-cell compartment by antigen targeting to DNGR-1/CLEC9A. Eur. J. Immunol 40: 1255-1265.

188. Corbett, A. J., I. Caminschi, B. S. McKenzie, J. L. Brady, M. D. Wright, P. L. Mottram, P. M. Hogarth, A. N. Hodder, Y. Zhan, D. M. Tarlinton, K. Shortman, and A. M. Lew. 2005. Antigen delivery via two molecules on the CD8- dendritic cell subset induces humoral immunity in the absence of conventional "danger". Eur. J. Immunol 35: 2815-2825.

189. Caminschi, I., M. H. Lahoud, and K. Shortman. 2009. Enhancing immune responses by targeting antigen to DC. Eur. J. Immunol. 39: 931-938.

190. Shortman, K., M. H. Lahoud, and I. Caminschi. 2009. Improving vaccines by targeting antigens to dendritic cells. Exp. Mol. Med. 41: 61-66.

191. Lahoud, M. H., A. I. Proietto, F. Ahmet, S. Kitsoulis, L. Eidsmo, L. Wu, P. Sathe, S. Pietersz, H. W. Chang, I. D. Walker, E. Maraskovsky, H. Braley, A. M. Lew, M. D. Wright, W. R. Heath, K. Shortman, and I. Caminschi. 2009. The C-type lectin Clec12A present on mouse and human dendritic cells can serve as a target for antigen delivery and enhancement of antibody responses. J. Immunol 182: 75877594.

192. van Dullemen, H. M., S. J. van Deventer, D. W. Hommes, H. A. Bijl, J. Jansen, G. N. Tytgat, and J. Woody. 1995. Treatment of Crohn's disease with anti-tumor necrosis factor chimeric monoclonal antibody (cA2). Gastroenterology 109: 129135. 
193. Ge, L., A. Lupas, S. Peraldi-Roux, S. Spada, and A. Pluckthun. 1995. A mouse Ig kappa domain of very unusual framework structure loses function when converted to the consensus. J. Biol. Chem. 270: 12446-12451.

194. Wolbink, G. J., M. Vis, W. Lems, A. E. Voskuyl, G. E. de, M. T. Nurmohamed, S. Stapel, P. P. Tak, L. Aarden, and B. Dijkmans. 2006. Development of antiinfliximab antibodies and relationship to clinical response in patients with rheumatoid arthritis. Arthritis Rheum. 54: 711-715.

195. Bendtzen, K., P. Geborek, M. Svenson, L. Larsson, M. C. Kapetanovic, and T. Saxne. 2006. Individualized monitoring of drug bioavailability and immunogenicity in rheumatoid arthritis patients treated with the tumor necrosis factor alpha inhibitor infliximab. Arthritis Rheum. 54: 3782-3789.

196. Maini, R. N., F. C. Breedveld, J. R. Kalden, J. S. Smolen, D. Davis, J. D. Macfarlane, C. Antoni, B. Leeb, M. J. Elliott, J. N. Woody, T. F. Schaible, and M. Feldmann. 1998. Therapeutic efficacy of multiple intravenous infusions of anti-tumor necrosis factor alpha monoclonal antibody combined with low-dose weekly methotrexate in rheumatoid arthritis. Arthritis Rheum. 41: 1552-1563.

197. Farrell, R. J., M. Alsahli, Y. T. Jeen, K. R. Falchuk, M. A. Peppercorn, and P. Michetti. 2003. Intravenous hydrocortisone premedication reduces antibodies to infliximab in Crohn's disease: a randomized controlled trial. Gastroenterology 124: 917-924.

198. Raulf-Heimsoth, M. 2008. T cell - primary culture from peripheral blood. Methods Mol. Med. 138: 17-30.

199. Moser, J. M., E. R. Sassano, d. C. Leistritz, J. M. Eatrides, S. Phogat, W. Koff, and D. R. Drake. 2010. Optimization of a dendritic cell-based assay for the in vitro priming of naive human CD4+ T cells. J. Immunol Methods 353: 8-19.

200. Genestier, L., R. Paillot, L. Quemeneur, K. Izeradjene, and J. P. Revillard. 2000. Mechanisms of action of methotrexate. Immunopharmacology 47: 247-257.

201. Tanguay, S., and J. J. Killion. 1994. Direct comparison of ELISPOT and ELISAbased assays for detection of individual cytokine-secreting cells. Lymphokine Cytokine Res 13: 259-263.

202. Carter, L. L., and S. L. Swain. 1997. Single cell analyses of cytokine production. Curr. Opin. Immunol 9: 177-182.

203. Moodie, Z., L. Price, C. Gouttefangeas, A. Mander, S. Janetzki, M. Lower, M. J. Welters, C. Ottensmeier, S. H. van der Burg, and C. M. Britten. 2010. Response definition criteria for ELISPOT assays revisited. Cancer Immunol Immunother. 59: 1489-1501.

204. Moodie, Z., L. Price, S. Janetzki, and C. M. Britten. 2012. Response determination criteria for ELISPOT: toward a standard that can be applied across laboratories. Methods Mol. Biol. 792: 185-196. 
205. Moodie, Z., Y. Huang, L. Gu, J. Hural, and S. G. Self. 2006. Statistical positivity criteria for the analysis of ELISpot assay data in HIV-1 vaccine trials. J. Immunol Methods 315: 121-132.

206. Wild D. 2005. The Immunoassay Handbook, Third edition ed.

207. Petersen, Toldbod, Holtz, Hokland, Bolund, and Agger. 2000. Strain-Specific Variations in the Development of Dendritic Cells in Murine Bone-Marrow Cultures. Scandinavian Journal of Immunology 51: 586-594.

208. Schijns, V. E., and E. C. Lavelle. 2011. Trends in vaccine adjuvants. Expert Rev Vaccines. 10: 539-550.

209. Strid, J., R. Callard, and S. Strobel. 2006. Epicutaneous immunization converts subsequent and established antigen-specific T helper type 1 (Th1) to Th2-type responses. Immunology 119: 27-35.

210. Cribbs, D. H., A. Ghochikyan, V. Vasilevko, M. Tran, I. Petrushina, N. Sadzikava, D. Babikyan, P. Kesslak, T. Kieber-Emmons, C. W. Cotman, and M. G. Agadjanyan. 2003. Adjuvant-dependent modulation of Th1 and Th2 responses to immunization with beta-amyloid. Int. Immunol. 15: 505-514.

211. Fernando, Stewart, Tindle, and Frazer. 1998. Vaccine-Induced Th1-Type Responses are Dominant over Th2-Type Responses in the Short Term whereas Pre-existing Th2 Responses are Dominant in the Longer Term. Scandinavian Journal of Immunology 47: 459-465.

212. Matzinger, P. 2007. Friendly and dangerous signals: is the tissue in control? Nat Immunol 8: 11-13.

213. Schjetne, K. W., K. M. Thompson, T. Aarvak, B. Fleckenstein, L. M. Sollid, and B. Bogen. 2002. A mouse C kappa-specific T cell clone indicates that DC-SIGN is an efficient target for antibody-mediated delivery of $\mathrm{T}$ cell epitopes for $\mathrm{MHC}$ class II presentation. Int. Immunol 14: 1423-1430. 